\title{
Ruthenium(II) Conjugates of Boron-Dipyrromethene and Biotin for Targeted Photodynamic Therapy in Red Light
}

Subhadeep Paul,,$^{\dagger}$ Paramita Kundu, ${ }^{+}$Utso Bhattacharyya, ${ }^{\dagger}$ Aditya Garai, ${ }^{\dagger}$ Ram Chandra Maji, ${ }^{\dagger}$ Paturu Kondaiah ${ }^{*}+\dot{t}$ and Akhil R. Chakravarty ${ }^{*}+$

†Department of Inorganic and Physical Chemistry and Department of Molecular Reproduction, Development and Genetics, Indian Institute of Science, Bangalore 560 012, India

\section{SUPPORTING INFORMATION}




\section{$\underline{\text { Table of contents }}$}

\section{Preparations -}

Synthesis and characterization of ligand $\mathrm{L}^{5}$.

Preparation of $\mathrm{RuCl}_{3} .3 \mathrm{H}_{2} \mathrm{O}$ from $\mathrm{RuCl}_{3} \cdot \mathrm{xH}_{2} \mathrm{O}$.

Preparation of $\left[\mathrm{RuCl}\left(\mathrm{L}^{1}\right)\left(\mathrm{L}^{3}\right)\right] \mathrm{PF}_{6}(\mathbf{1 a})$

\section{Characterization -}

Discussion on ${ }^{1} \mathrm{H}$ NMR, cyclic voltammetry and IR characterization of the complexes.

\section{Protocol -}

Protocol for the DCFDA experiment.

\section{Schemes -}

Scheme $\mathrm{S} 1$ - Preparation of the ligands $\mathrm{L}^{1}$ and $\mathrm{L}^{2}$.

Scheme $\mathrm{S} 2$ - Preparation of the ligands $\mathrm{L}^{3}, \mathrm{~L}^{4}$ and $\mathrm{L}^{5}$.

Scheme S3 - Preparation of Complexes 1-5.

\section{Figures -}

Figure S1: ${ }^{1} \mathrm{H}$ NMR and ${ }^{13} \mathrm{C}$ NMR spectra of the ligand $\mathrm{L}^{5}$.

Figures S2- S6: ${ }^{1} \mathrm{H}$ NMR spectra of the complexes $\mathbf{1}-\mathbf{5}$ in DMSO- $\mathrm{d}_{6}$.

Figure S7: Mass spectrum of ligand $\mathrm{L}^{5}$ in $\mathrm{MeOH}$.

Figure S8- S12: Mass spectra of the complexes $\mathbf{1}-\mathbf{5}$ in $\mathrm{MeOH}$.

Figure S13: IR spectra of the complexes $\mathbf{1}-\mathbf{5}$ and complex $\mathbf{1 a}$.

Figure S14: Concentration dependent aggregation study monitored by UV spectroscopy in 1:1 DMSODPBS $(\mathrm{V} / \mathrm{V})$.

Figure S15: Cyclic voltammograms of the complexes $\mathbf{1}-\mathbf{5}$ in DMF.

Figure S16: Dark stability and photostability of the complexes checked by UV $10 \%$ (V/V) DMSODPBS. 
Figure S17A: Photostability of the complexes checked by emission spectroscopy in $10 \%$ (V/V) DMSODPBS.

Figure S17B: Photobleaching experiment of complex 5 monitored by confocal microscopy.

Figure S18: Crystal cell packing diagram of complex 1a.

Figure S19: Energy-minimized structures of complexes $\mathbf{2}-\mathbf{5}$.

Figure S20: Frontier molecular orbitals of the complexes $\mathbf{2}$ and $\mathbf{3}$.

Figure S21: DPBF titration plots for complexes $\mathbf{2}-\mathbf{5}$ in DMSO.

Figure S22: The $\Delta \mathrm{OD}$ vs. time plots for determination of singlet oxygen quantum yield.

Figure S23A: DCFDA assay in A549 cells obtained by flow cytometry.

Figure S23B: Individual plots for the DCFDA experiment.

Figure S24: DNA binding constant $\left(K_{\mathrm{b}}\right)$ determination of the complexes using UV- Vis spectroscopy.

Figure S25: Apparent DNA binding constant $\left(K_{\text {app }}\right)$ determination of the complexes using emission spectroscopy.

Figure S26: DNA photocleavage assay.

Figure S27: Cytotoxicity assay plots in A549 and HPL1D cell line.

Figure S28: Confocal imaging and co-localization studies in A549 cells.

Figures S29, S30: Cellular uptake studies monitored by flow cytometric analysis.

\section{Tables -}

Table S1: Selected bond angles and bond lengths obtained from crystal structure of 1a.

Table S2: Coordinates for the energy minimized structure of complex 2.

Table S3: Coordinates for the energy minimized structure of complex 3.

Table S4: Coordinates for the energy minimized structure of complex 4.

Table S5: Coordinates for the energy minimized structure of complex $\mathbf{5}$.

Table S6: Excitation energies and oscillator strengths obtained from TD-DFT calculations for complex 2.

Table S7: Excitation energies and oscillator strengths obtained from TD-DFT calculations for complex 3.

Table S8: Excitation energies and oscillator strengths obtained from TD-DFT calculations for complex 4.

Table S9: Excitation energies and oscillator strengths obtained from TD-DFT calculations for complex 5. 


\section{Synthesis and characterization of ligand $L^{5}$.}

The compound was prepared and purified following a modification of a procedure reported by $\mathrm{Ng}$ et al. ${ }^{\mathrm{S} 1}$ (+) ESI-MS in methanol: $\mathrm{m} / \mathrm{z}=1382.7849[\mathrm{M}+\mathrm{Na}]^{+} .{ }^{1} \mathrm{H}-\mathrm{NMR}\left(\mathrm{CDCl}_{3}, 400 \mathrm{MHz}, 298 \mathrm{~K}\right) \delta / \mathrm{ppm}: 8.57(\mathrm{~d}$, $J=4.5 \mathrm{~Hz}, 2 \mathrm{H}), 7.72(\mathrm{td}, J=7.7,1.7 \mathrm{~Hz}, 2 \mathrm{H}), 7.60-7.55(\mathrm{~m}, 6 \mathrm{H}), 7.32-7.26(\mathrm{~m}, 4 \mathrm{H}), 7.26(\mathrm{~m}, 3 \mathrm{H}), 7.14$ $(\mathrm{m}, 3 \mathrm{H}), 6.96(\mathrm{~d}, J=8.4 \mathrm{~Hz}, 2 \mathrm{H}), 6.60(\mathrm{~s}, 2 \mathrm{H}), 4.27-4.22(\mathrm{~m}, 8 \mathrm{H}), 3.90(\mathrm{t}, J=4.2 \mathrm{~Hz}, 8 \mathrm{H}), 3.85(\mathrm{~s}, 4 \mathrm{H})$, 3.79- $3.77(\mathrm{~m}, 10 \mathrm{H}), 3.70-3.65(\mathrm{~m}, 16 \mathrm{H}), 3.58-3.54(\mathrm{~m}, 8 \mathrm{H}), 3.40(\mathrm{~s}, 6 \mathrm{H}), 3.37(\mathrm{~s}, 6 \mathrm{H}), 1.40(\mathrm{~s}, 6 \mathrm{H}) .{ }^{13} \mathrm{C}-$ NMR $\left(\mathrm{CDCl}_{3}, 500 \mathrm{MHz}, 298 \mathrm{~K}\right) \delta / \mathrm{ppm}: 159.63,150.06,149.12,148.85,141.80,139.91,138.25,136.67$, $136.61,134.14,133.37,130.38,129.87,128.58,122.93,122.23,121.50,117.62,114.21,72.00,70.92$, $70.75,70.59,69.85,69.72,69.15,68.70,59.85,59.10,58.21,14.70$.

Reference S1: He, H.; Lo, P. C.; Yeung, S. L.; Fong, W. P.; Ng, D. K. P. Synthesis and in Vitro Photodynamic Activities of Pegylated Distyryl Boron Dipyrromethene Derivatives. J. Med. Chem. 2011, 54, 3097-3102.

\section{Preparation of $\mathrm{RuCl}_{3} .3 \mathrm{H}_{2} \mathrm{O}$ from $\mathrm{RuCl}_{3} \cdot \mathrm{xH}_{2} \mathrm{O}$.}

A 5 g quantity of commercial $\mathrm{RuCl}_{3} \cdot \mathrm{xH}_{2} \mathrm{O}$ was boiled with $20 \mathrm{~mL}$ of concentrated $\mathrm{HCl}$ and the acid was evaporated on a hot plate to dryness. The black residue was cooled and the treatment with acid was repeated twice. The residue obtained was finally kept at $80{ }^{\circ} \mathrm{C}$ for $\sim 2 \mathrm{~h}$ and cooled inside a calcium chloride desiccator to obtain pure $\mathrm{RuCl}_{3} .3 \mathrm{H}_{2} \mathrm{O}$ as a reddish-black solid.

\section{Preparation of $\left[\operatorname{RuCl}\left(\mathbf{L}^{1}\right)\left(\mathrm{L}^{3}\right)\right] \mathrm{PF}_{6}(1 \mathrm{a})$.}

A $70 \mathrm{mg}(0.1 \mathrm{mmol})$ quantity of complex 1 was taken in a $100 \mathrm{~mL}$ round bottom flask and $20 \mathrm{~mL}$ distilled water was added to it. The complex was dissolved by stirring and to the solution excess ammonium hexafluorophosphate $(65 \mathrm{mg}, 0.4 \mathrm{mmol})$ was added. The reaction mixture was stirred for $\sim 30 \mathrm{~min}$ at room temperature. The precipitate thus formed was filtered, washed thoroughly with water and vacuum dried to give the complex as a brown solid. Yield: $76 \mathrm{mg}, ~ 95 \%$

\section{Discussion on ${ }^{1} \mathrm{H}$ NMR, cyclic voltammetry and IR characterization of the complexes.}

The biotin containing complexes $\mathbf{3}$ and $\mathbf{5}$ showed additional peaks as a pair of singlets around $\delta 6.4 \mathrm{ppm}$ assignable to biotin $-\mathrm{NH}-$ protons and within $\delta$ 4.3-1.4 ppm for aliphatic protons in comparison to the control complexes 1, 2 and 4 showing a singlet at $\delta 2.3 \mathrm{ppm}$ for the $\mathrm{CH}_{3}$ protons. Complexes 2 and 3 containing $\mathrm{L}^{4}$ displayed three singlets at $\delta 6.15,2.42$ and 1.27 ppm corresponding to the BODIPY based protons (pyrrole $\mathrm{C}-\mathrm{H}$, pyrrole $\mathrm{CH}_{3}$ ). The protons belonging to the polyethylene glycol chains in complexes 4 and 5 appeared within $\delta 4.15-3.39$ ppm (- $\mathrm{OCH}_{2} \mathrm{CH}_{2} \mathrm{O}-$ protons) and 3.23-3.19 ppm (-OCH $\mathrm{OH}_{3}$ protons).

The IR spectral peaks were observed in the ranges $3000-3070 \mathrm{~cm}^{-1}$ for the amide $\mathrm{N}-\mathrm{H}$ stretch, 2800-2960 $\mathrm{cm}^{-1}$ for $\mathrm{C}-\mathrm{H}$ and $\mathrm{C}=\mathrm{C}$ stretches, and $1540-1690 \mathrm{~cm}^{-1}$ for $\mathrm{C}=\mathrm{C}, \mathrm{C}=\mathrm{O}$, and $\mathrm{C}-\mathrm{N}$ stretches.

The metal-bound phenanthroline bases showed reduction peaks $\left(\mathrm{E}_{\mathrm{pc}}\right)$ near $-1.58 \mathrm{~V}$ vs. SCE. BODIPY based reversible reduction peaks in the complexes were found near $-1.06 \mathrm{~V}$ for complexes 2 and $\mathbf{3}$ and near -0.86 $\mathrm{V}$ vs. SCE for complexes 4 and 5. Redox inactivity within +0.5 to $-0.5 \mathrm{~V}$ (vs. SCE) suggested the low possibility of any dark toxicity arising from radical generation. 


\section{Protocol for the DCFDA experiment.}

Briefly, A549 cells were seeded $\left(2 \times 10^{5}\right.$ cells/well $)$ in 6 well plates and allowed to attach for 24 hours. Cells were treated with complex 3 and $5(2 \mu \mathrm{M})$ for 4 hours in dark condition in $0.2 \%$ serum containing media, washed with buffer and replaced with media containing $20 \mu \mathrm{M}$ DCFDA for 45 minutes at $37^{\circ} \mathrm{C}$. The media was changed with buffer and the cells were either irradiated (Light dose $\sim 1.5 \mathrm{~J} / \mathrm{cm}^{2}(400-700 \mathrm{~nm}, 10 \mathrm{~min}$ exposure time) for complex 3 and $20 \mathrm{~J} / \mathrm{cm}^{2}$ (600- $720 \mathrm{~nm}, 10 \mathrm{~min}$ exposure time) for complex 5.) or kept in dark, followed by trypsinization with $0.5 \%$ Trypsin-EDTA solution for 5 minutes at $37^{\circ} \mathrm{C}$. Cells were collected as single-cell suspensions in PBS containing $20 \mu \mathrm{M}$ DCFDA and at least 10,000 events were analyzed on FACS Aria (BD Biosciences). Data was interpreted and analyzed on FCS Express 5 software (DeNovo Software). 
Scheme S1 - Preparation of the ligands $\mathrm{L}^{1}$ and $\mathrm{L}^{2}$ : a) $\mathrm{H}_{2} \mathrm{SO}_{4}, \mathrm{HNO}_{3}, 165-170^{\circ}, 2 \mathrm{~h}$; b) $10 \% \mathrm{Pd} / \mathrm{C}$, $\mathrm{N}_{2} \mathrm{H}_{4}$, EtOH, $70{ }^{\circ} \mathrm{C}, 24 \mathrm{~h}$; c) i) $\mathrm{SOCl}_{2}$, Biotin, $20 \mathrm{~min}$, R.T. and ii) DMAP, DMF, $16 \mathrm{~h}$, R.T. and d) acetic anhydride, R. T., pyridine, $12 \mathrm{~h}\left(\right.$ R.T. $=$ Room Temperature; $\left.25^{\circ} \mathrm{C}\right)$.

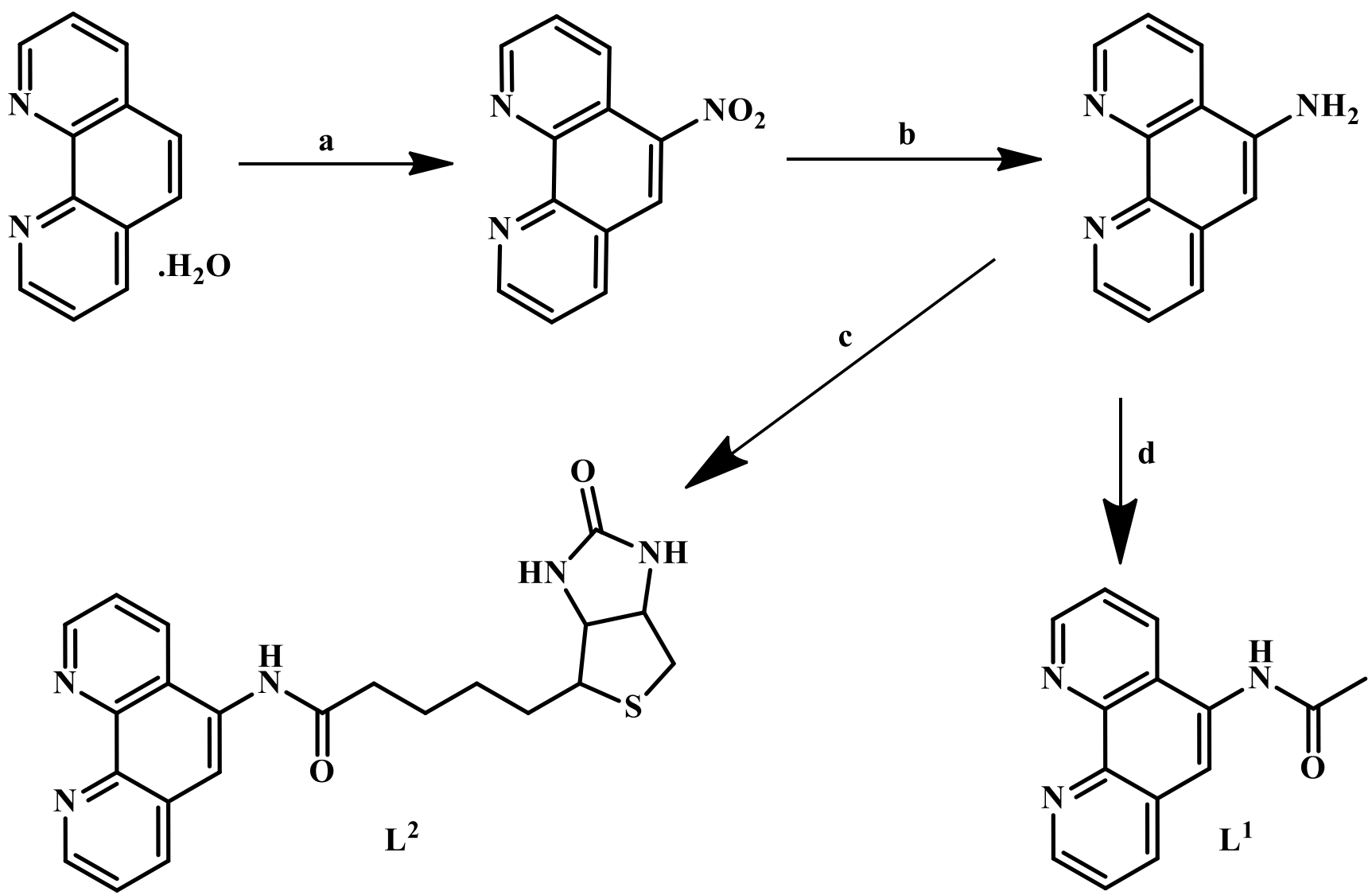


Scheme S2 - Preparation of the ligands $\mathrm{L}^{3}, \mathrm{~L}^{4}$ and $\mathrm{L}^{5}$ : a) i) $\mathrm{DCM}, 50{ }^{\circ} \mathrm{C}, 80 \mathrm{~min}$; ii) triethylamine, $\mathrm{BF}_{3} . \mathrm{Et}_{2} \mathrm{O}, \mathrm{CH}_{2} \mathrm{Cl}_{2}, 5_{0}^{\circ} \mathrm{C}, 1 \mathrm{~h}$; b) $\mathrm{NaBH}_{4}, \mathrm{MeOH}, 12 \mathrm{~h}$, R.T.; c) benzyl bromide, $\mathrm{K}_{2} \mathrm{CO}_{3}$, acetonitrile, $24 \mathrm{~h}$ reflux; d) Triethylamine, KI, Acetonitrile, 5 h R. T. and e) Aldehyde A, piperidine, acetic acid, toluene $24 \mathrm{~h}$ reflux.
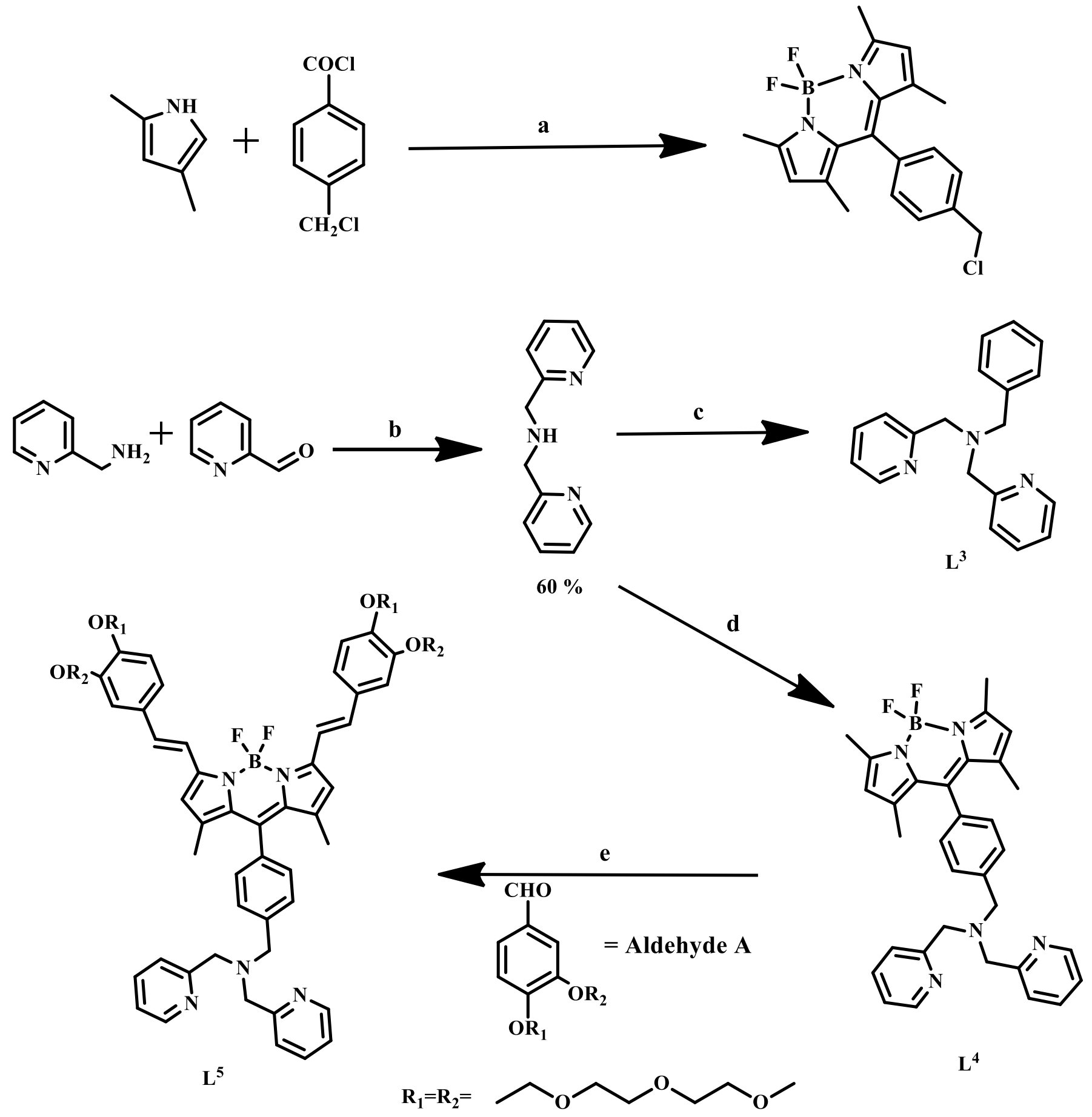
Scheme S3 - Preparation of Complexes 1-5: a) i) EtOH- $\mathrm{H}_{2} \mathrm{O}$ (4:1 v/v) 4 h reflux, $0.4 \mathrm{~mL}$ conc. HCl, 1 eq. $\mathrm{L} 3$ dissolved in EtOH was added drop-wise and stirred at $75^{\circ} \mathrm{C}, 3 \mathrm{~h}$ (for preparation of complex 1) or ii) EtOH, 1 eq. L4/L5 dissolved in EtOH was added drop-wise and stirred at $75^{\circ} \mathrm{C}, 4 \mathrm{~h}$ (for preparation of the complexes 2-5); b) i) 1 eq. L1/L2, 3 eq. LiCl, 1.5 eq. triethylamine, EtOH 16 h reflux (for preparation of the complexes 1-3) or ii) 1 eq. L1/ L2, 3 eq. LiCl, 1.5 eq. triethylamine, EtOH- $\mathrm{H}_{2} \mathrm{O}(4: 1 \mathrm{v} / \mathrm{v}) 24 \mathrm{~h}$ reflux (for preparation of the complexes 4, 5).
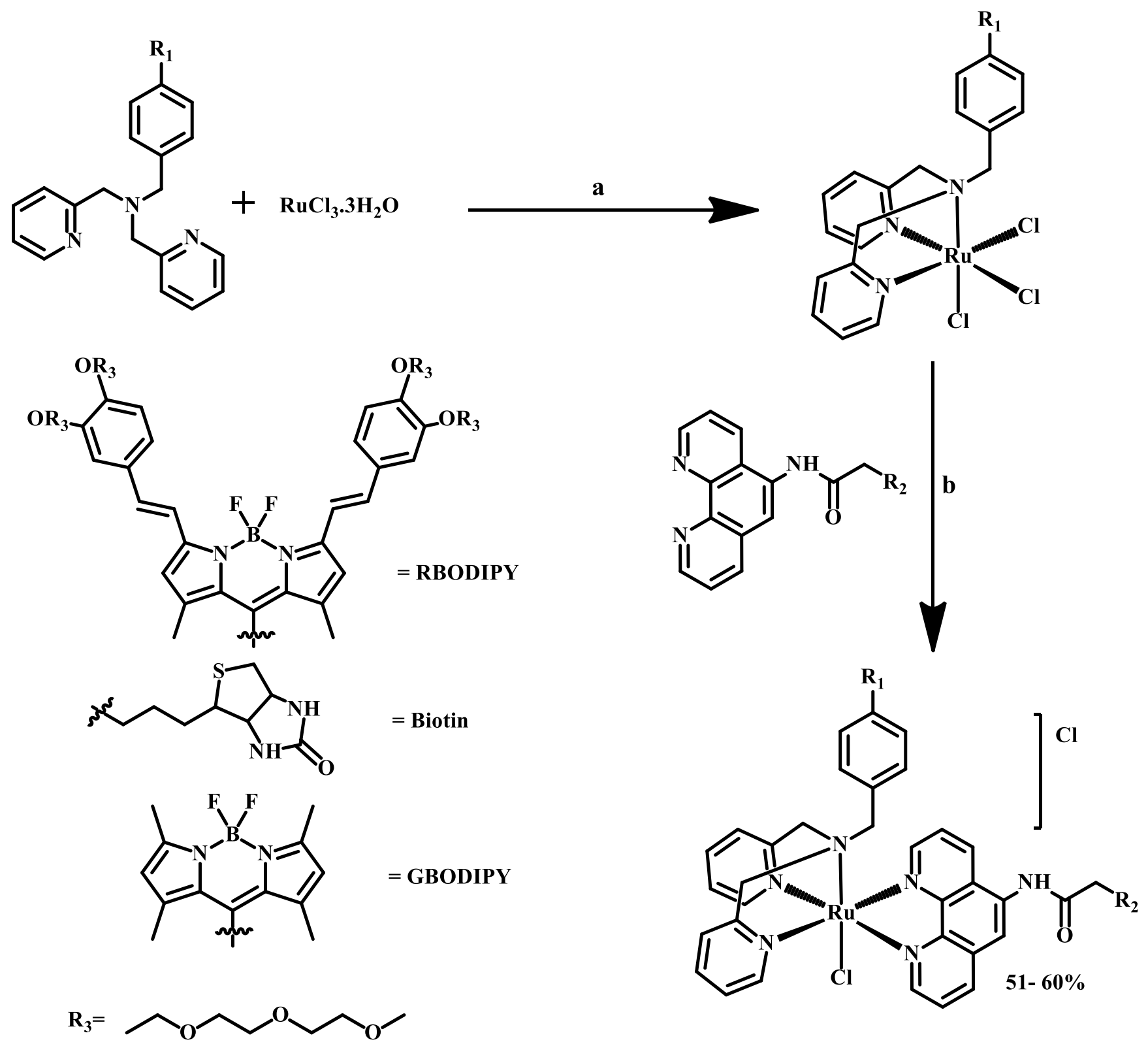

For Complex $1 \mathbf{R}_{1}=\mathbf{H}, \mathbf{R}_{2}=\mathbf{H}$.

For Complex4 $\mathbf{R}_{1}=\mathbf{R B O D I P Y}, \mathbf{R}_{2}=$ Biotin.

For Complex $2 \mathbf{R}_{1}=$ GBODIPY, $\mathbf{R}_{2}=H$.

For Complex $5 \mathbf{R}_{1}=\mathbf{R B O D I P Y}, \mathbf{R}_{2}=$ Biotin.

For Complex $3 \mathbf{R}_{1}=$ GBODIPY, $\mathbf{R}_{2}=$ Biotin. 
a)

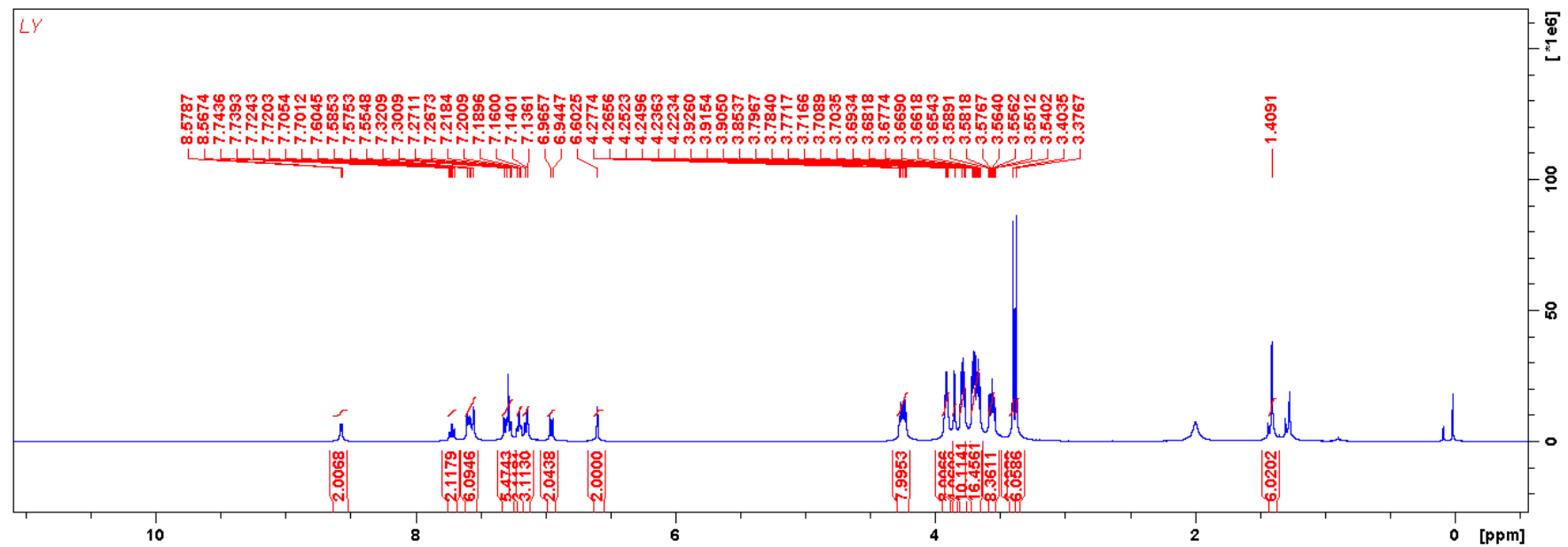

b)

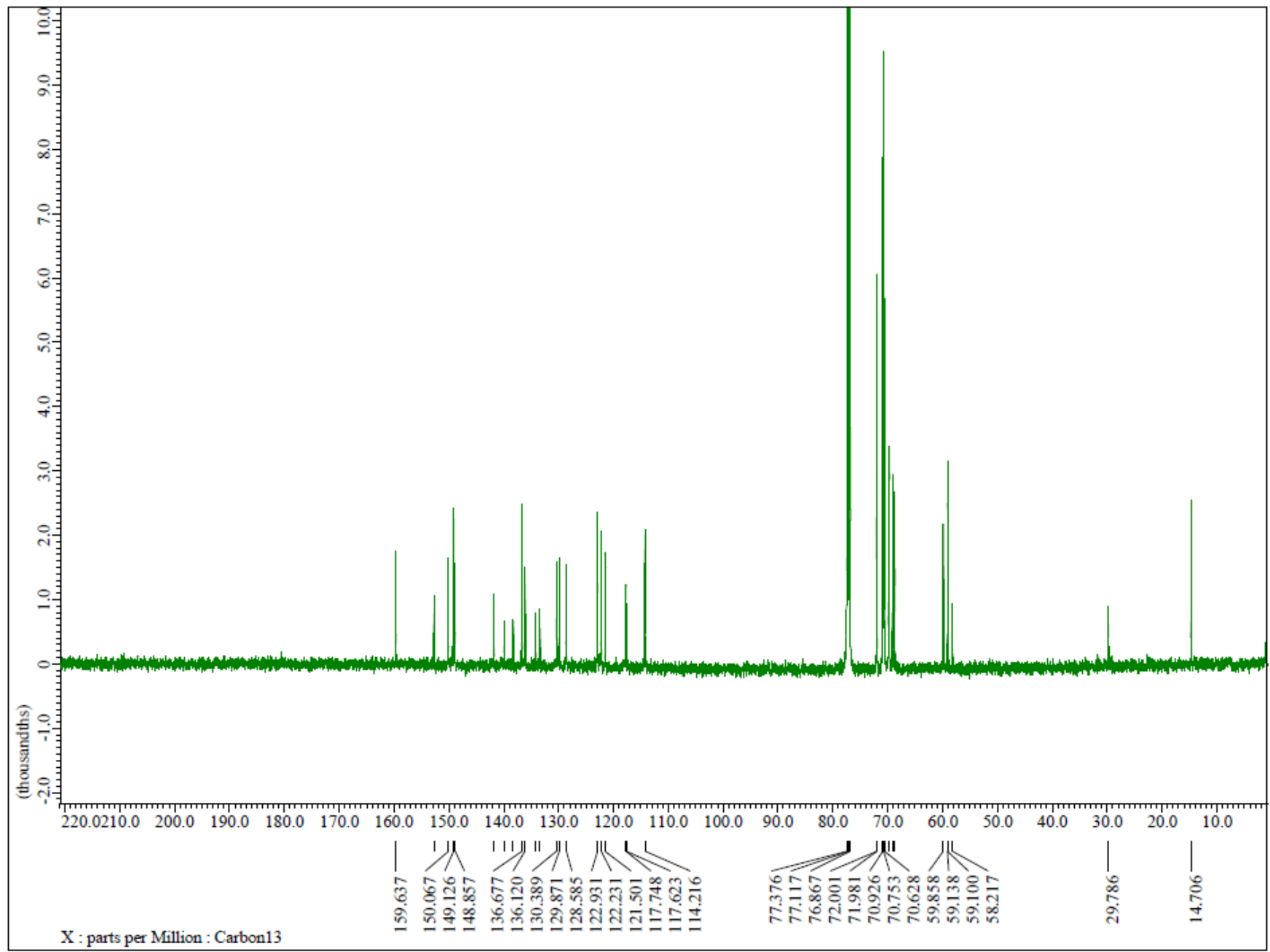

Figure S1: a) ${ }^{1} \mathrm{H}$ and b) ${ }^{13} \mathrm{C}$ NMR spectra of ligand $\mathrm{L}^{5}$ recorded in $\mathrm{CDCl}_{3}$. 


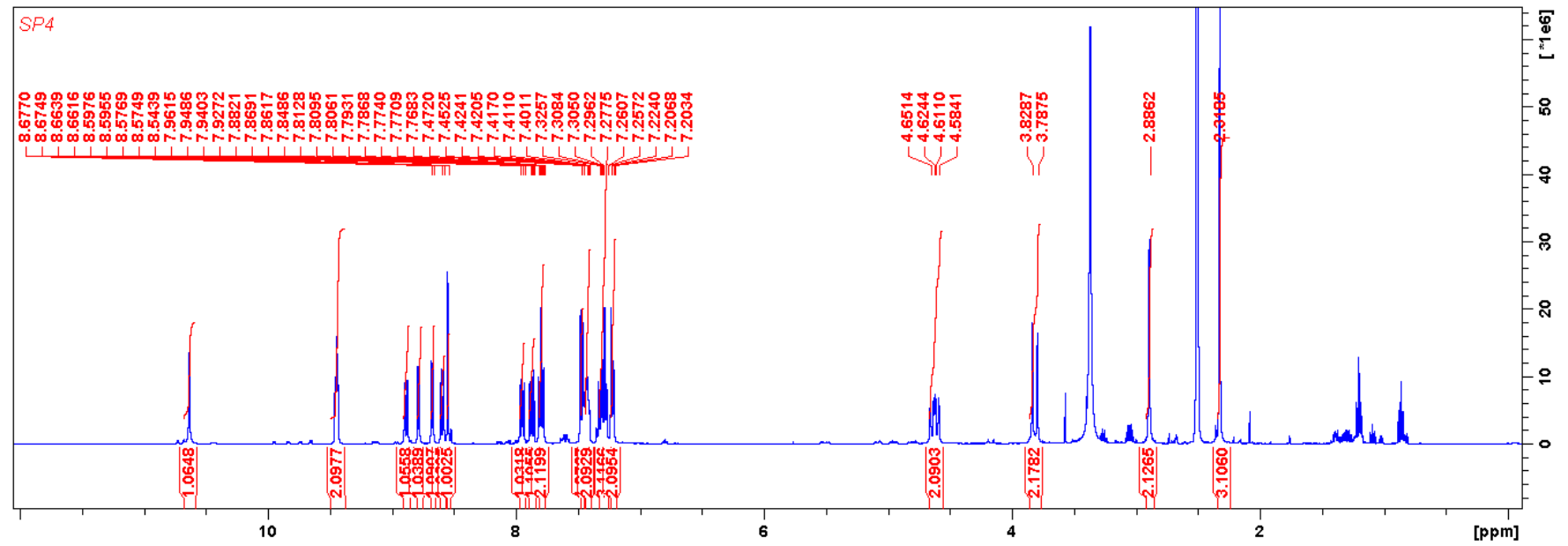

Figure S2: ${ }^{1} \mathrm{H}$ NMR spectrum of complex 1 in DMSO- $\mathrm{d}_{6}$.

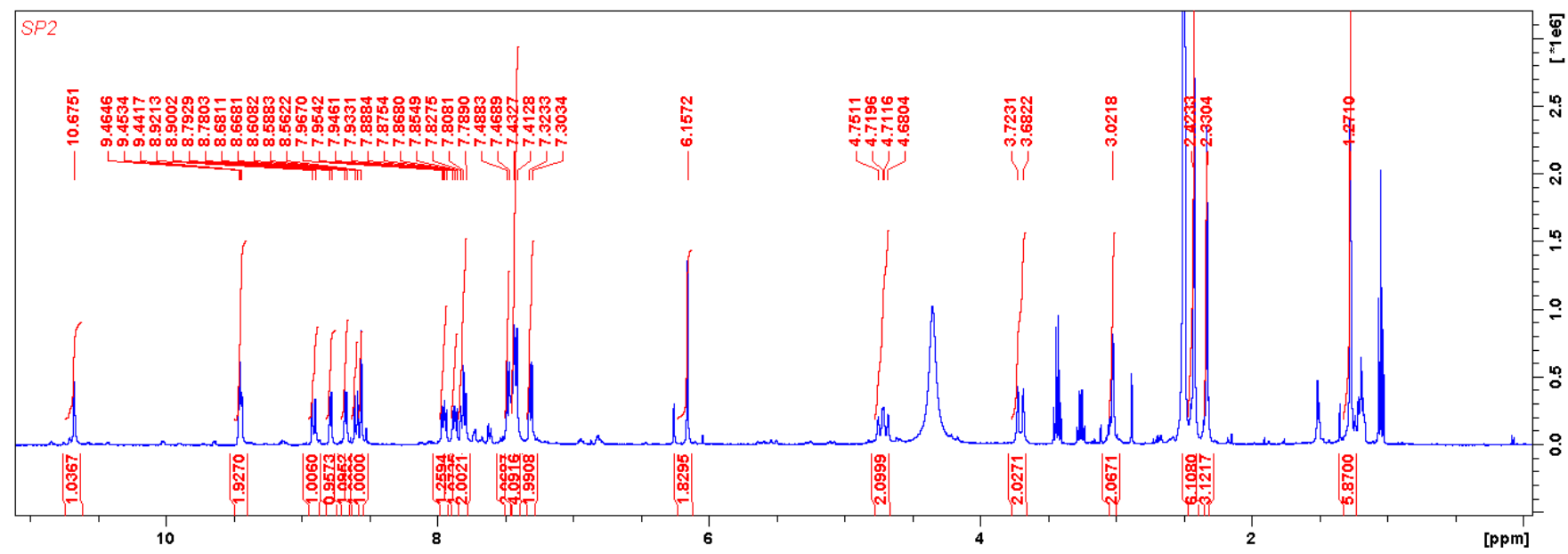

Figure S3: ${ }^{1} \mathrm{H}$ NMR spectrum of complex 2 in DMSO- $\mathrm{d}_{6}$.

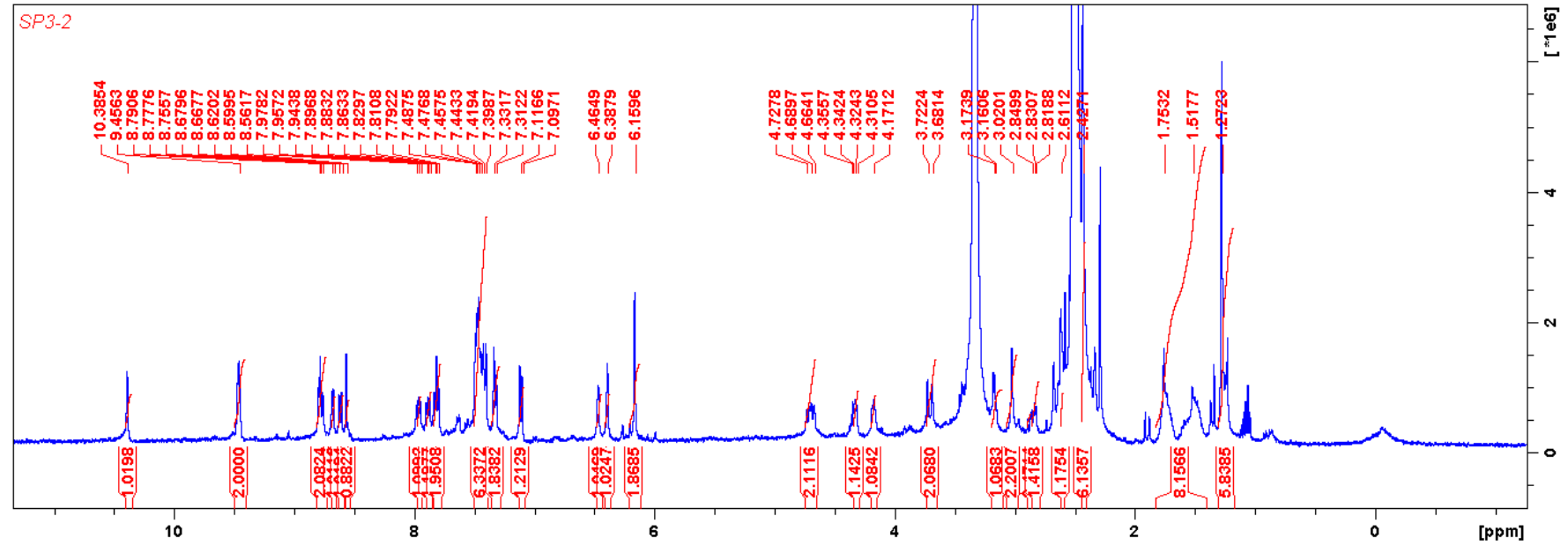

Figure S4: ${ }^{1} \mathrm{H}$ NMR spectrum of complex 3 in DMSO- $\mathrm{d}_{6}$. 


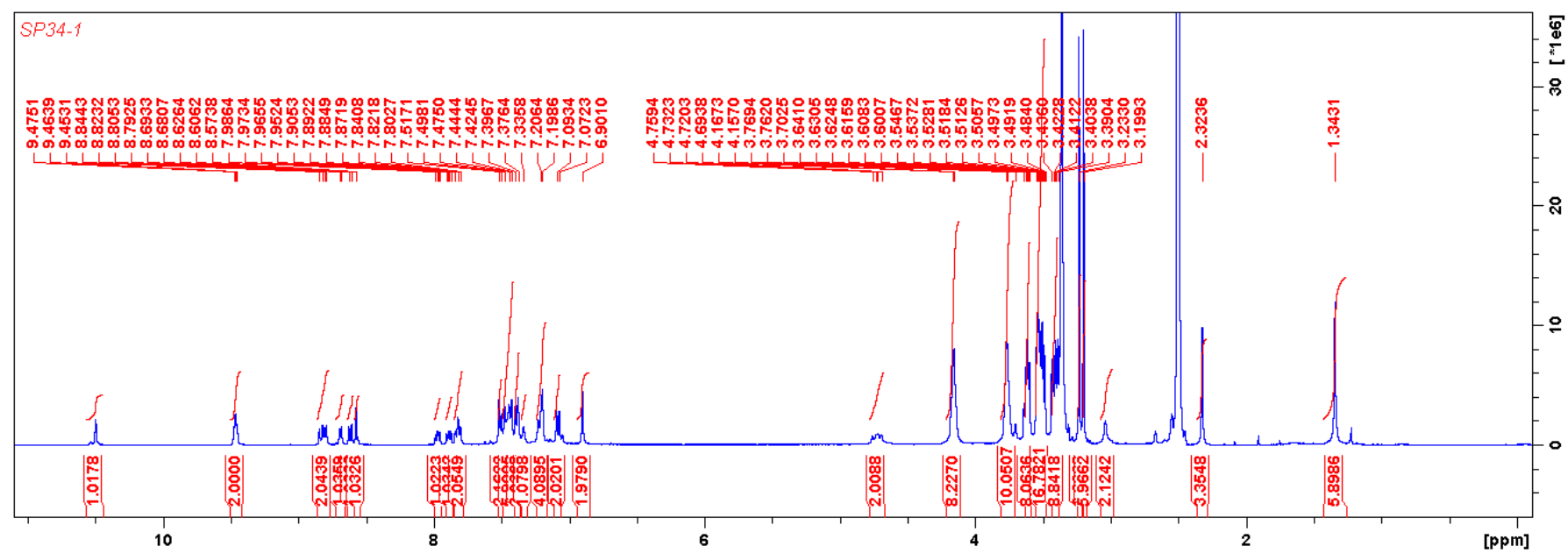

Figure S5: ${ }^{1} \mathrm{H}$ NMR spectrum of complex 4 in DMSO- $\mathrm{d}_{6}$.

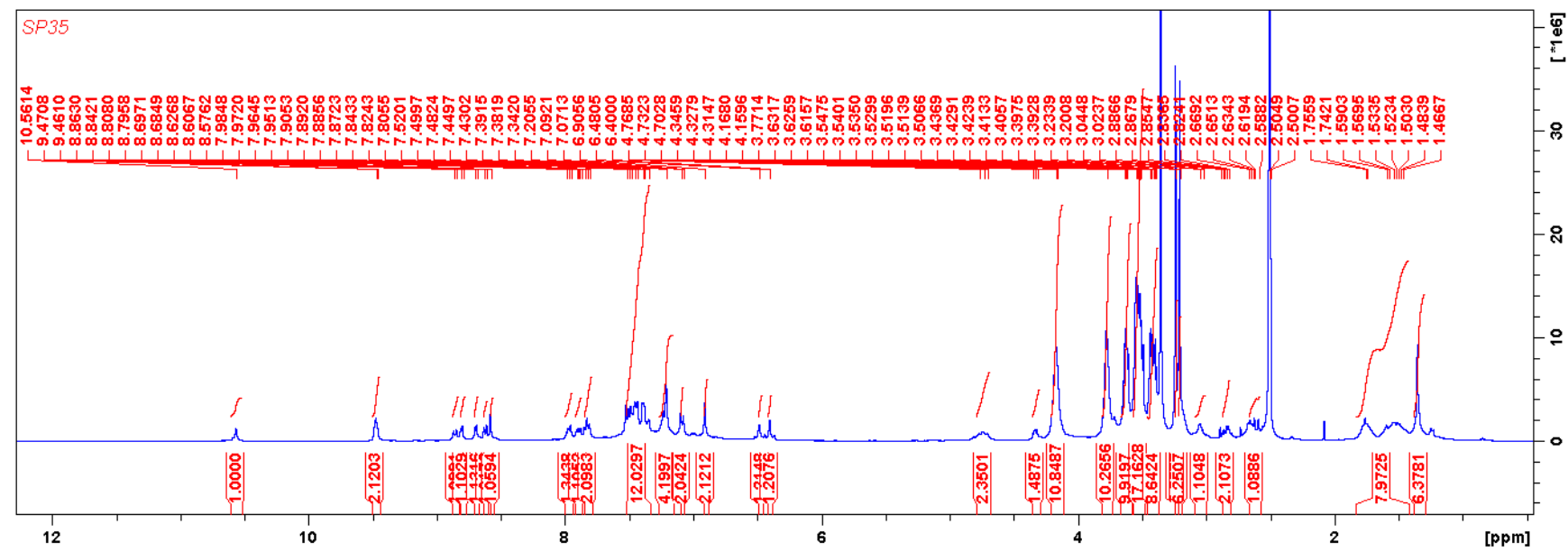

Figure S6: ${ }^{1} \mathrm{H}$ NMR spectrum of complex 5 in DMSO- $\mathrm{d}_{6}$.

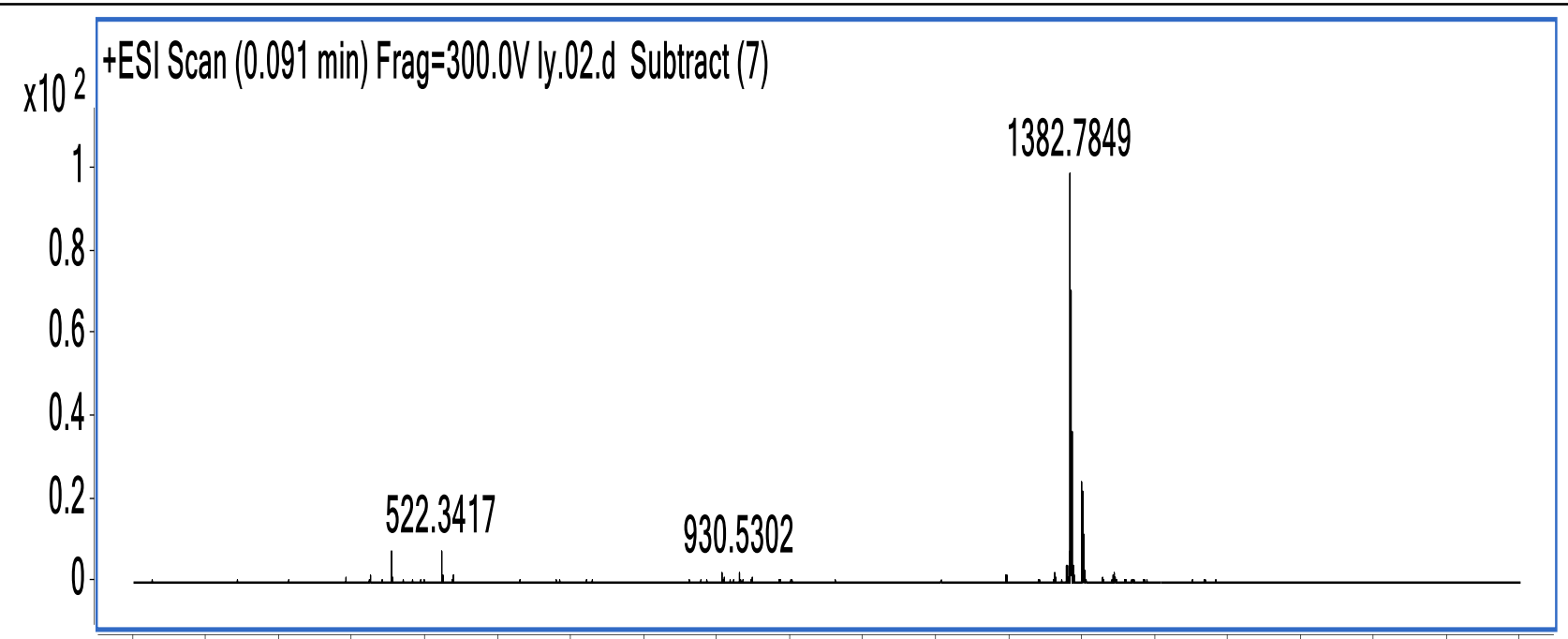

$100200300400500600700 \quad 80090010001100120013001400150016001700180019002000$ Counts $\% \%$ vs. Mass-to-Charge (m/z)

Figure S7: Mass spectrum of $\mathrm{L}^{5}$ in $\mathrm{MeOH}$ with peak corresponding to $[\mathrm{M}+\mathrm{Na}]^{+}(\mathrm{m} / \mathrm{z})$ at 1382.7849. 

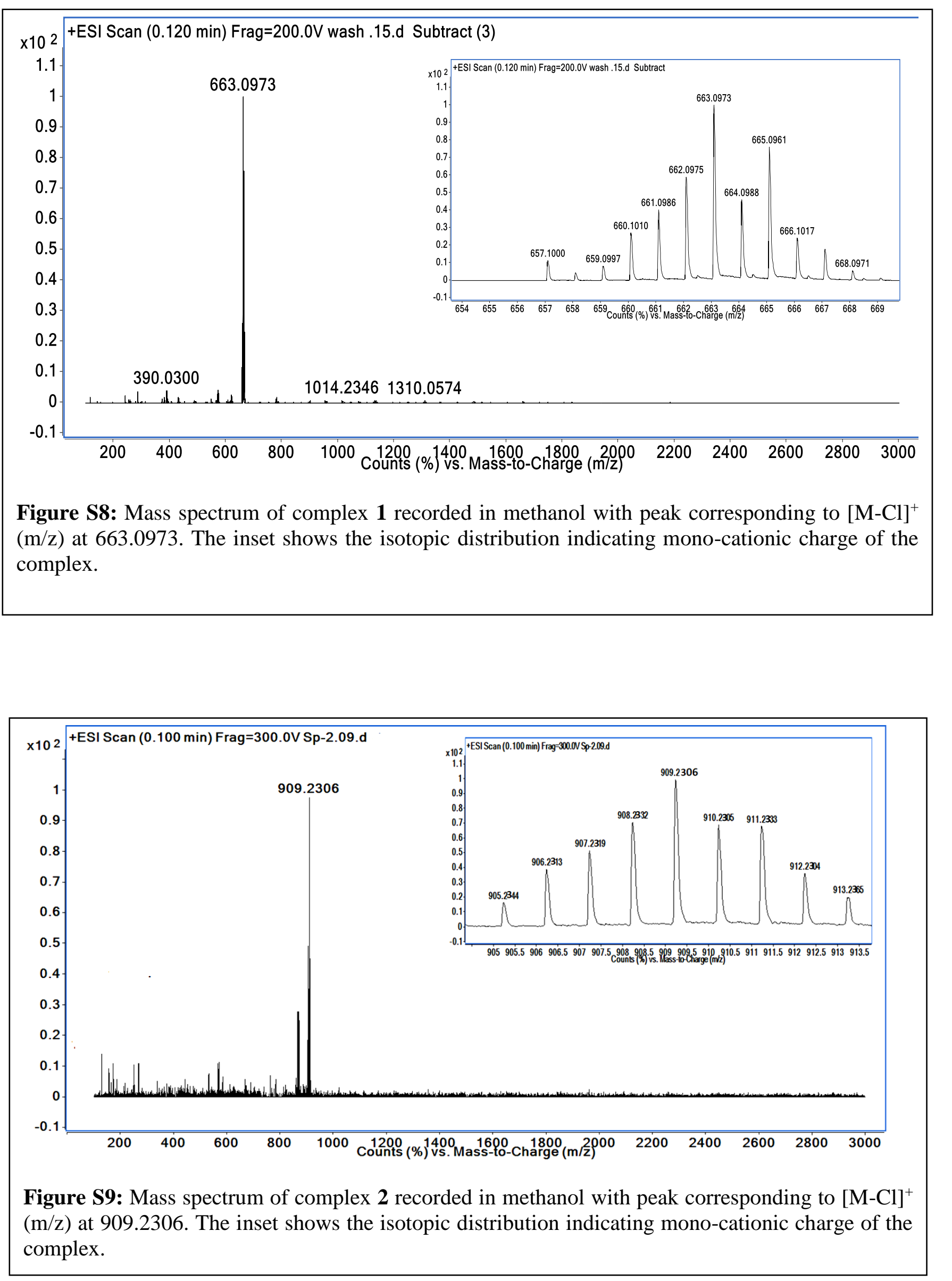

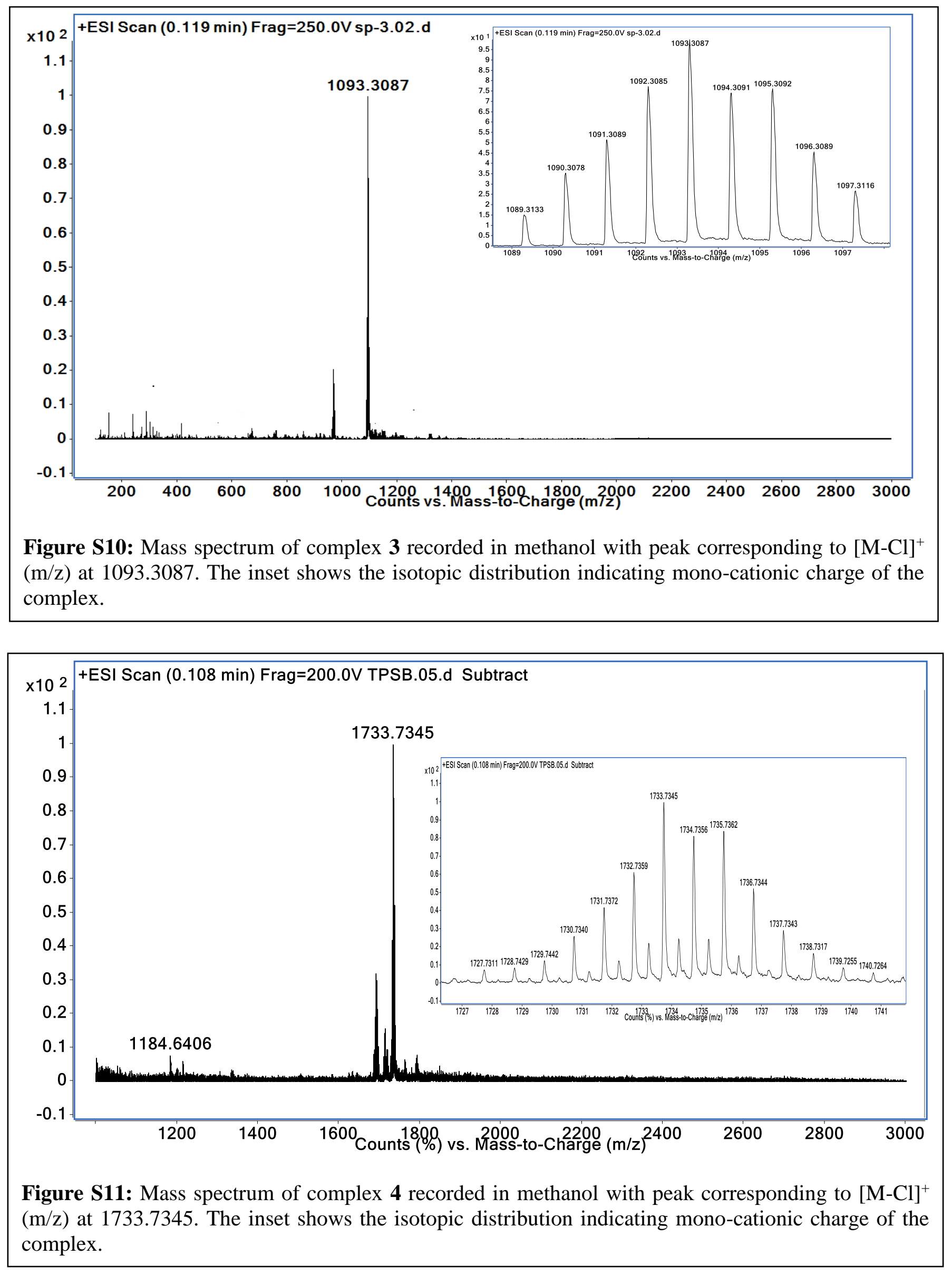

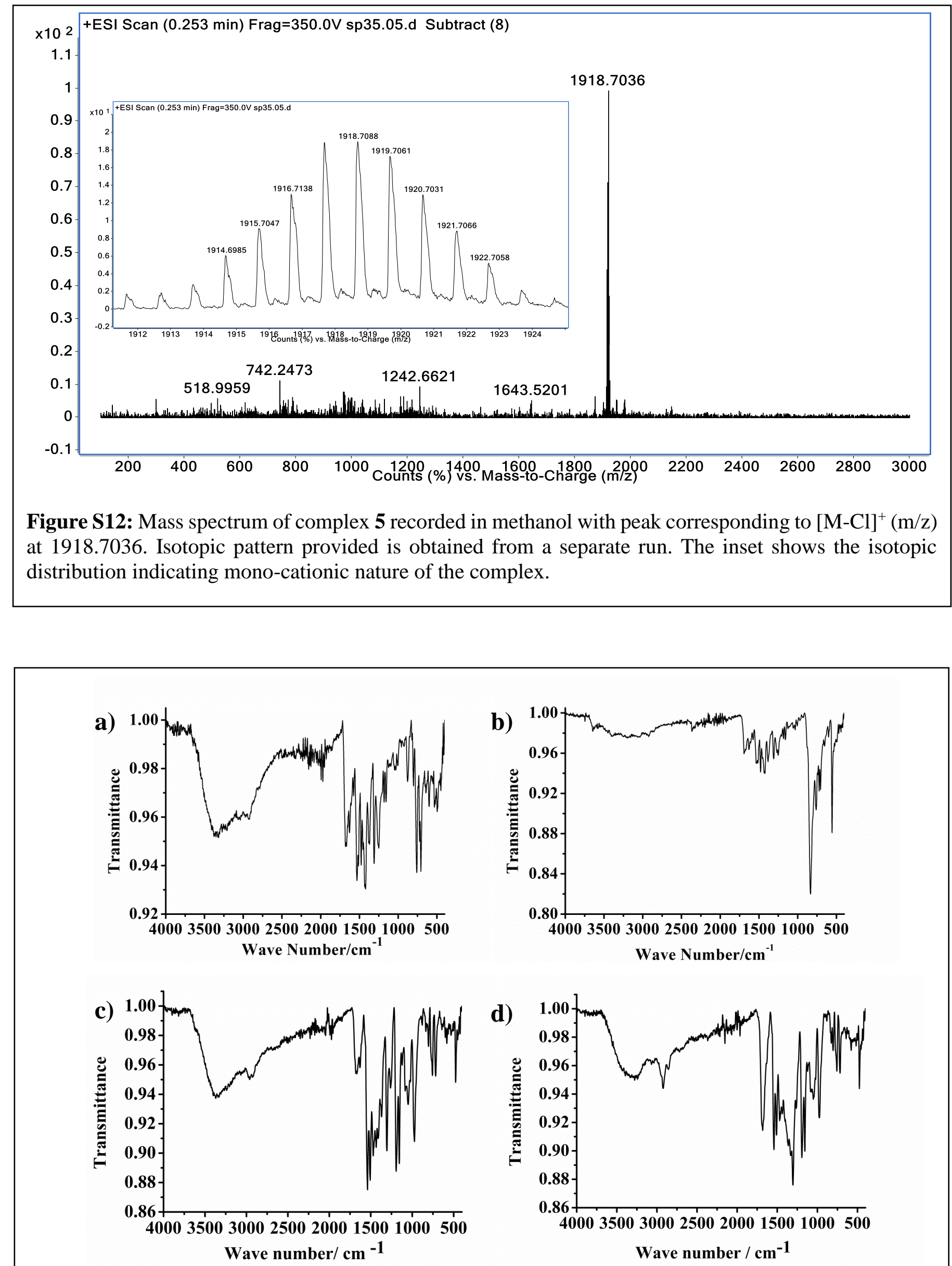

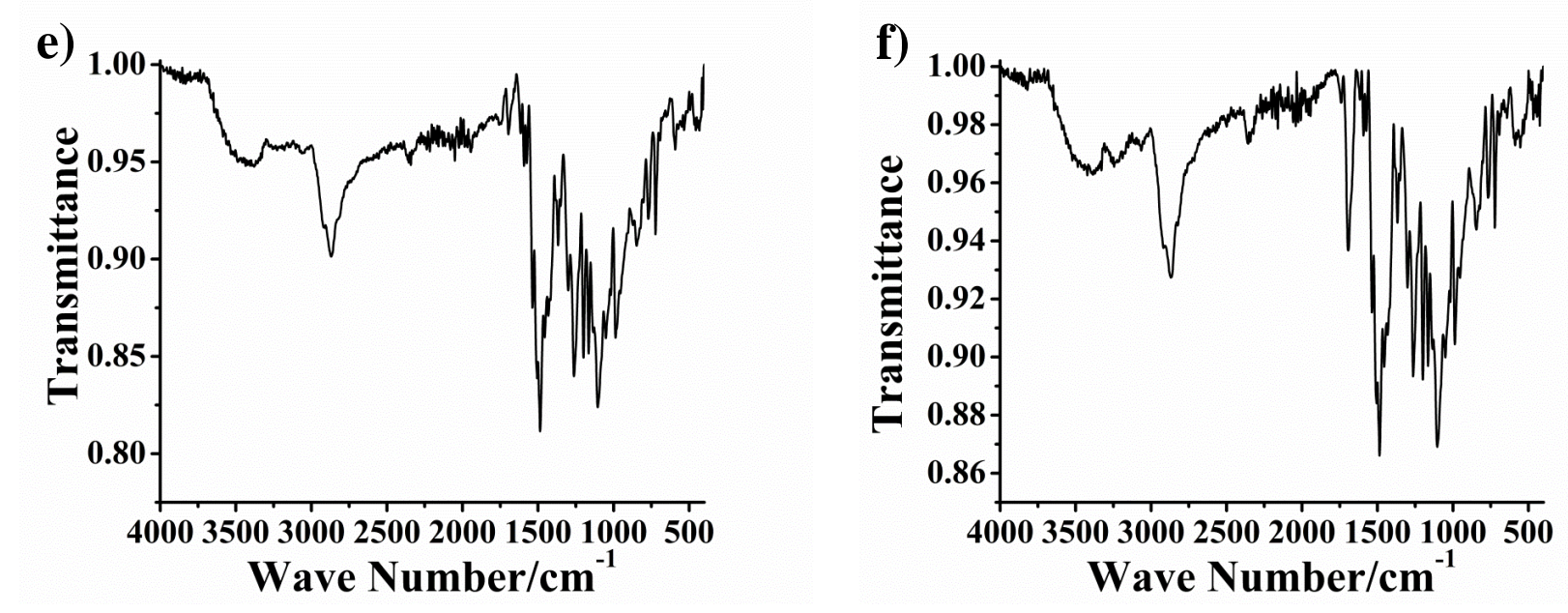

Figure S13: IR spectra of the complexes: a) complex 1; b) complex 1a; c) complex 2; d) complex 3; e) complex 4; f) complex 5. The strong peak of $\mathrm{PF}_{6}$ anion for $\mathbf{1 a}$ is visible in the IR spectrum shown in (b).
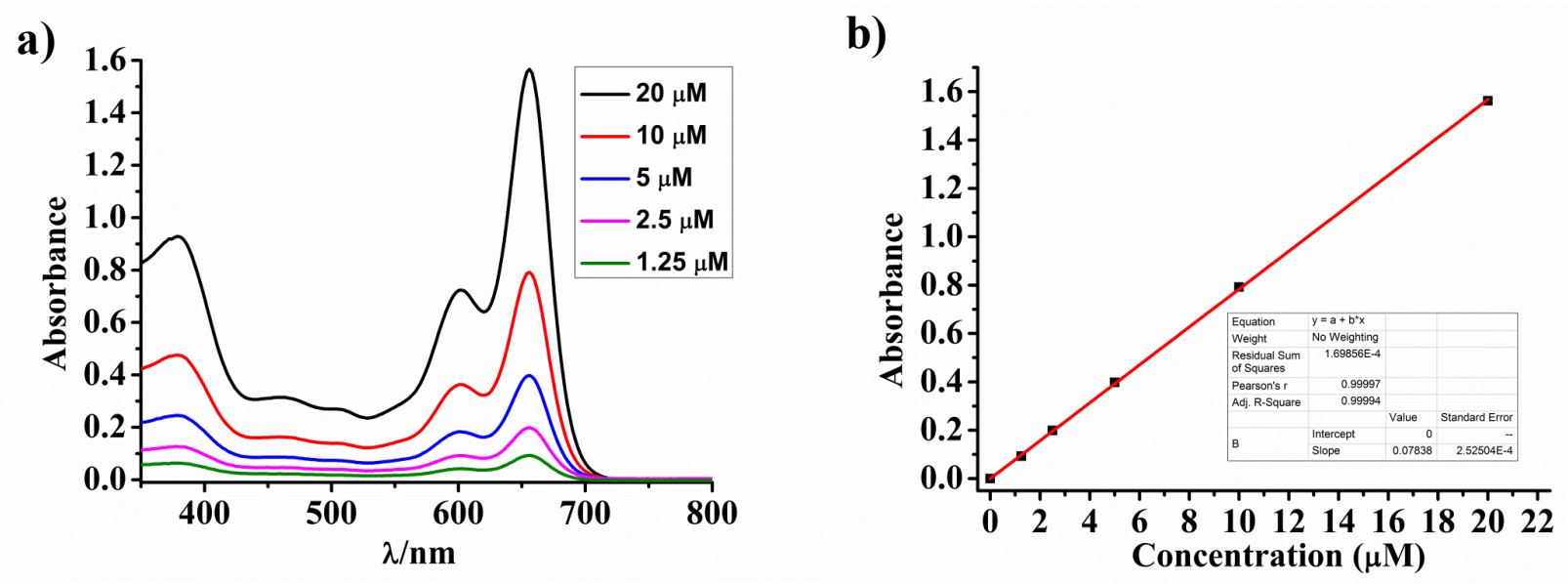

Figure S14: a) UV- VIS spectra of complex 5 recorded in 1:1 DMSO- DPBS (V/V) at different concentrations. b) Absorbance vs. concentration plot for complex $\mathbf{5}$. 

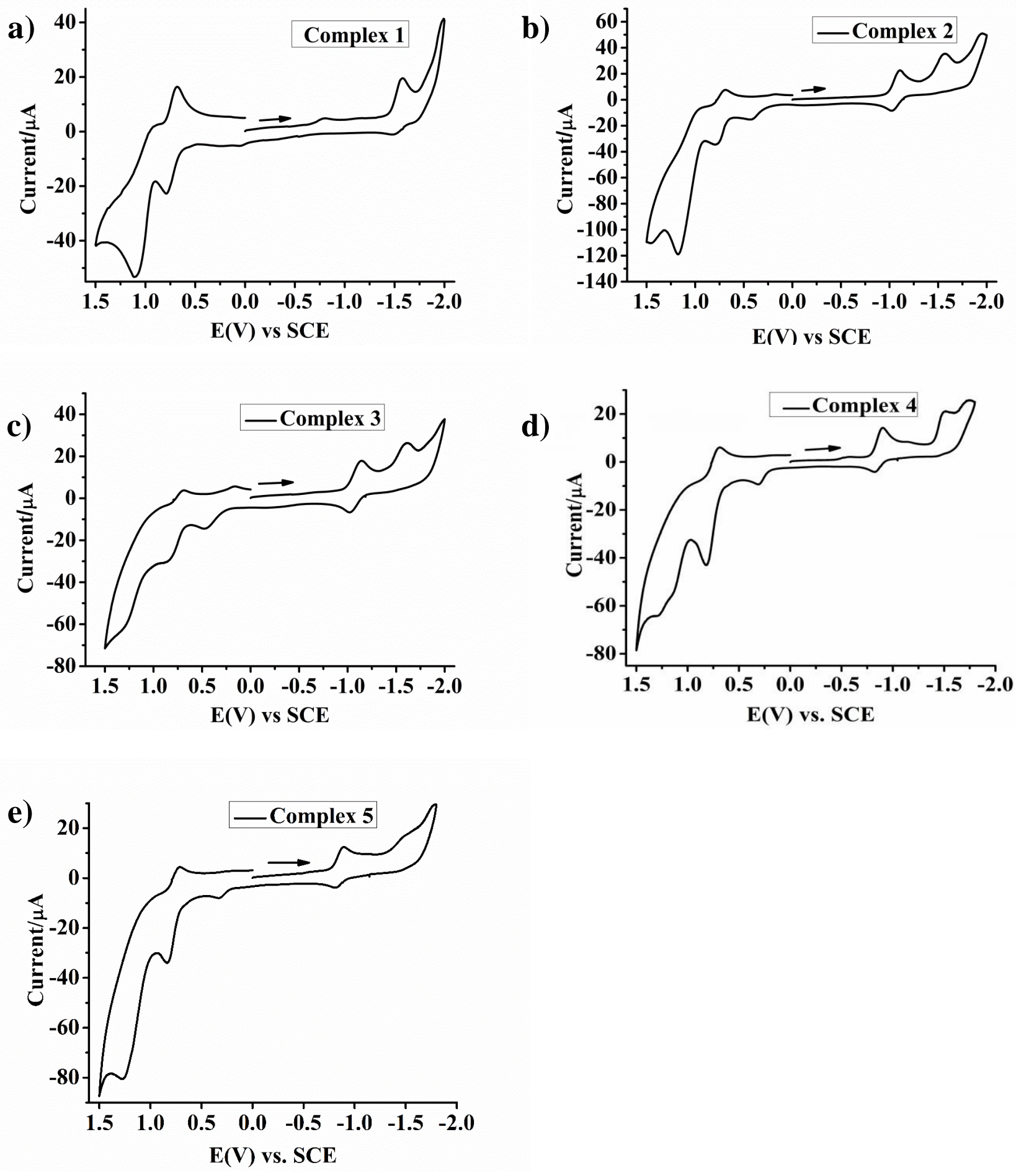

Figure S15: Cyclic voltammograms of the complexes: a) complex 1, b) complex 2, c) complex 3, d) complex 4, and e) complex 5 in 0.1M TBAP-DMF using 2.0 mmol concentration at a scan rate of 100 $\mathrm{mV} \mathrm{sec}{ }^{-1}$. 

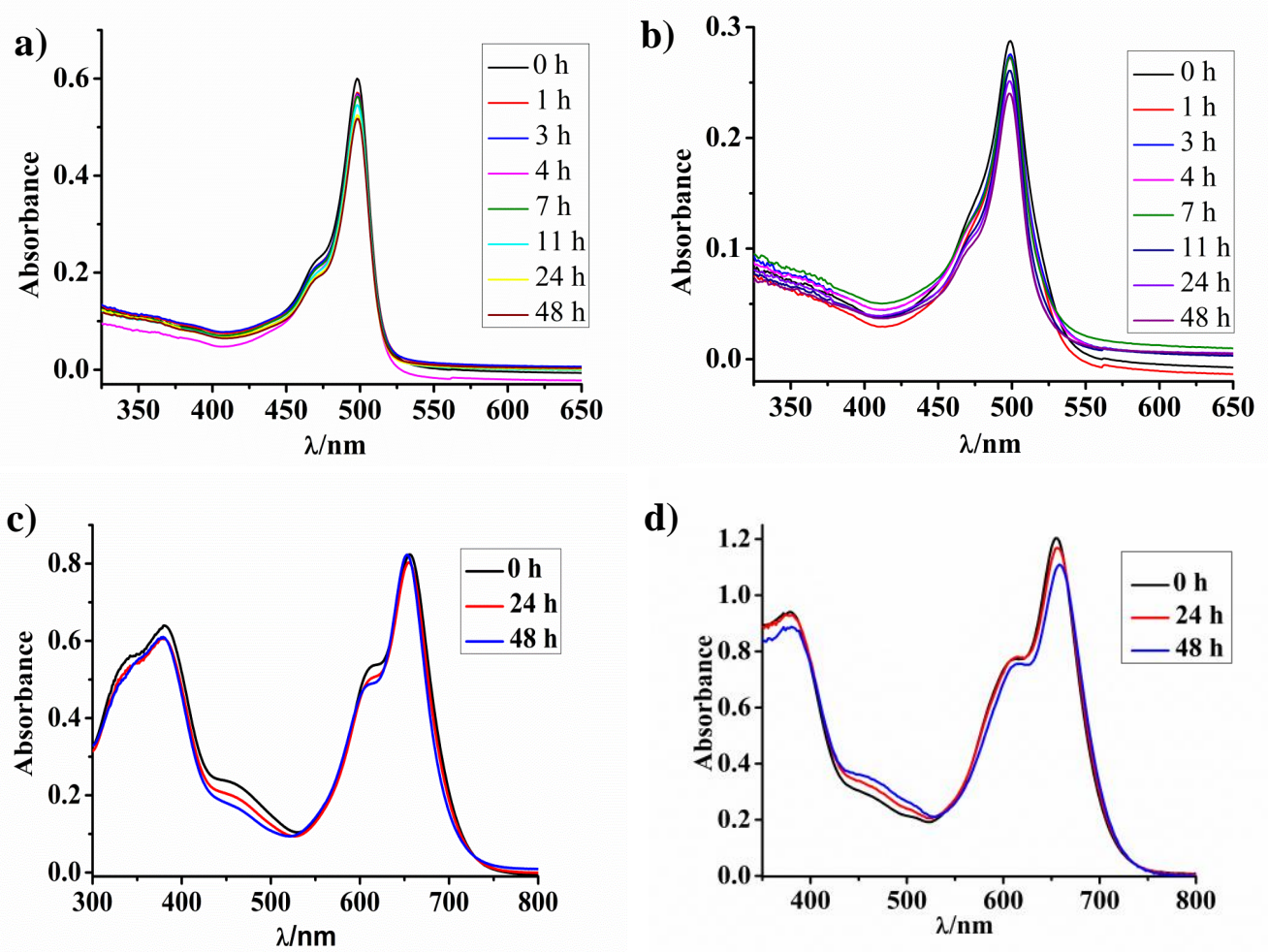

d)
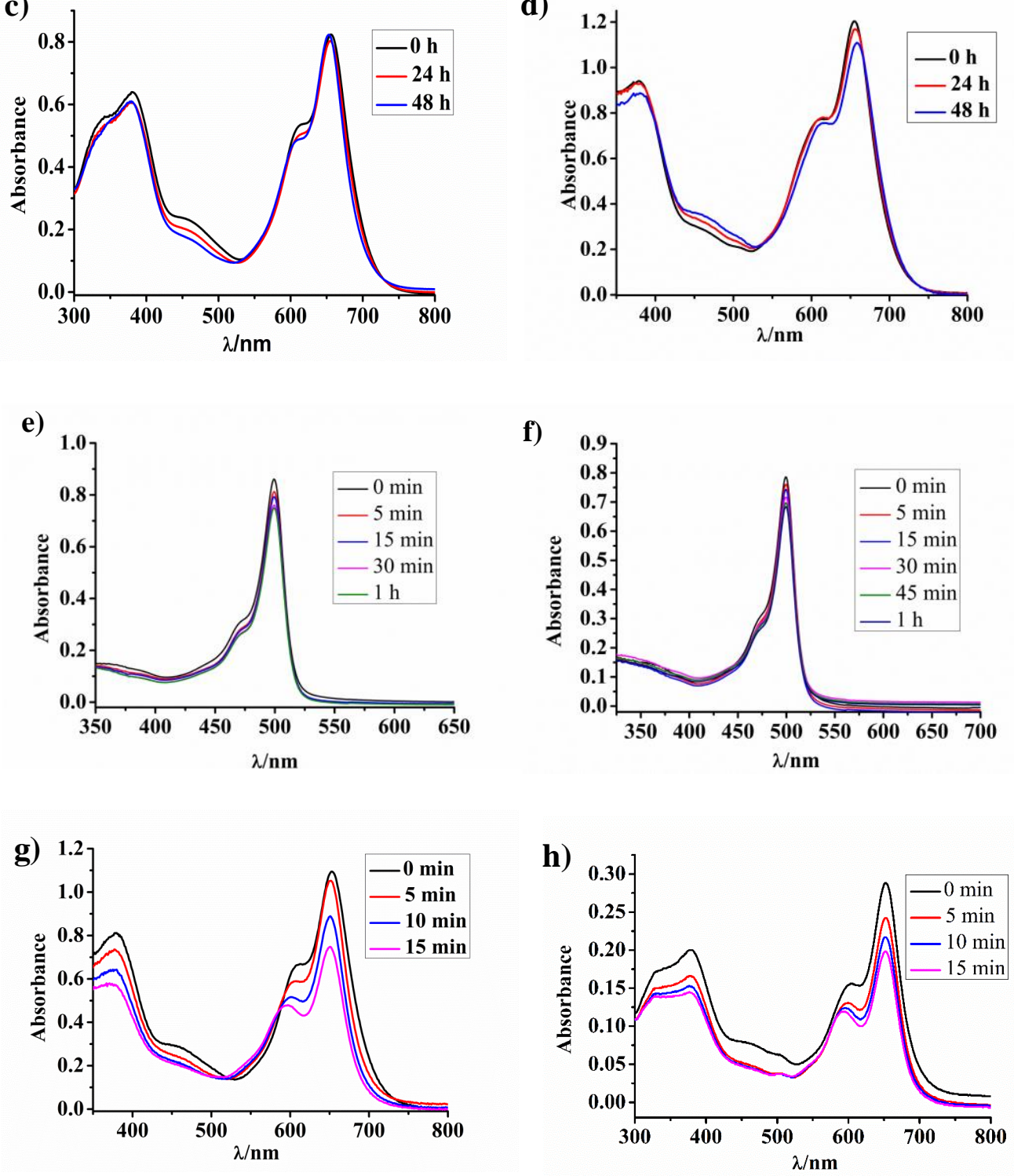

Figure S16: Change in the absorption spectral traces with time for the complexes: a) complex 2; b) complex 3; c) complex 4; and d) complex 5 in 10\% (V/V) DMSO-DPBS. The experiments were carried out over a period of $48 \mathrm{~h}$ and the spectra are recorded at certain intervals as mentioned in the figures. Photostability studies: e) complex 2; f) complex 3; g) complex 4; h) complex 5 in $10 \%$ (V/V) DMSODPBS $\left[10 \mathrm{~J} / \mathrm{cm}^{2}\right.$ (400- $700 \mathrm{~nm}, 1 \mathrm{~h}$ irradiation time) light dose for complexes 2 and $\mathbf{3}$ and $30 \mathrm{~J} / \mathrm{cm}^{2}(600$ $720 \mathrm{~nm}, 15 \mathrm{~min}$ irradiation time) light dose for complexes $\mathbf{4}$ and $\mathbf{5}$. 

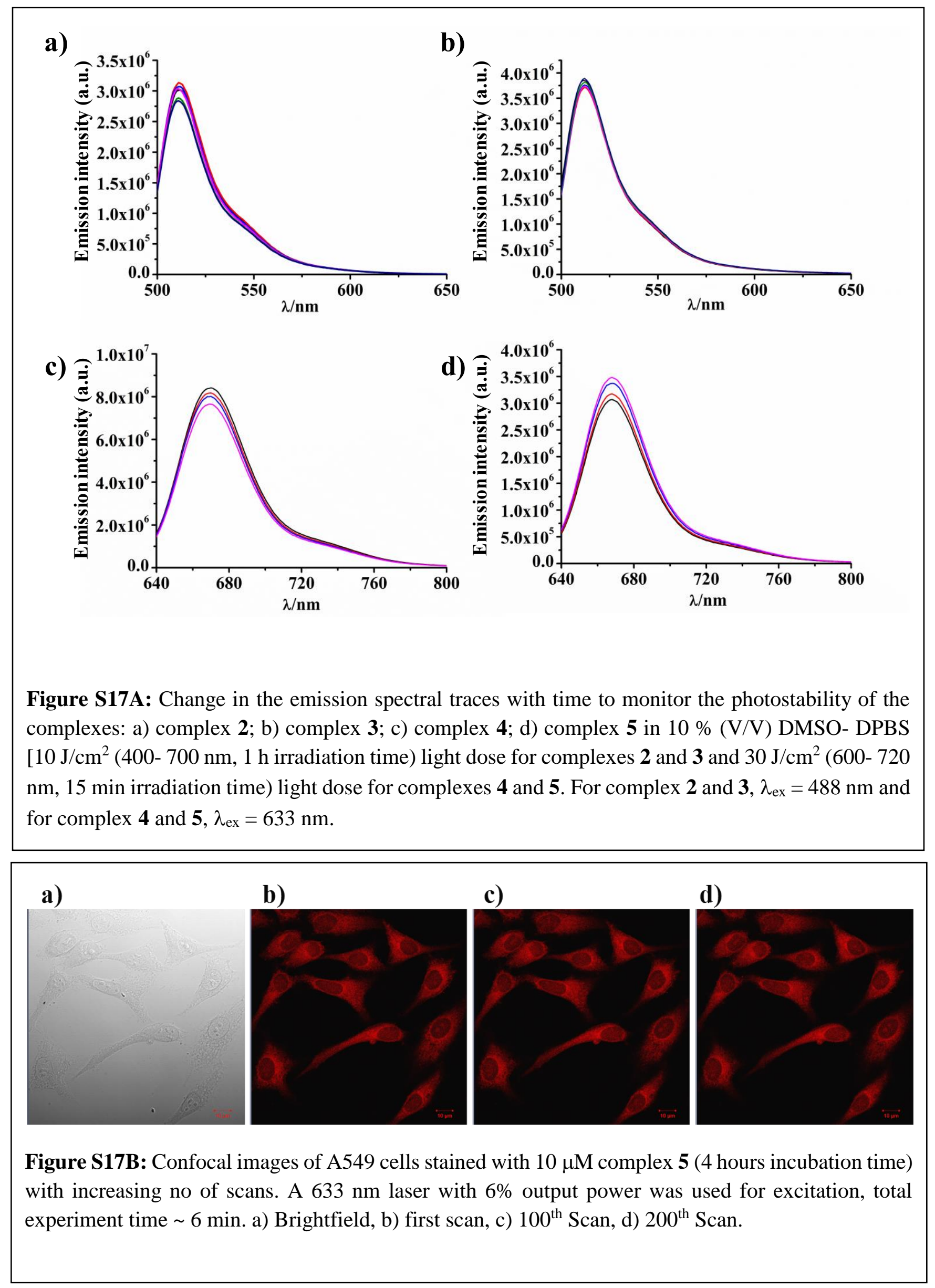


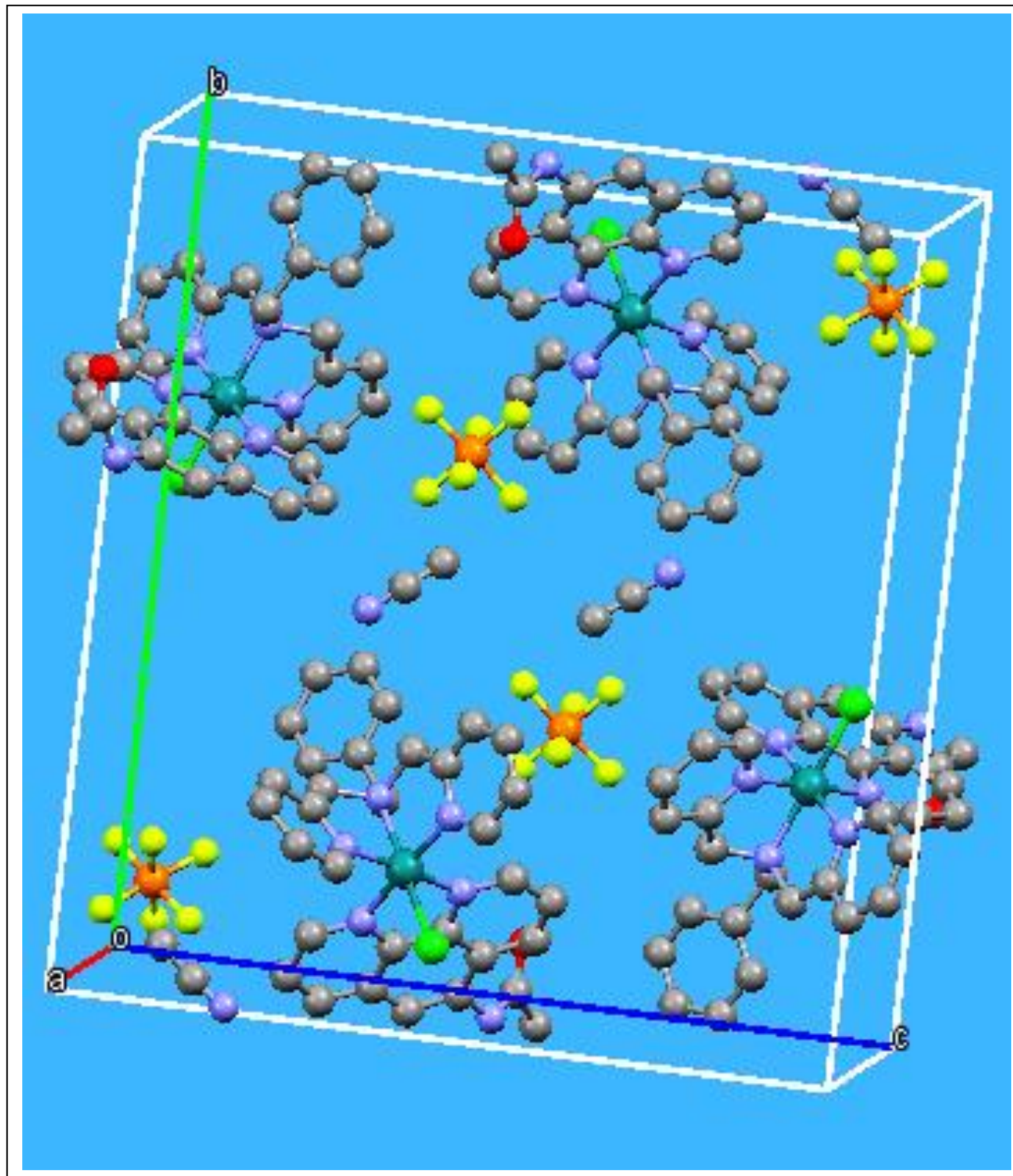

Figure S18: Unit cell packing diagram of complex 1a. Colour codes: Ruthenium, cyan; Chlorine, green; carbon, grey; Fluorine, lemon yellow; Phosphorus, dark yellow; Oxygen, red; Nitrogen, blue. 
a)
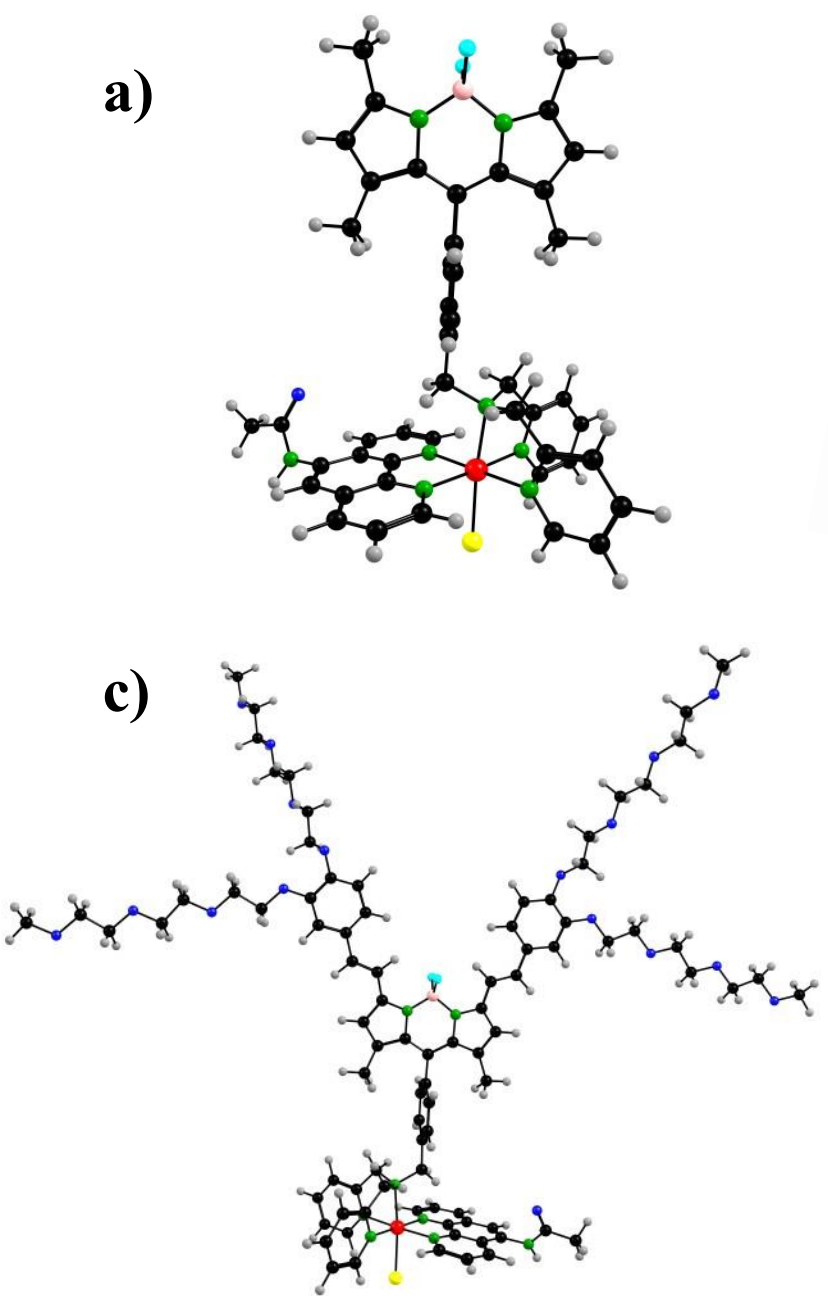

b)

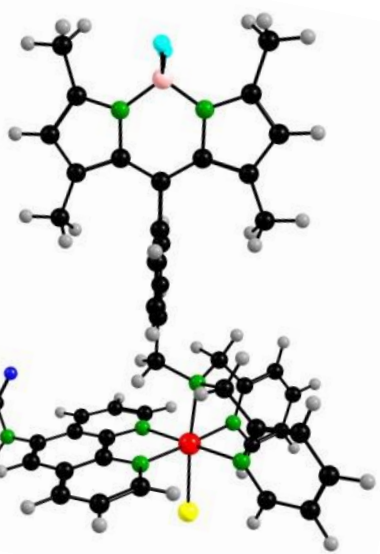

d)

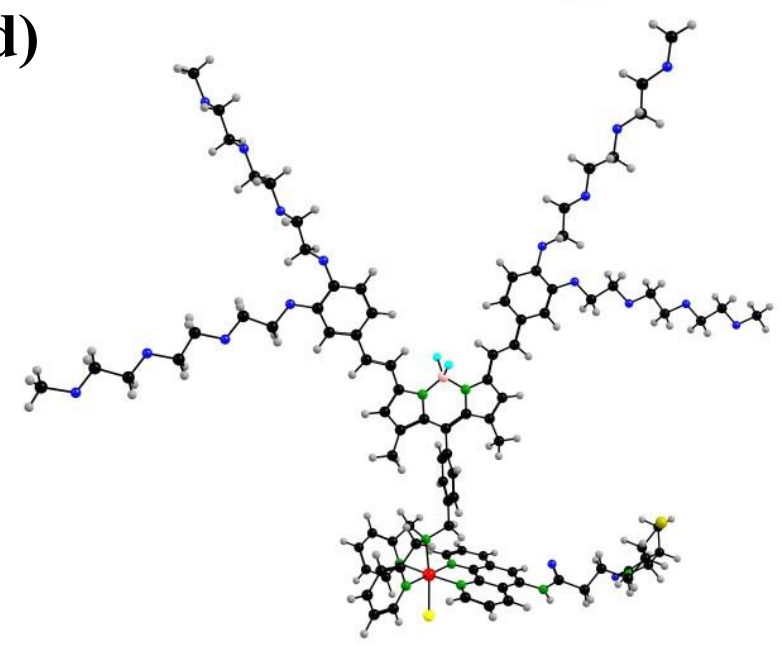

Figure S19: Energy minimized structures of the complexes: a) Complex 2; b) Complex 3; c) Complex 4; d) Complex 5. Colour codes: Red, Ruthenium; Green, Nitrogen; Black, Carbon; Blue, Oxygen; Grey, Hydrogen; Lemon yellow, Chlorine; Dark yellow, Sulphur; Pink, Boron; Sky blue, Fluorine. 


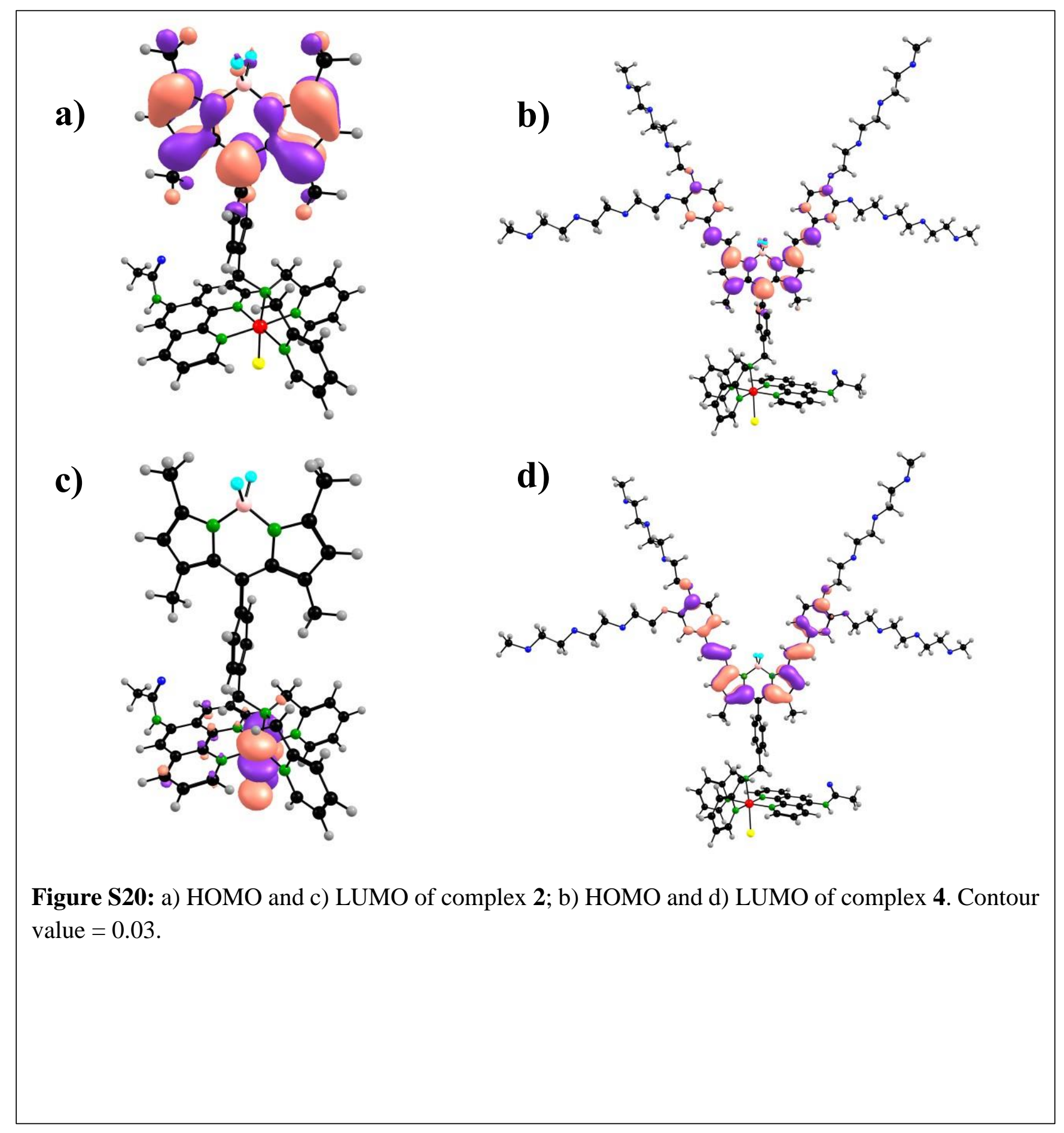


a)

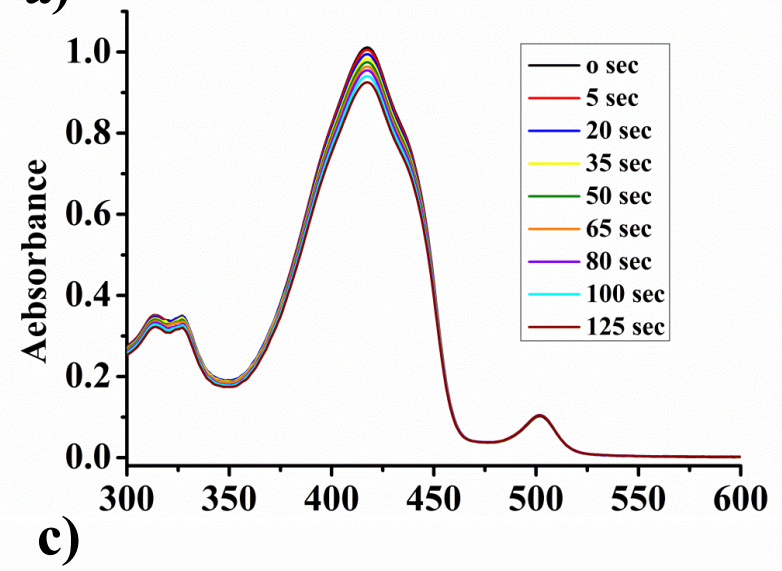

c)

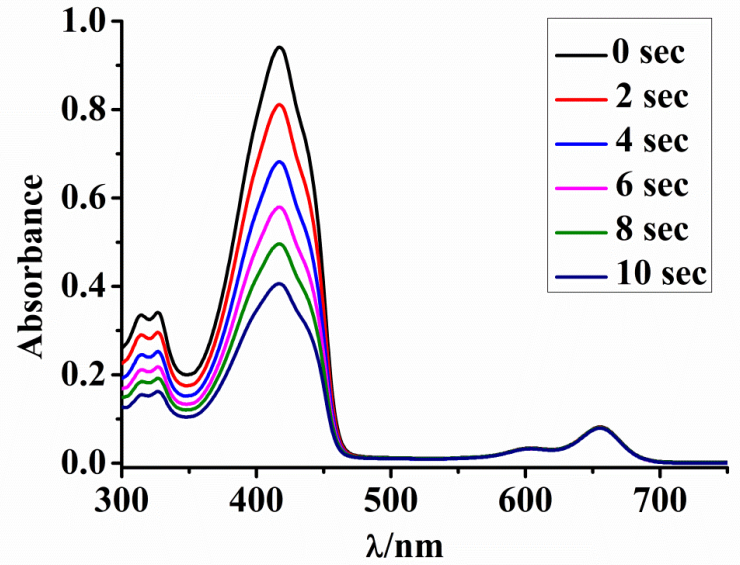

b)
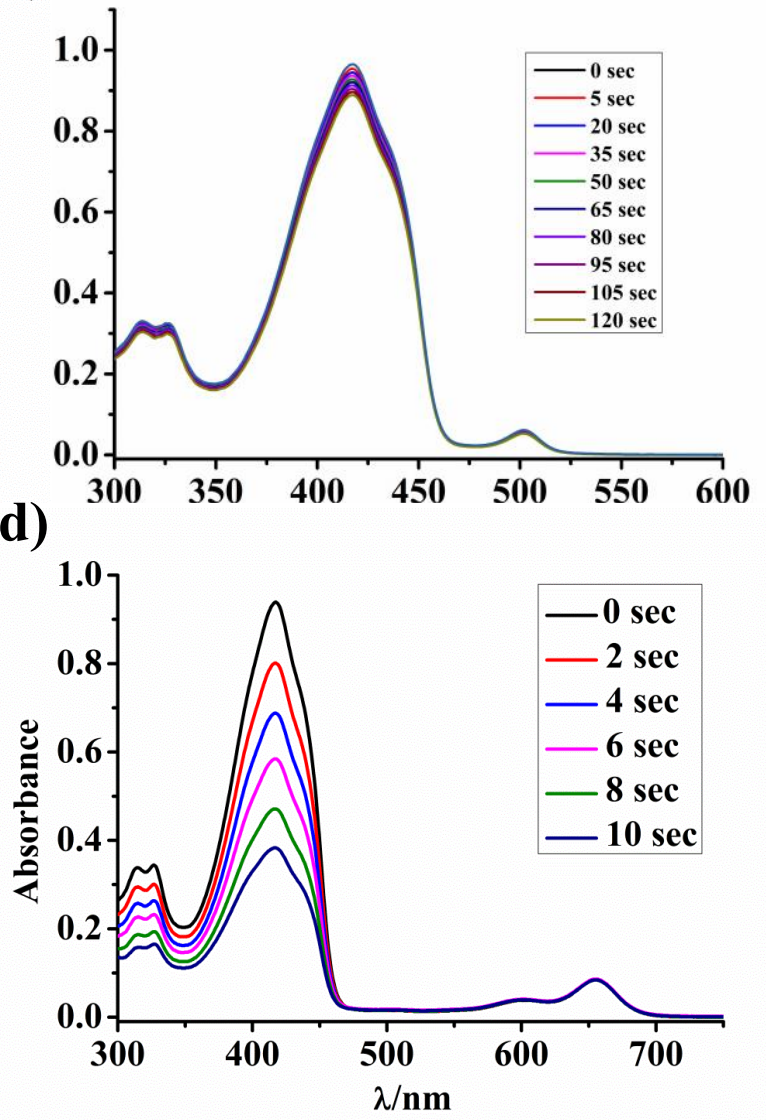

Figure S21: Changes in the absorption spectra of DPBF containing complexes (50: 1 concentration ratio) with light irradiation: a) complex 2 ; b) complex 3 ; c) complex $\mathbf{4}$ and d) complex 5 . For complexes $\mathbf{2}$ and 3, a $400-700 \mathrm{~nm}$ light source $\left(2.4 \mathrm{~mW} / \mathrm{cm}^{2}\right)$ was used for irradiation, while for complexes 4 and $\mathbf{5}$, a $660 \mathrm{~nm}$ laser $(100 \mathrm{~mW})$ was used.
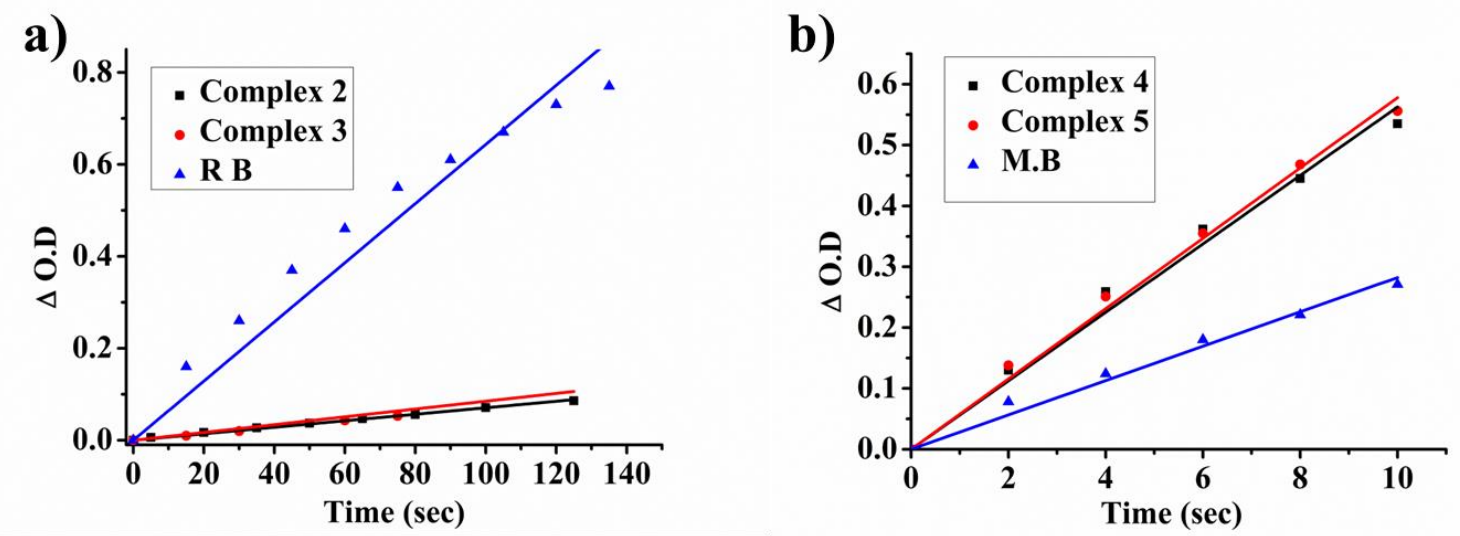

Figure S22: Linear fits of $\Delta$ O.D. vs. irradiation time for determination of singlet oxygen quantum yield. 


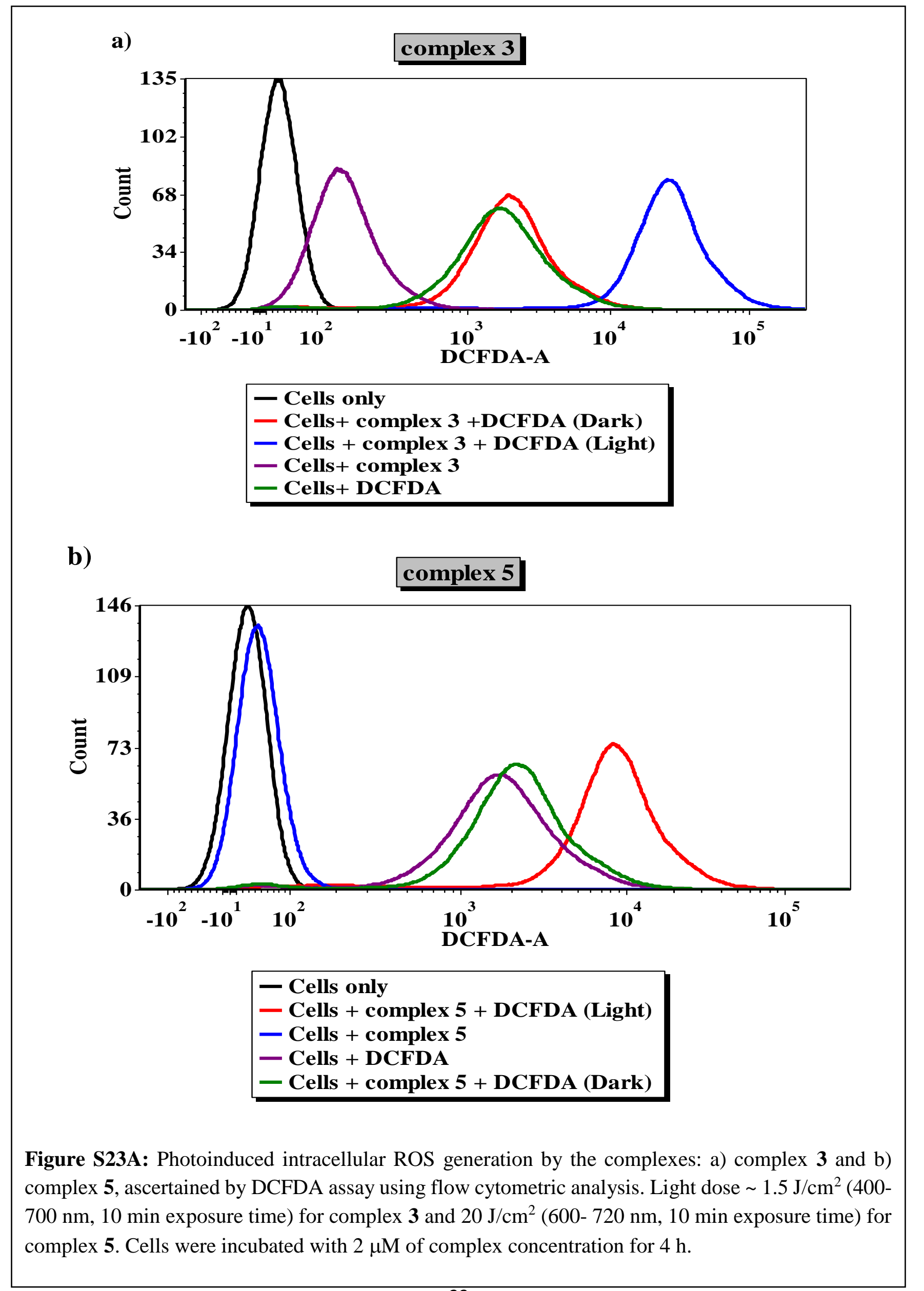


a)

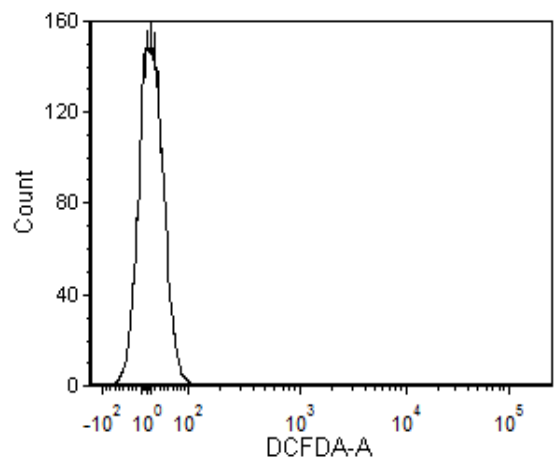

d)

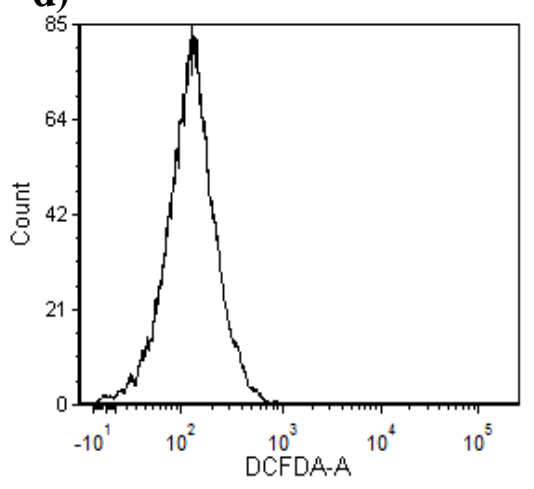

i)

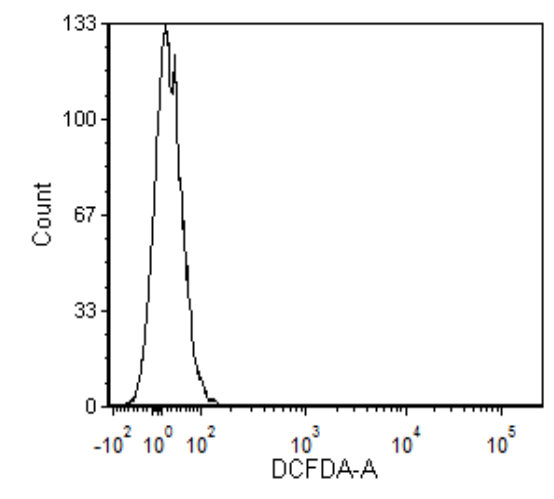

b)
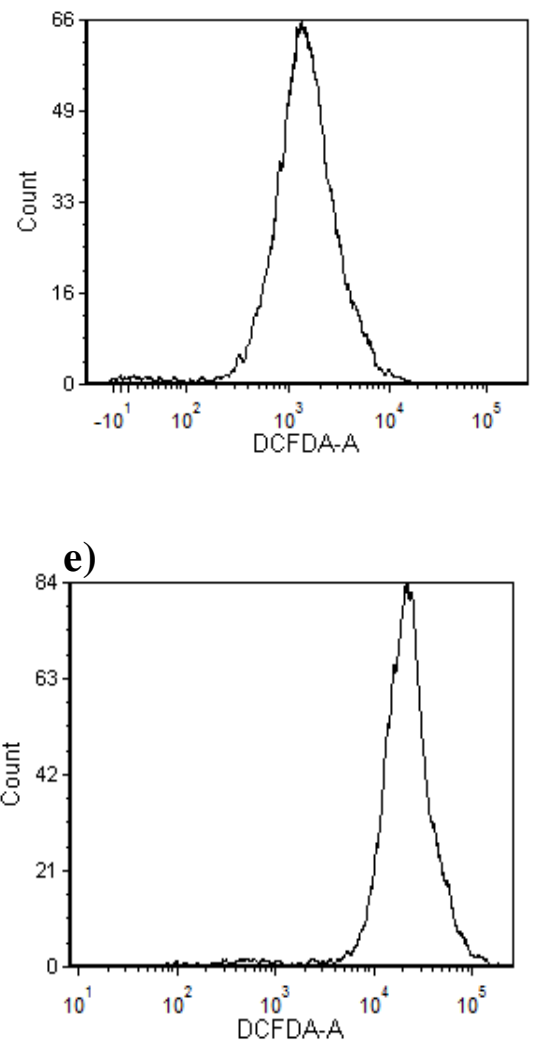

j)

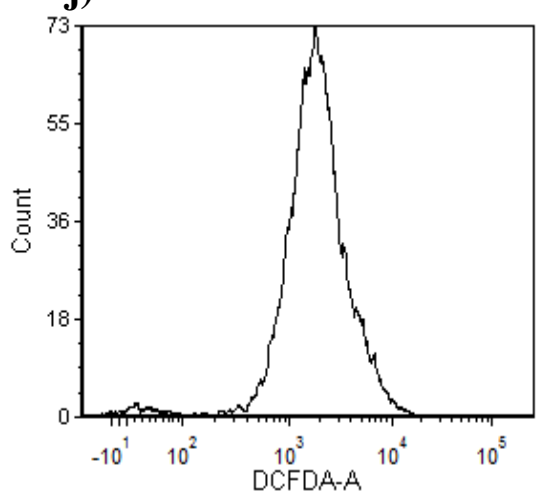

c)
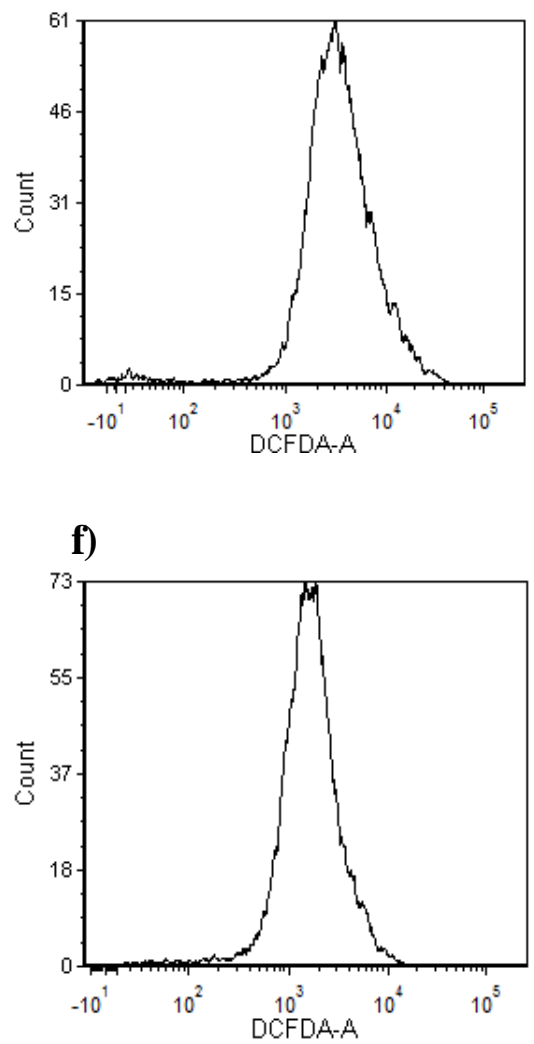

k)

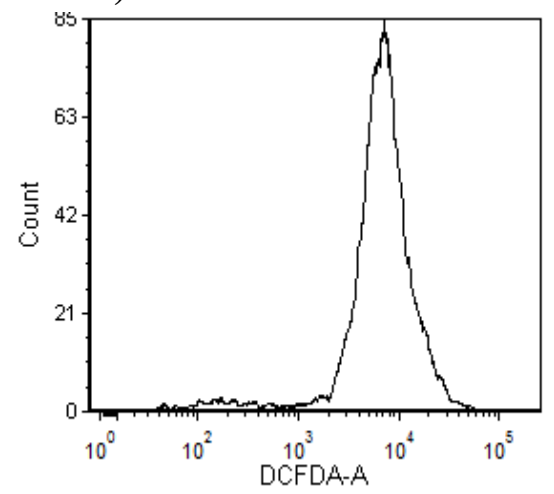

Figure S23B: Individual plots for the DCFDA experiment. a) Cells only, b) Cells with DCFDA, c) Cells with DCFDA and $\mathrm{H}_{2} \mathrm{O}_{2}$, d) Cells treated with complex 3, e) Cells with DCFDA and complex 3 in dark, f) Cells with DCFDA and complex 3 with light treatment, d) Cells treated with complex $\mathbf{5}$, e) Cells with DCFDA and complex 5 in dark, f) Cells with DCFDA and complex 5 with light treatment. 


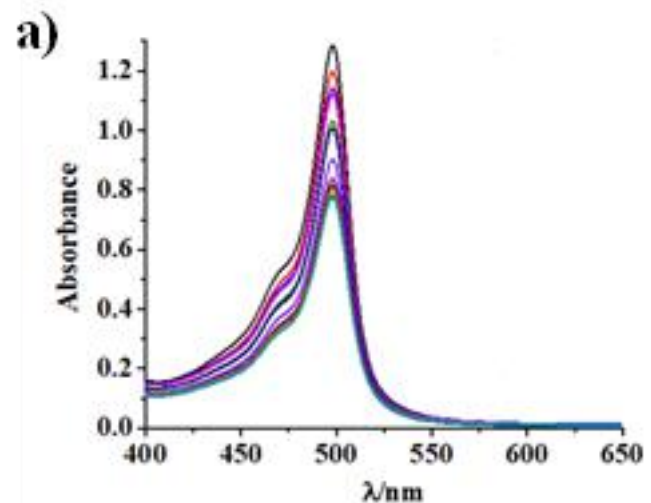

c)

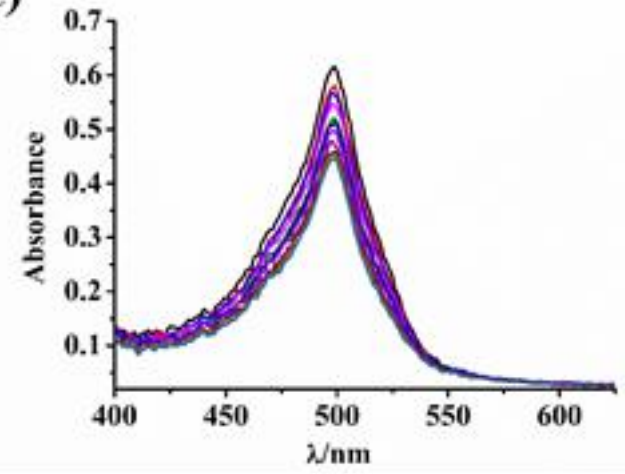

b)

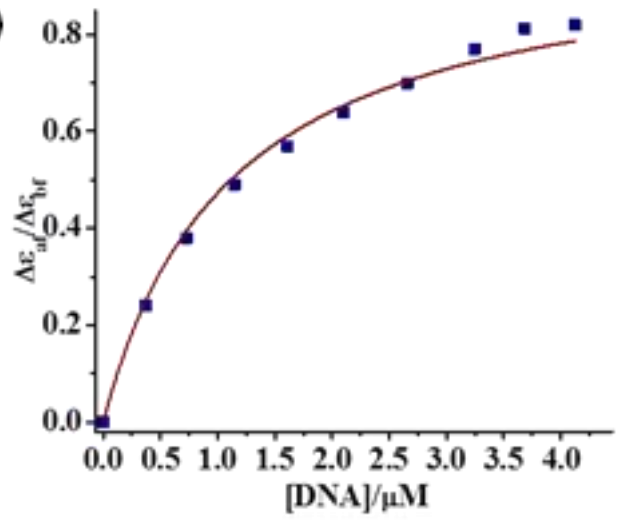

d)

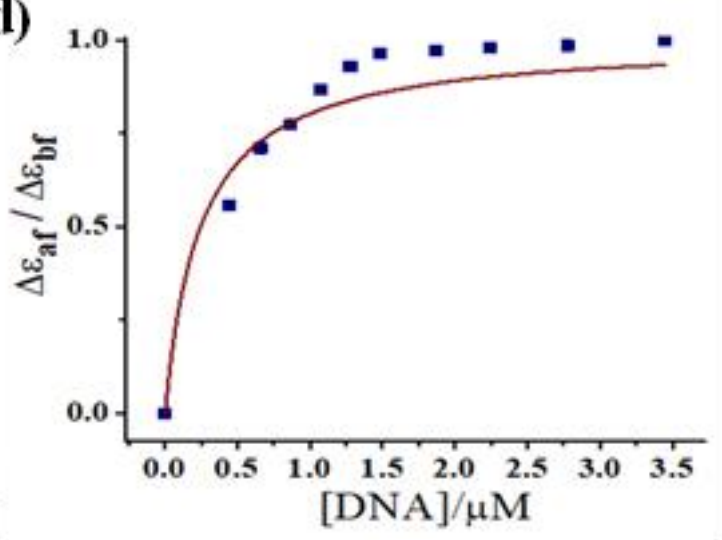

f)

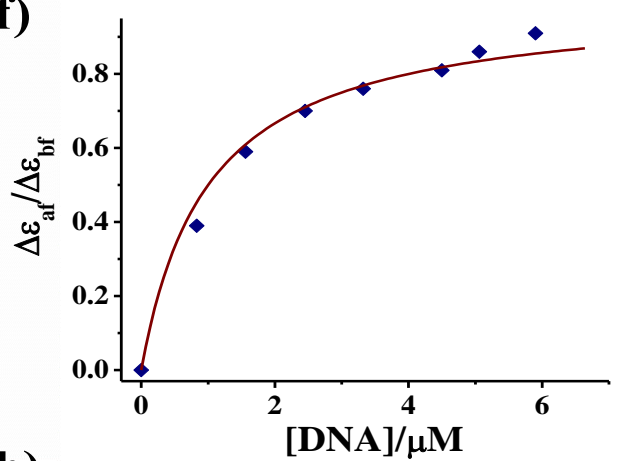

h)

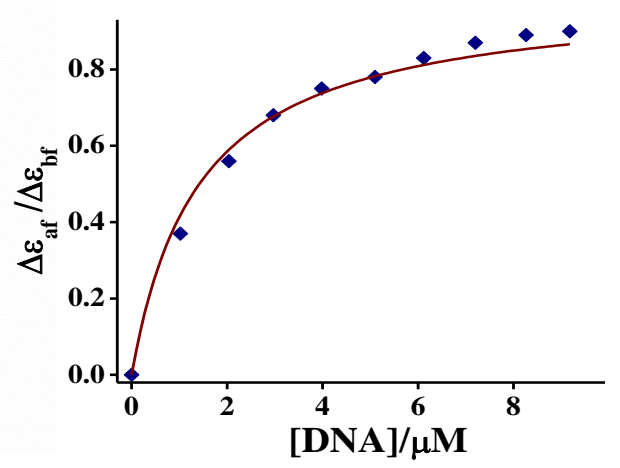

Figure S24: Changes in the absorption spectra of the complexes: a) complex 2; c) complex 3; e) complex 4 and g) complex 5, with increasing concentration of ct-DNA in 10\% DMF- Tris- $\mathrm{HCl}$ buffer (pH 7.2) at $25^{\circ} \mathrm{C}$. McGhee-von Hippel (MvH) plot: $\Delta \varepsilon_{\mathrm{af}} / \Delta \varepsilon_{\mathrm{bf}}$ vs. [DNA], b) complex 2; d) complex 3; f) complex 4; h) complex 5. 
a)

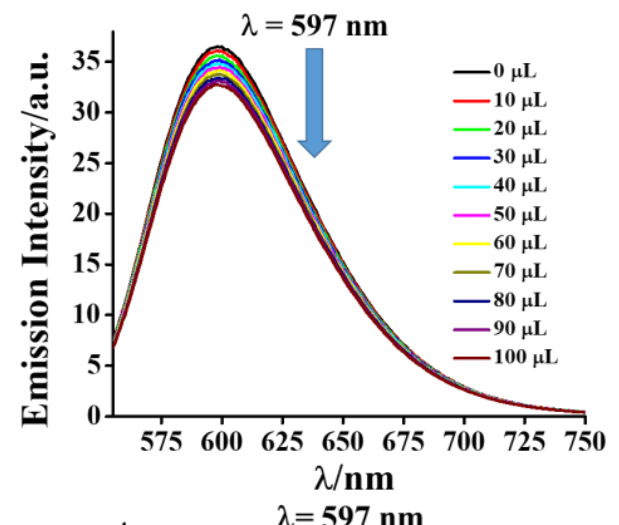

c)

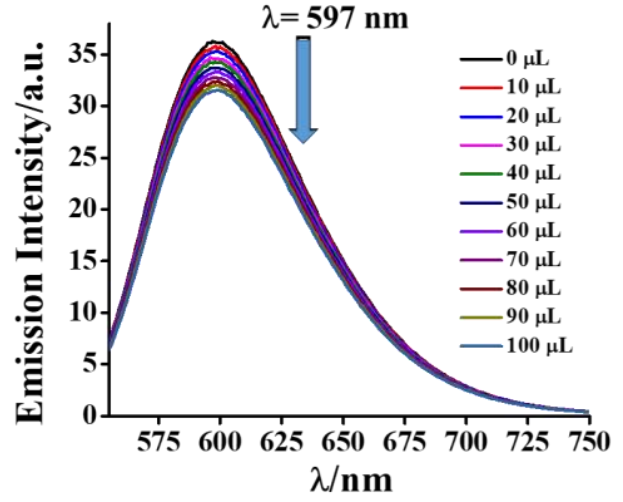

b)

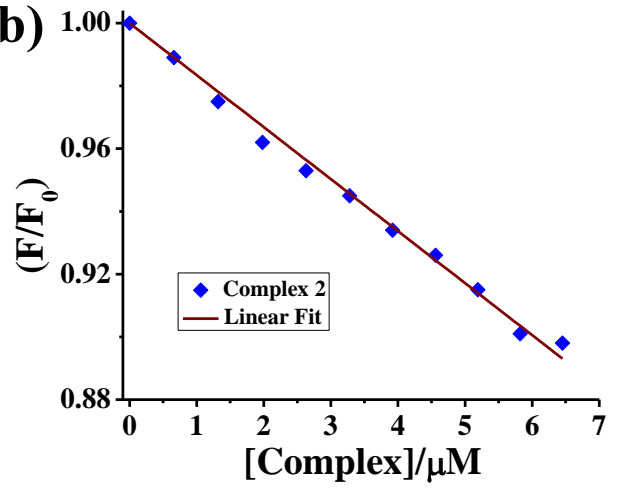

d)

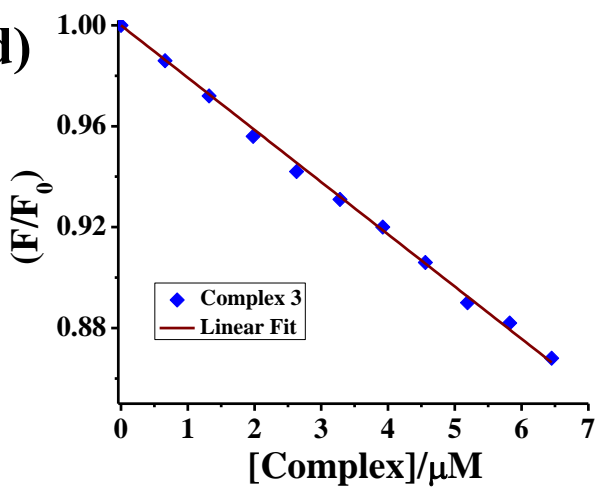

e)

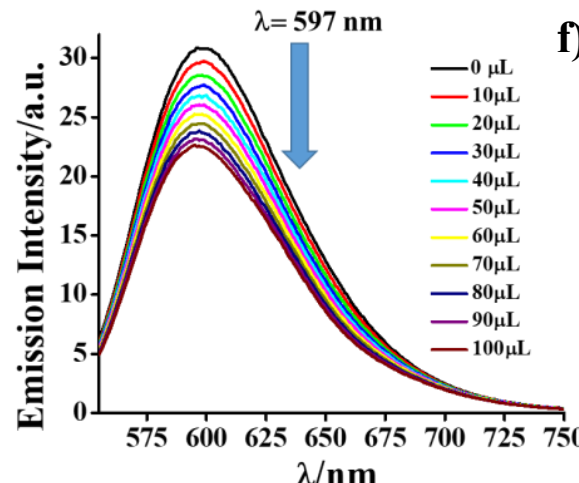

g)

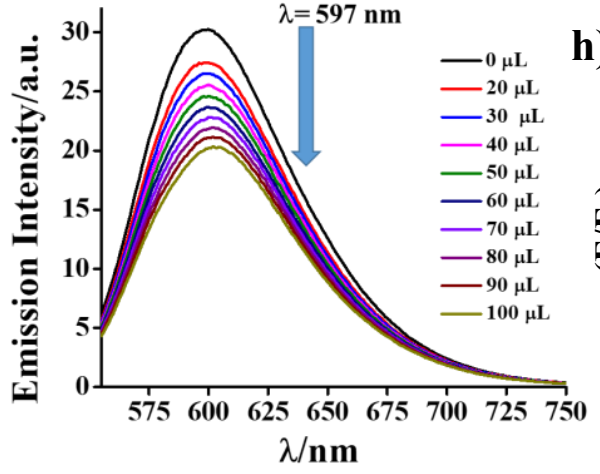

f)

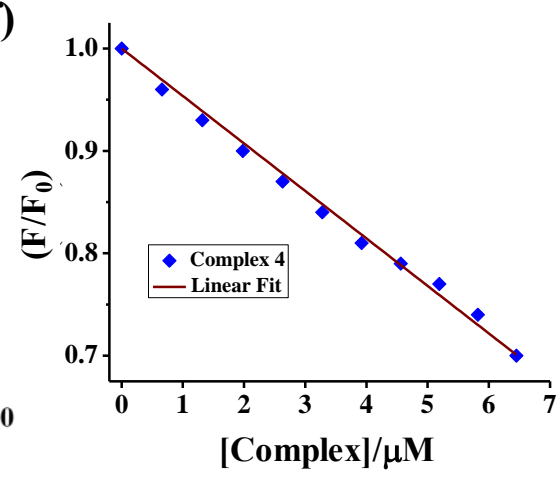

h)

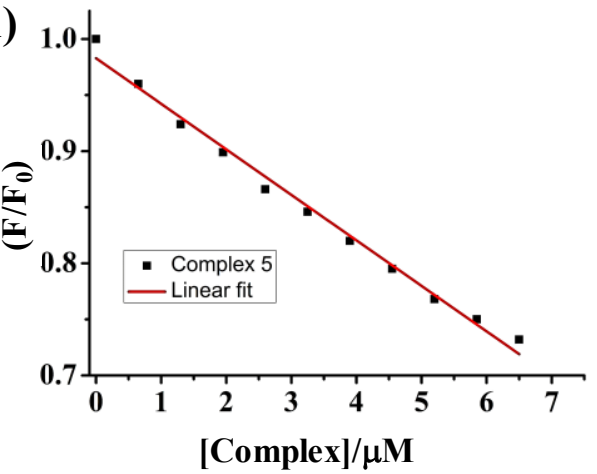

Figure S25: Changes in the emission spectra of ethidium bromide (EB)- bound DNA with increasing complex concentration: a) complex 2; c) complex 3; e) complex 4; g) complex 5 and corresponding linear plots of $\left(\mathrm{F} / \mathrm{F}_{0}\right)$ vs. [complex] for b) complex 2 ; d) complex $3 ;$ f) complex 4 ; h) complex 5 (where $F_{0}$ is initial emission intensity of ct-DNA bound $\mathrm{EB}$ and $\mathrm{F}$ is emission intensity for each measure). 
a) Lanes $\begin{array}{llllll}1 & 2 & 3 & 4 & 5 & 6\end{array}$

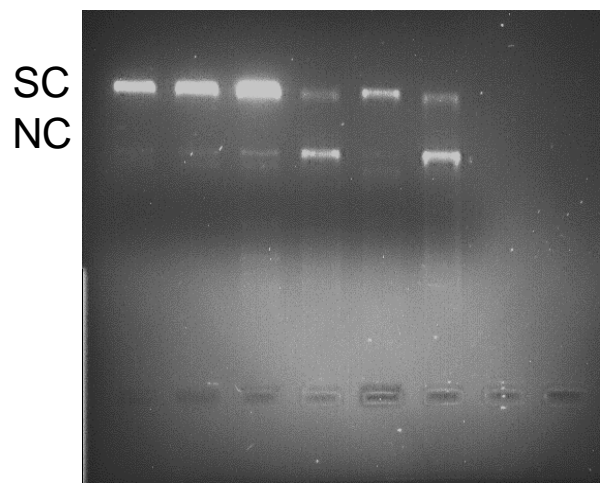

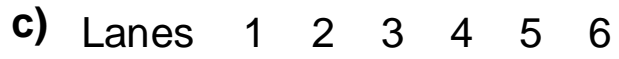

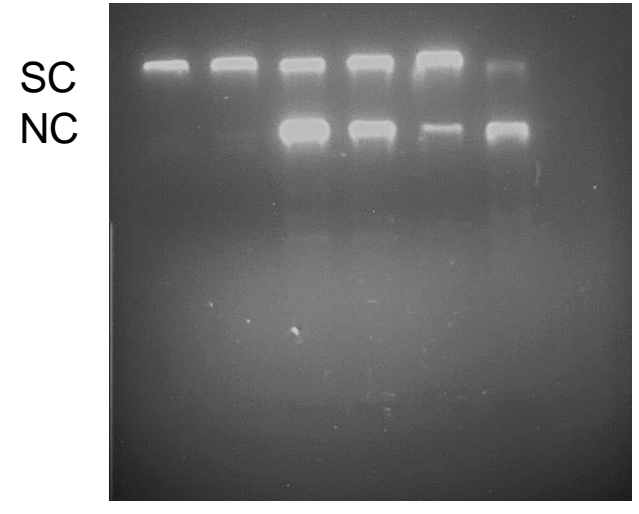

e)

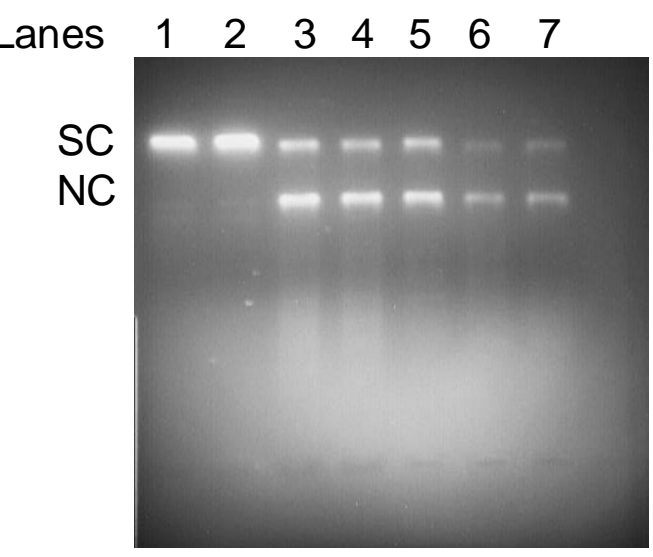

b)

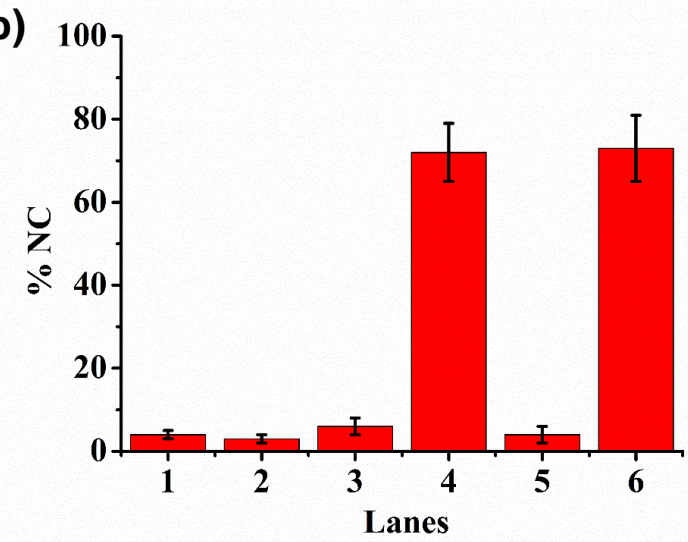

d)
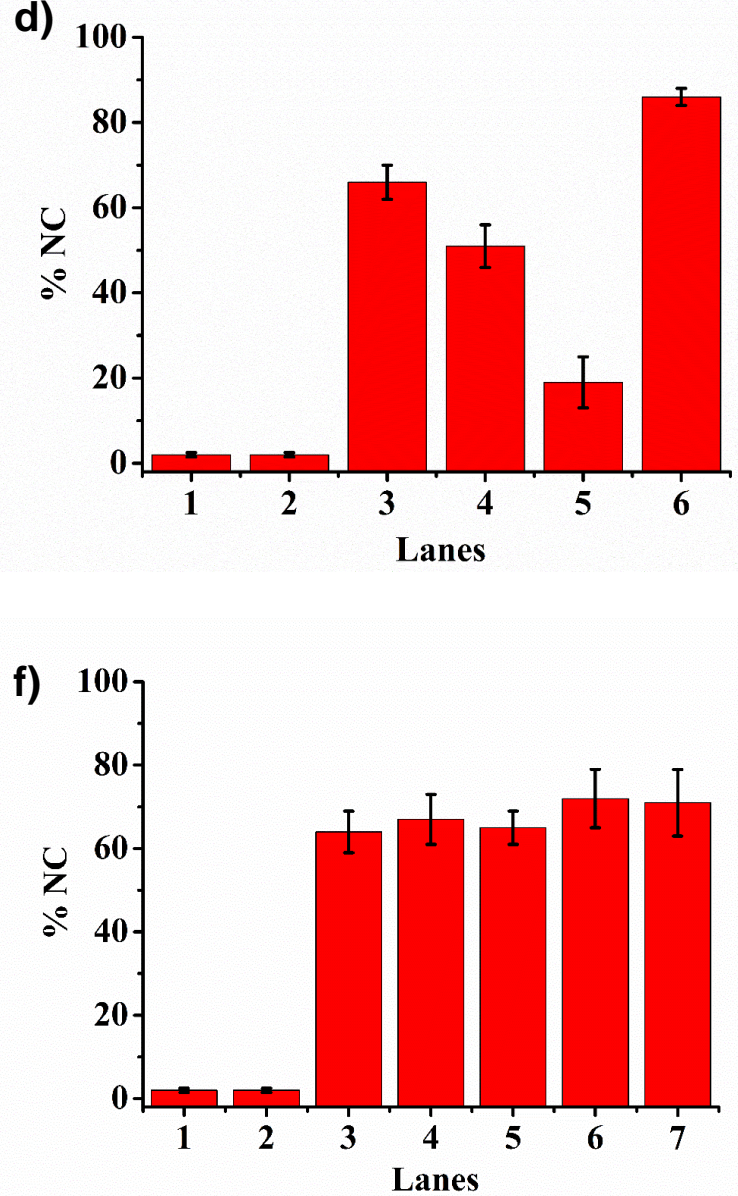

Figure S26: Ethidium bromide stained agarose gels for the photocleavage of pUC19 DNA by $33 \mathrm{mM}$ complex 4 or complex 5 (a, c, e) and the respective bar diagrams (b, d, e): a) and b) Lane 1, DNA in dark; Lane 2, DNA in light; Lane 3, complex 4 in dark; Lane 4, complex 4 in light; Lane 5, complex 5 in dark; Lane 6, complex 5 in light; c) and d) Lane 1, DNA in dark; Lane 2, DNA in light; Lane 3, complex 5 in light; Lane 4, complex 5 with TEMP in light; Lane 5, complex 5 with $\mathrm{NaN}_{3}$ in light; ; Lane 6, complex 5 with $\mathrm{D}_{2} \mathrm{O}$ in light; e) and f) Lane 1, DNA in dark; Lane 2, DNA in light; Lane 3, complex 5 in light; Lane 4, complex 5 with KI in light; Lane 5, complex 5 with DMSO in light; ; Lane 6, complex $\mathbf{5}$ with SOD in light; Lane 7, complex $\mathbf{5}$ with catalase in light (Light irradiation was performed using a red light $100 \mathrm{~mW}$ diode laser of $660 \mathrm{~nm}$ for $15 \mathrm{~min}$ ). 
a)

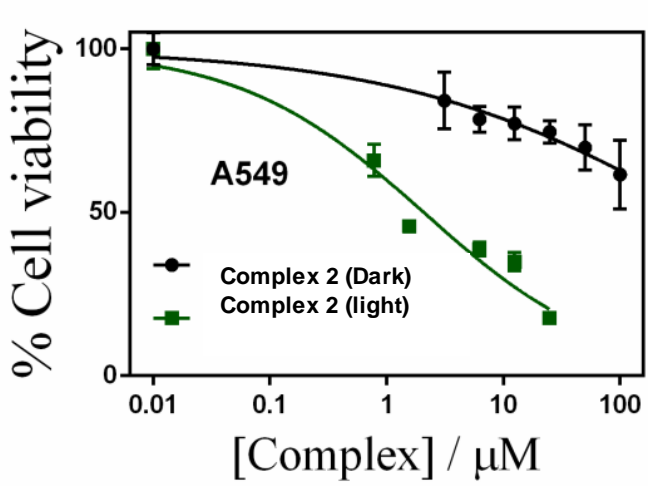

c)

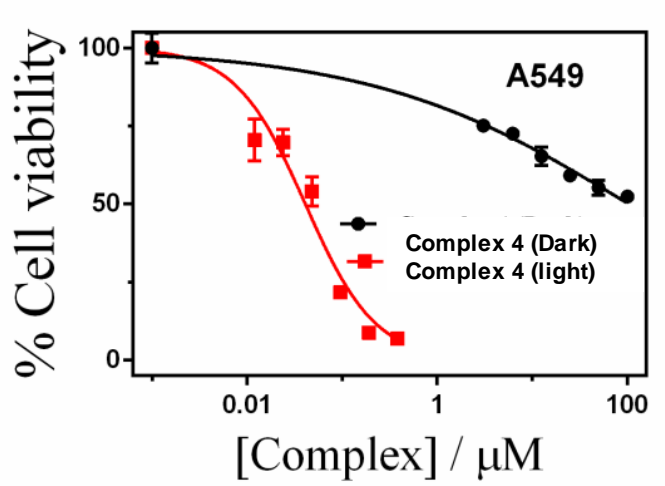

e)

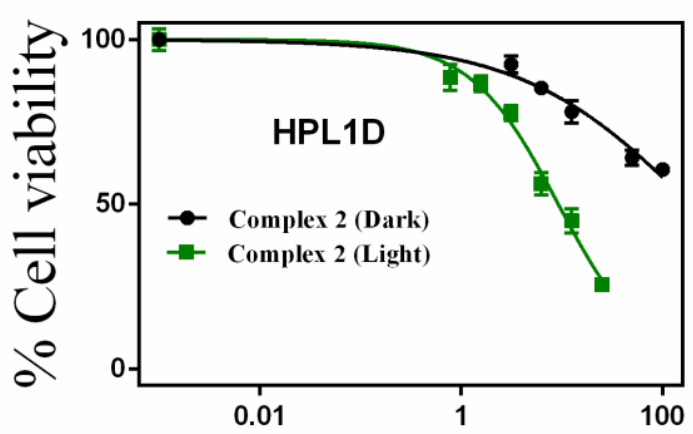

[Complex] / $\mu \mathrm{M}$

g)

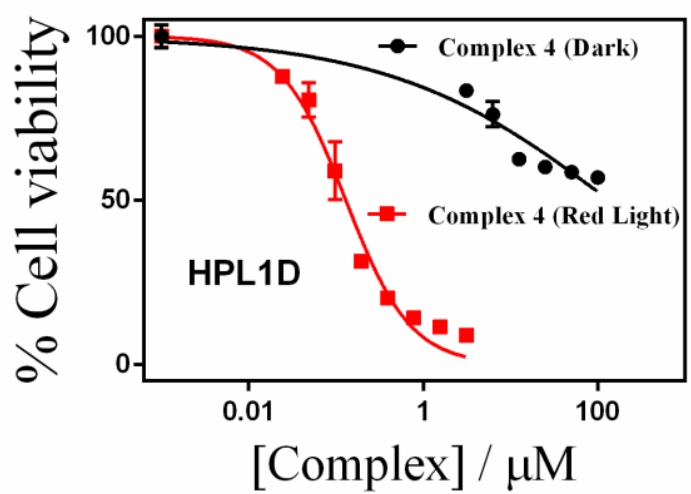

b)

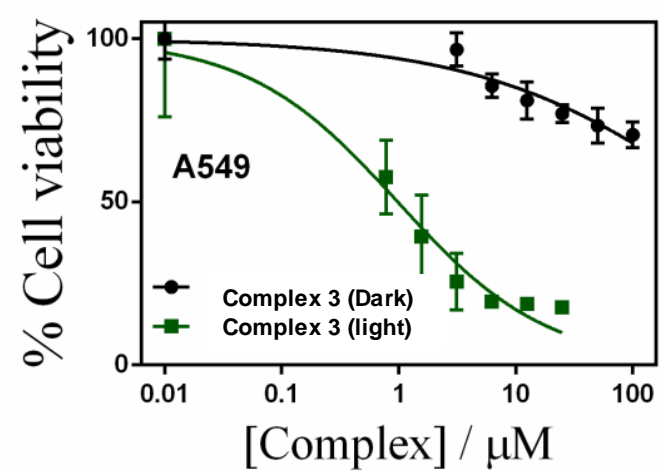

d)

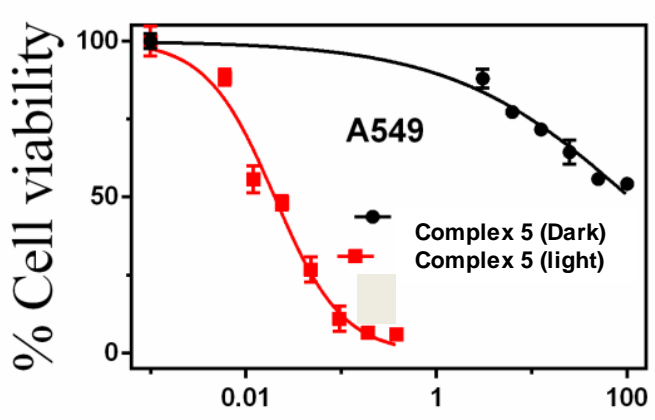

[Complex] / $\mu \mathrm{M}$

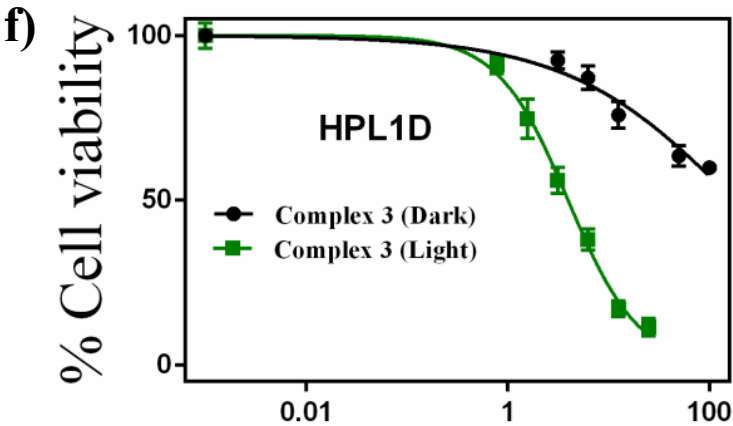

[Complex] / $\mu \mathrm{M}$

h)

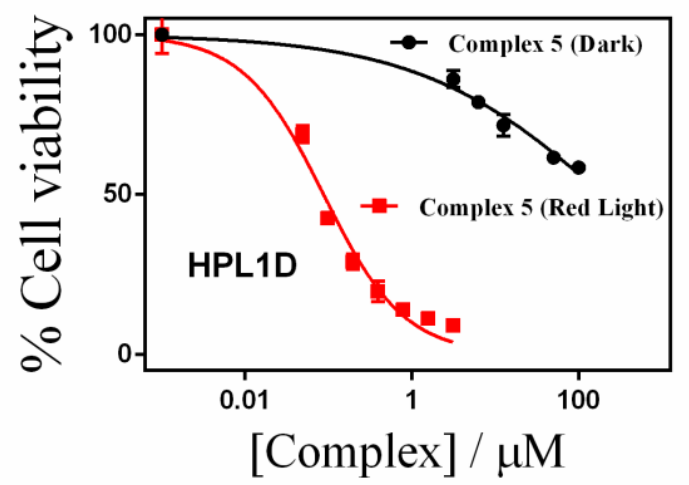

Figure S27: Cell viability assay plots obtained from MTT assay: a) complex 2; b) complex 3; c) complex 4; d) complex 5 in A549 cell line and e) complex 2; f) complex 3; g) complex 4; h) complex 5 in HPL1D cell line. Light dose: $400-700 \mathrm{~nm}\left(10 \mathrm{~J} / \mathrm{cm}^{2}, 1 \mathrm{~h}\right.$ exposure) for complexes $\mathbf{2}$ and $\mathbf{3}$, and 600- $720 \mathrm{~nm}$ (30 $\mathrm{J} / \mathrm{cm}^{2}, 15 \mathrm{~min}$ exposure) for complexes 4 and $\mathbf{5}$. 


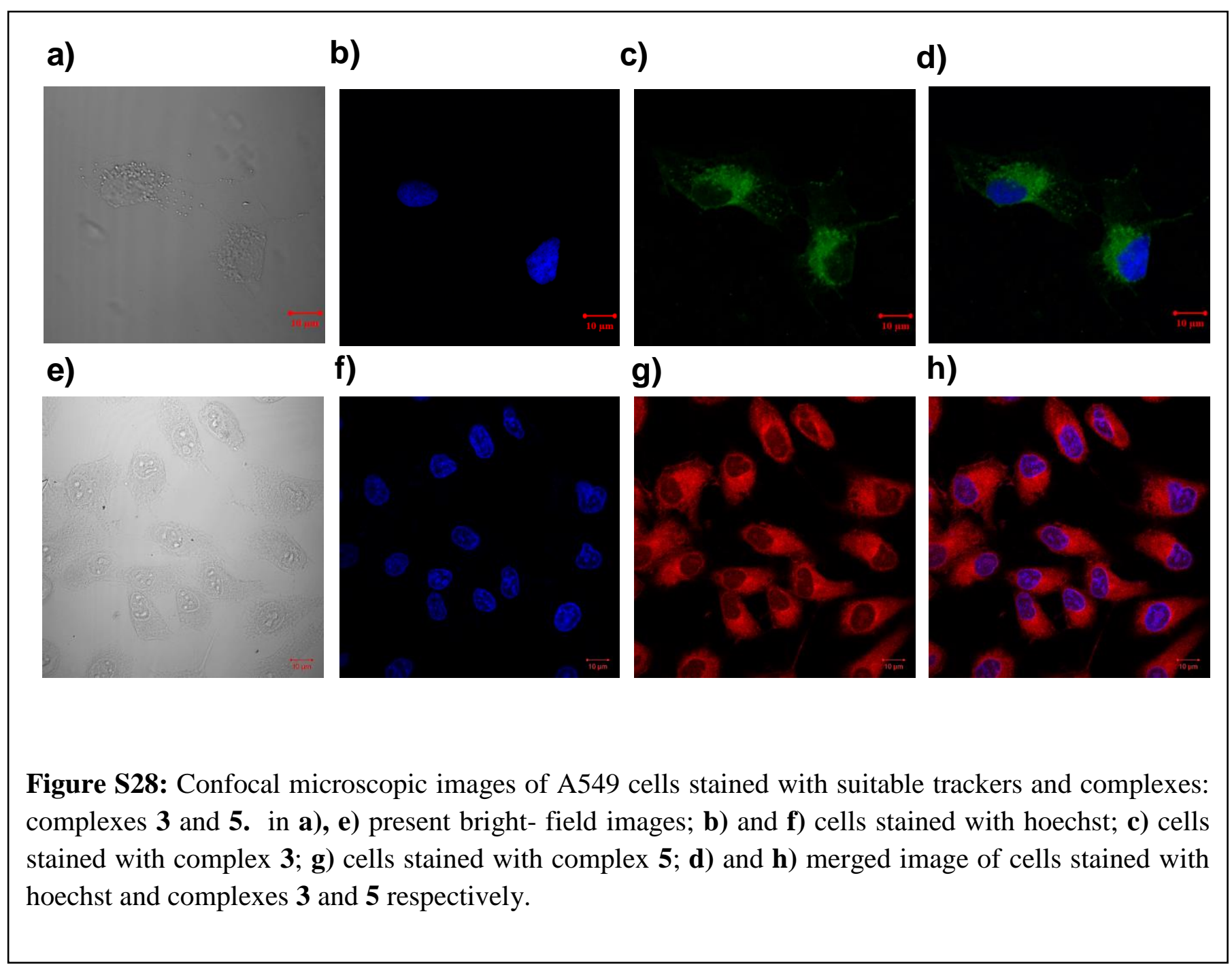


a)

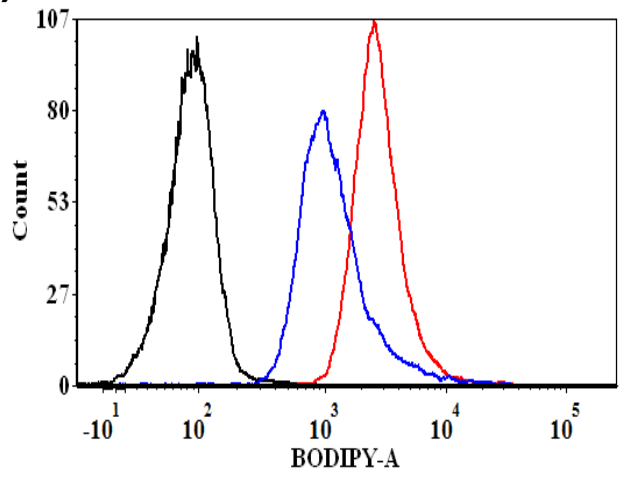

b)
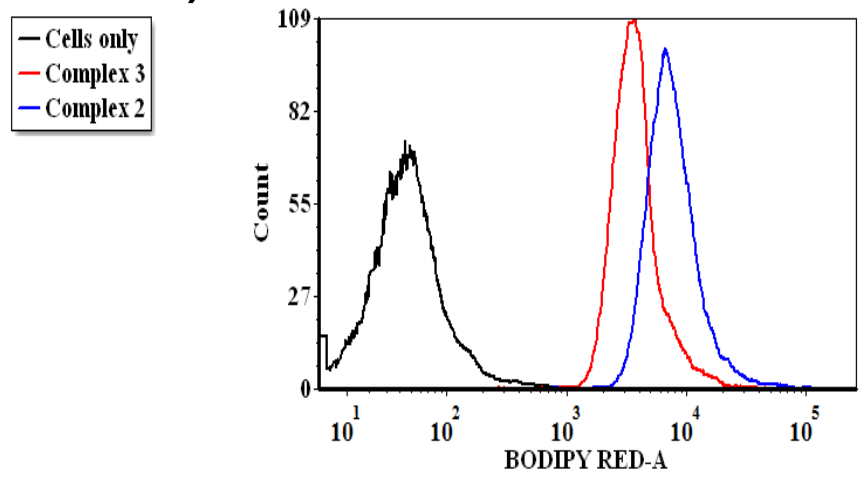

- Cells only

- Complex 4

- Complex 5

e)

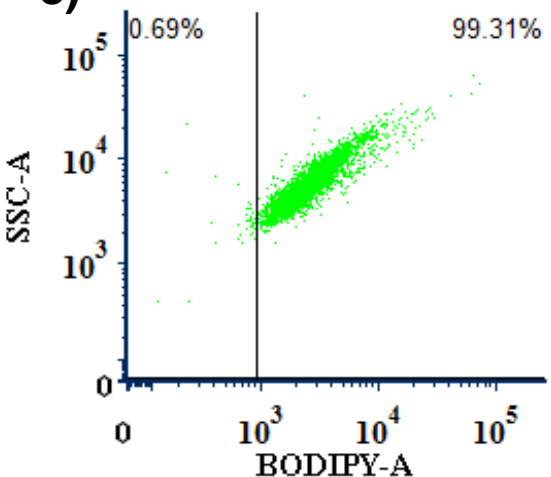

g)

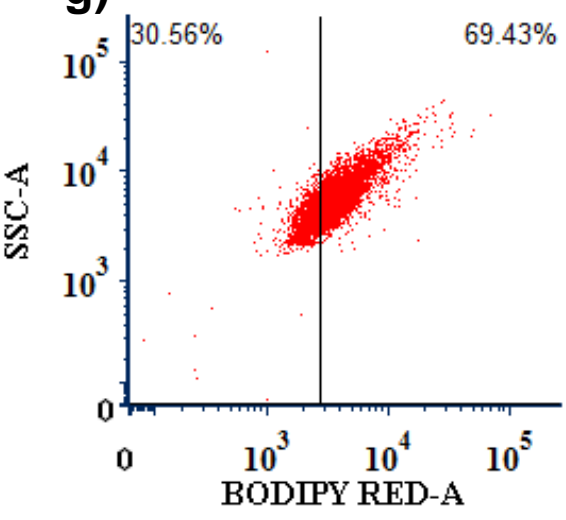

h)

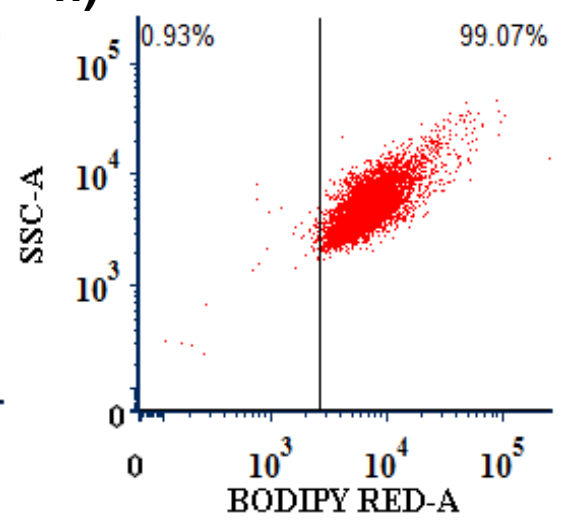

Figure S29: Cellular uptake studies in A549 cells monitored by flow cytometric analysis of complexes 2 and 3 (a); complexes 4 and 5 (b). Dot plots of flow cytometric analysis: untreated cells (c) and (f); cells treated with complex 2 (d); complex $3(\mathbf{e})$; complex 4 (g) and complex 5 (h). 
Table S1: Selected bond lengths and bond angles obtained from crystal structure of complex 1a.0.5MeCN.

\begin{tabular}{|c|c|}
\hline Bond & Bond length $(\AA)$ \\
\hline Ru1 C11 & $2.401(3)$ \\
\hline Ru1 N2 & $2.108(8)$ \\
\hline Ru1 N3 & $2.071(8)$ \\
\hline Ru1 N5 & $2.044(8)$ \\
\hline Ru1 N4 & $2.027(8)$ \\
\hline Ru1 N1 & $2.038(8)$ \\
\hline
\end{tabular}

\begin{tabular}{|c|c|}
\hline & Angle in degree \\
\hline N2 Ru1 C11 & $175.7(2)$ \\
\hline N3 Ru1 C11 & $94.3(3)$ \\
\hline N3 Ru1 N2 & $82.8(3)$ \\
\hline N5 Ru1 C11 & $85.8(2)$ \\
\hline N5 Ru1 N2 & $97.2(3)$ \\
\hline N5 Ru1 N3 & $176.6(3)$ \\
\hline N4 Ru1 C11 & $85.4(2)$ \\
\hline N4 Ru1 N2 & $98.2(3)$ \\
\hline N4 Ru1 N3 & $97.8(3)$ \\
\hline N4 Ru1 N5 & $78.8(3)$ \\
\hline N4 Ru1 N1 & $176.6(3)$ \\
\hline N1 Ru1 Cl1 N2 & $95.7(2)$ \\
\hline N1 Ru1 N3 & $80.9(3)$ \\
\hline N1 Ru1 N5 & $85.4(3)$ \\
\hline & $98.0(3)$ \\
\hline
\end{tabular}


Table S2: Coordinates for energy minimized structure of Complex 2.

\begin{tabular}{|c|c|c|c|}
\hline $\mathrm{Ru}$ & -3.468246000000 & & \\
\hline $\mathrm{Cl}$ & -6.018912000000 & -1.148162000000 & 0.092644000000 \\
\hline & -1.289026000000 & -1.236779000000 & \\
\hline $\mathrm{C}$ & -3.988218000000 & 2.696255000000 & \\
\hline C & -3.987810000000 & 2.429614000000 & \\
\hline $\mathrm{H}$ & -4.132856000000 & 3.238686000000 & \\
\hline $\mathrm{O}$ & -2.332745000000 & 5.777224000000 & 0000 \\
\hline $\mathrm{C}$ & -4.164437000000 & 4.223005000000 & \\
\hline $\mathrm{C}$ & -4.003438000000 & 3.110008000000 & -0.77859 \\
\hline C & -0.888711000000 & 5701000000 & \\
\hline $\mathrm{H}$ & 000000 & 000000 & \\
\hline $\mathrm{H}$ & 0.062277000000 & 20000000 & \\
\hline $\mathbf{N}$ & -4.378101000000 & 2000000 & -0.3624 \\
\hline $\mathrm{N}$ & 000000 & -2.4 & \\
\hline $\mathrm{N}$ & -3.60 & & \\
\hline $\mathrm{C}$ & -3.790892000000 & 1.6023 & \\
\hline C & -0.597553000000 & 0.1 & 0.22573 \\
\hline $\mathrm{H}$ & -0.94 & & \\
\hline $\mathrm{H}$ & -0.99 & & \\
\hline $\mathrm{C}$ & -1.99 & -2.6 & \\
\hline $\mathrm{C}$ & -3.80 & & \\
\hline $\mathrm{C}$ & -4.0 & & \\
\hline $\mathrm{H}$ & -4.24 & & \\
\hline $\mathrm{C}$ & -1.70 & & \\
\hline $\mathrm{H}$ & -0.67 & -3.8 & \\
\hline $\mathrm{C}$ & -4.1( & & \\
\hline $\mathrm{H}$ & -4.28 & & \\
\hline $\mathrm{C}$ & 0.92 & 0.1 & 0.17 \\
\hline $\mathrm{C}$ & 1.69 & & \\
\hline $\mathrm{H}$ & 1.194 & & \\
\hline $\mathrm{C}$ & -4.307 & & -2.0945 \\
\hline $\mathrm{H}$ & -5.3012 & 0000 & -1.7454 \\
\hline $\mathrm{C}$ & -4.02 & & 2.244 \\
\hline $\mathrm{H}$ & -4.86 & -5.4 & \\
\hline $\mathrm{N}$ & -3.635 & & -1.0237 \\
\hline $\mathrm{N}$ & & & \\
\hline $\mathrm{C}$ & -3.65 & 0.8 & -2.36 \\
\hline $\mathrm{H}$ & 5000000 & 7000000 & 00000 \\
\hline $\mathrm{C}$ & -4.082025000000 & 2000000 & -3.0537 \\
\hline $\mathrm{H}$ & -4.92 & & -3.4764 \\
\hline $\mathrm{C}$ & -3.873003000000 & & -1.498534000000 \\
\hline $\mathrm{H}$ & -4.793300000000 & 79000000 & -1.006737000000 \\
\hline $\mathrm{H}$ & -4.027487000000 & & \\
\hline $\mathrm{H}$ & -3.067 & 8.369088000000 & -1.258449000000 \\
\hline $\mathrm{C}$ & -3.801874000000 & 1.117512000000 & 3.898838000000 \\
\hline $\mathrm{H}$ & -3.799047000000 & 0.872689000000 & 4.955196000000 \\
\hline $\mathrm{C}$ & & & \\
\hline $\mathrm{C}$ & -3.911933000000 & 2.083336000000 & -2.978493000000 \\
\hline $\mathrm{H}$ & -3.959937000000 & 2.137485000000 & -4.060348000000 \\
\hline
\end{tabular}




\begin{tabular}{|c|c|c|c|}
\hline & 1.652427000000 & -4.430618000000 & \\
\hline & 0.616390000000 & -4.711859000000 & \\
\hline & -1.956192000000 & -3.202004000000 & \\
\hline & & & \\
\hline & 3.662001000000 & -0.227309000000 & 2.223227000000 \\
\hline & 3.771471000000 & 0.154441000000 & 000000 \\
\hline & -2.760373000000 & & \\
\hline & -2.555827000000 & 1037000000 & 000000 \\
\hline & 2000000 & 000000 & \\
\hline & 000000 & & \\
\hline & 53000000 & & \\
\hline & 4943000000 & 0000000 & \\
\hline & 000000 & & \\
\hline & -3.6 & & \\
\hline & 3274000000 & 7000000 & \\
\hline & 74000000 & & \\
\hline & -2.48 & & \\
\hline & & & \\
\hline & 1.0 & & \\
\hline & -4.26 & & \\
\hline & & & \\
\hline & & & \\
\hline & & & \\
\hline & & & \\
\hline & & & \\
\hline & & & \\
\hline & & & \\
\hline & & & \\
\hline & & -3.1 & \\
\hline & & & \\
\hline & & & -0.0 \\
\hline & & & \\
\hline & & & \\
\hline & & & \\
\hline & & & \\
\hline & & & \\
\hline & & & 0000 \\
\hline & & & \\
\hline & & & \\
\hline & & & \\
\hline & 6000000 & & 00000 \\
\hline & & & \\
\hline & & & \\
\hline $\mathrm{C}$ & & & 0.705810000000 \\
\hline & 000000 & & 9000000 \\
\hline & & & \\
\hline & & & \\
\hline $\mathrm{C}$ & & -2.912543000000 & -0.550562000000 \\
\hline & 3.595467000000 & -2.760609000000 & 0.386608000000 \\
\hline & & & \\
\hline & 4.176457000000 & -3.987697000000 & -0.754855000000 \\
\hline
\end{tabular}


$\begin{array}{llll}\mathrm{N} & 7.403071000000 & -1.009269000000 & -0.255381000000\end{array}$

$\begin{array}{llll}\mathrm{N} & 7.381346000000 & 1.424038000000 & 0.254345000000\end{array}$

$\mathrm{H} \quad-5.211470000000 \quad 6.035192000000 \quad-0.047575000000$ 
Table S3: Coordinates for energy minimized structure of Complex 3.

\begin{tabular}{|c|c|c|c|}
\hline $\mathrm{Ru}$ & & & \\
\hline $\mathrm{Cl}$ & 0.440565000000 & -6.404730000000 & 0.182004000000 \\
\hline & 2.590675000000 & -2.194471000000 & -0000201000000 \\
\hline $\mathrm{C}$ & -2.213346000000 & -2.773592000000 & 1.825102000000 \\
\hline$c$ & -2.044985000000 & -2.816365000000 & \\
\hline$\pi$ & -2.868460000000 & -2.549405000000 & 3.892010000000 \\
\hline $\mathrm{O}$ & -4.037657000000 & 397000000 & 3000000 \\
\hline $\mathrm{C}$ & -3.558952000000 & -2.359046000000 & -0.1918 \\
\hline C & -2.447736000000 & -2.762810000000 & -1.038442000000 \\
\hline C & 22000000 & -2.181( & \\
\hline $\mathrm{H}$ & 000000 & -1.7 & 0000 \\
\hline $\mathrm{H}$ & 4.380250000000 & -1.5 & 0000 \\
\hline $\mathbf{N}$ & -4.810759000000 & -1.9 & 00000 \\
\hline$v$ & 2.86 & -4.5 & 23944000000 \\
\hline $\mathrm{N}$ & 0.11 & -3.5 & \\
\hline$C$ & 50000000 & -3.1 & 0000 \\
\hline $\mathrm{C}$ & $1.66^{\circ}$ & -0.97 & 0.05 \\
\hline & $1.0^{\circ}$ & -1.0 & \\
\hline $\mathrm{H}$ & 0.9 & & \\
\hline C & 3.715 & & 0000 \\
\hline $\mathrm{C}$ & -1.22 & -3.1 & -0.412568 \\
\hline C & -2.51 & & 0000 \\
\hline $\mathrm{H}$ & -3.42 & -2.6 & 00000 \\
\hline C & & & \\
\hline $\mathrm{H}$ & 5.45 & -2.9 & \\
\hline $\mathrm{C}$ & -3.4 & -2.3 & \\
\hline $\mathrm{H}$ & -4.28 & -2.0 & 000 \\
\hline $\mathrm{C}$ & 2.35 & & \\
\hline $\mathrm{C}$ & 2.67 & & \\
\hline $\mathrm{H}$ & 2.44 & 0.5 & 000 \\
\hline $\mathrm{C}$ & 3.07 & -5.8 & 0000 \\
\hline $\mathrm{H}$ & 2.37 & -6.5 & 000 \\
\hline $\mathrm{C}$ & 4.55 & -6.1 & \\
\hline $\mathrm{H}$ & 4.74 & & 000 \\
\hline $\mathrm{N}$ & 000000 & & 00000 \\
\hline $\mathrm{N}$ & & & \\
\hline $\mathrm{C}$ & -0.14 & & -2.4 \\
\hline $\mathrm{H}$ & & & 00000 \\
\hline $\mathrm{C}$ & 00000 & & 00000 \\
\hline $\mathrm{H}$ & & & 0000 \\
\hline $\mathrm{C}$ & 000000 & -0.63 & -2.073713000000 \\
\hline $\mathrm{H}$ & 000000 & 00000 & -1.651820000000 \\
\hline $\mathrm{H}$ & -6.41 & & 63448000000 \\
\hline $\mathrm{C}$ & -0.81 & -3.20 & 3.758171000000 \\
\hline $\mathrm{H}$ & 71000000 & 61000000 & 4.828465000000 \\
\hline $\mathrm{C}$ & -4.994213000000 & -0.864334000000 & -1.578034000000 \\
\hline $\mathrm{C}$ & & & -3.162738000000 \\
\hline $\mathrm{H}$ & -1.40 & 53000000 & -4.243752000000 \\
\hline $\mathrm{C}$ & 5.174156000000 & -3.781607000000 & 2.299165000000 \\
\hline
\end{tabular}




\begin{tabular}{|c|c|c|c|}
\hline & 5.856688000000 & -2.955174000000 & \\
\hline & 3.970553000000 & -3.561248000000 & 1.612739000000 \\
\hline & 3.278801000000 & 2.308999000000 & 1.270086000000 \\
\hline & & & \\
\hline & 3.567171000000 & 2.964587000000 & 0.055664000000 \\
\hline & 5.007349000000 & -5.098143000000 & -3.168597000000 \\
\hline & 5.838174000000 & -5.295808000000 & -3.838658000000 \\
\hline & 3.232292000000 & 2.332994000000 & \\
\hline & 3.432477000000 & 2.833663000000 & -2.102949000000 \\
\hline & 3.355562000000 & -2.190370000000 & -1.3107 \\
\hline & 2.697467000000 & 132000000 & \\
\hline & 4.247280000000 & 8005000000 & 9000000 \\
\hline & 0.24744 & 4105000000 & \\
\hline & 00000 & -3.8 & \\
\hline & & -5.0 & \\
\hline & 6.3 & -5.2 & \\
\hline & 2.6281 & & -1.158 \\
\hline & & & \\
\hline & 3.38 & -5.8 & \\
\hline & & -6.5 & \\
\hline & 4.20 & & \\
\hline & & & \\
\hline & & & \\
\hline & 2.97 & 7.7 & \\
\hline & & & \\
\hline & & & \\
\hline & & & \\
\hline C & & & \\
\hline 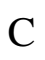 & & & \\
\hline & & & \\
\hline & & & \\
\hline & & & \\
\hline & & & \\
\hline & & & \\
\hline & & & \\
\hline I & & & \\
\hline $\mathrm{H}$ & & 7.1 & \\
\hline $\mathrm{H}$ & 9.577 & & \\
\hline & & & \\
\hline & 3.95 & 9.4 & -0.5 \\
\hline $\mathrm{H}$ & & & \\
\hline $\mathrm{H}$ & 3.62 & & \\
\hline C & & & \\
\hline $\mathrm{H}$ & 0.909 & & -0.722221000000 \\
\hline $\mathrm{H}$ & 0.94 & & \\
\hline & & & \\
\hline $\mathrm{C}$ & & & -0.015967000000 \\
\hline $\mathrm{H}$ & & & 0.874919000000 \\
\hline & 5.995912000000 & 1.580896000000 & -0.886078000000 \\
\hline & & & -0.043932000000 \\
\hline & 6.229597000000 & 5.717119000000 & 0.022948000000 \\
\hline
\end{tabular}




$\begin{array}{cccc}\mathrm{N} & 3.978918000000 & 6.771546000000 & 0.103023000000 \\ \mathrm{C} & -6.920290000000 & 0.797916000000 & -1.760906000000 \\ \mathrm{H} & -6.947311000000 & 0.938566000000 & -0.671618000000 \\ \mathrm{H} & -6.201938000000 & 1.525861000000 & -2.160041000000 \\ \mathrm{C} & -8.312299000000 & 1.055441000000 & -2.378183000000 \\ \mathrm{H} & -9.034679000000 & 0.316642000000 & -1.998407000000 \\ \mathrm{H} & -8.250600000000 & 0.885204000000 & -3.463112000000 \\ \mathrm{C} & -8.849807000000 & 2.491208000000 & -2.153045000000 \\ \mathrm{H} & -9.755130000000 & 2.634858000000 & -2.759455000000 \\ \mathrm{H} & -8.101047000000 & 3.206566000000 & -2.522136000000 \\ \mathrm{C} & -9.184748000000 & 2.820382000000 & -0.686583000000 \\ \mathrm{C} & -10.381983000000 & 2.019297000000 & -0.097659000000 \\ \mathrm{H} & -8.312998000000 & 2.686942000000 & -0.038626000000 \\ \mathrm{C} & -10.549430000000 & 4.273675000000 & 1.105377000000 \\ \mathrm{C} & -11.256763000000 & 2.918097000000 & 0.866916000000 \\ \mathrm{H} & -10.999761000000 & 1.648457000000 & -0.924648000000 \\ \mathrm{H} & -9.801684000000 & 4.191806000000 & 1.899230000000 \\ \mathrm{H} & -11.248786000000 & 5.080516000000 & 1.333564000000 \\ \mathrm{H} & -12.240653000000 & 3.098865000000 & 0.424665000000 \\ \mathrm{~S} & -9.678195000000 & 4.670543000000 & -0.524395000000 \\ \mathrm{C} & -10.598871000000 & 0.939519000000 & 2.028349000000 \\ \mathrm{O} & -10.479099000000 & 0.076323000000 & 2.946036000000 \\ \mathrm{~N} & -9.984226000000 & 0.909474000000 & 0.787475000000 \\ \mathrm{H} & -9.481784000000 & 0.091170000000 & 0.472752000000 \\ \mathrm{~N} & -11.365891000000 & 2.088410000000 & 2.074519000000 \\ \mathrm{H} & -11.899709000000 & 2.346171000000 & 2.892774000000 \\ \mathrm{H} & -5.635023000000 & -2.503693000000 & -0.500639000000\end{array}$


Table S4: Coordinates for energy minimized structure of Complex 4.

\begin{tabular}{|c|c|c|c|}
\hline $\mathrm{Ru}$ & & & \\
\hline $\mathrm{Cl}$ & 13.182243000000 & -1.858158000000 & 0.029288000000 \\
\hline & 8.450517000000 & -1.884179000000 & 0.091494000000 \\
\hline $\mathrm{C}$ & 11.178111000000 & 1.894261000000 & -2.166981000000 \\
\hline & 11.196190000000 & 1.546267000000 & -3.546087000000 \\
\hline$\pi$ & 11.348382000000 & 2.312672000000 & 92000000 \\
\hline $\mathrm{O}$ & 3385000000 & 5.148109000000 & 37000000 \\
\hline $\mathrm{C}$ & 11.322297000000 & 3.531844000000 & 25000000 \\
\hline C & 11.161434000000 & 2.473482000000 & 7321000000 \\
\hline$\tau$ & 7000000 & -2.892857000000 & \\
\hline $\mathrm{H}$ & 7.88 & -2.33 & -1.8 \\
\hline $\mathrm{H}$ & 7.080603000000 & 164000000 & -0.705 \\
\hline $\mathbf{N}$ & 0000000 & 819000000 & 0.09 \\
\hline$v$ & 000000 & -3.000 & \\
\hline $\mathrm{N}$ & 10.7 & -0.4 & \\
\hline C & 10.9736 & & -1.224 \\
\hline $\mathrm{C}$ & 7.7823 & -0.535917000000 & -0.197 \\
\hline & 8.1 & -0.2 & \\
\hline $\mathrm{H}$ & & & \\
\hline$C$ & & -3.23 & \\
\hline $\mathrm{C}$ & 10.9 & & \\
\hline C & & & \\
\hline $\mathrm{H}$ & & & 000 \\
\hline C & & & \\
\hline $\mathrm{H}$ & 7.7 & & \\
\hline $\mathrm{C}$ & & & 000 \\
\hline $\mathrm{H}$ & & & -2.4 \\
\hline $\mathrm{C}$ & & -0.5 & -0.1 \\
\hline $\mathrm{C}$ & & & \\
\hline $\mathrm{H}$ & & & -2.318 \\
\hline $\mathrm{C}$ & 11.4 & & 39000000 \\
\hline $\mathrm{H}$ & 000000 & 0000 & 0000 \\
\hline $\mathrm{C}$ & & -5.6 & -1.8 \\
\hline $\mathrm{H}$ & & & -2.1 \\
\hline $\mathrm{N}$ & & & 0000 \\
\hline $\mathrm{N}$ & & & \\
\hline $\mathrm{C}$ & & & 2.36 \\
\hline $\mathrm{H}$ & & & 000 \\
\hline $\mathrm{C}$ & 000000 & & 3000000 \\
\hline $\mathrm{H}$ & & & \\
\hline $\mathrm{C}$ & 000000 & 256000000 & -3.907423000000 \\
\hline $\mathrm{H}$ & 000000 & 292000000 & 92000000 \\
\hline $\mathrm{C}$ & & & 5000000 \\
\hline $\mathrm{C}$ & & & 2.902508000000 \\
\hline $\mathrm{H}$ & 112000000 & 269000000 & 3.979663000000 \\
\hline $\mathrm{C}$ & 5000000 & -5.200263000000 & -1.758610000000 \\
\hline $\mathrm{H}$ & & & \\
\hline $\mathrm{C}$ & 9.092 & -3.940 & -1.229774000000 \\
\hline $\mathrm{C}$ & 4.118341000000 & -0.583023000000 & -1.379964000000 \\
\hline
\end{tabular}




\begin{tabular}{|c|c|c|c|}
\hline & .573704000000 & & \\
\hline & & & \\
\hline & .872865000000 & & \\
\hline & & & \\
\hline & 4.142264000000 & -0.175789000000 & \\
\hline & 088000000 & & \\
\hline & & & \\
\hline & 8000000 & 7000000 & \\
\hline & 00000 & & \\
\hline & 67000000 & -0.77 & 00000 \\
\hline & 1513000000 & -1.81 & 0000 \\
\hline & & -6.08 & 0000 \\
\hline & & -7.0 & \\
\hline & & & \\
\hline & & -0.0956 & \\
\hline & 000 & -4.4 & -1 \\
\hline & & & \\
\hline & & -0.2 & \\
\hline & & & \\
\hline & & -1.36 & \\
\hline & & & \\
\hline & & & \\
\hline & & & \\
\hline & & -2.7 & \\
\hline & & -3.4 & \\
\hline & & & \\
\hline & & & \\
\hline & & & \\
\hline & & & 0000 \\
\hline & & & \\
\hline & & & \\
\hline & & & \\
\hline & & & \\
\hline & & & \\
\hline & & & \\
\hline & & -3.4 & \\
\hline & & -3.28 & 0000 \\
\hline & & -2.98 & \\
\hline & & -4.48 & \\
\hline & -0.2 & -1.2 & 73000000 \\
\hline & & & 6000000 \\
\hline & & & 00000 \\
\hline & & & \\
\hline & -2.54 & 2.27736 & 97000000 \\
\hline & -2.088 & 4.352139000000 & 70000000 \\
\hline & & & \\
\hline & & 4.91948 & \\
\hline & -3.569031000000 & 6.332333000000 & 104000000 \\
\hline & -4.619413000000 & 4.131941000000 & -0.545936000000 \\
\hline & & & \\
\hline & -2.666935000000 & 6.935334000000 & -0.672351000000 \\
\hline
\end{tabular}




\begin{tabular}{|c|c|c|c|}
\hline & -5.878770000000 & & \\
\hline & & & \\
\hline & & & \\
\hline & & & \\
\hline & -2.259696000000 & & \\
\hline & & & \\
\hline & & & \\
\hline & -2.901492000000 & & \\
\hline & & & \\
\hline & & & \\
\hline & & & \\
\hline & & & \\
\hline & & & \\
\hline & & & \\
\hline & & & \\
\hline & & & \\
\hline & & & \\
\hline & & & \\
\hline & & & \\
\hline & & & \\
\hline & & & \\
\hline & & & \\
\hline & & & \\
\hline & & & \\
\hline & & & \\
\hline & & & \\
\hline & & & \\
\hline & & & \\
\hline & & & 000 \\
\hline & & & 000 \\
\hline & -14. & & 000 \\
\hline & & & \\
\hline & & & \\
\hline & & & \\
\hline & & & \\
\hline & & & \\
\hline & & & \\
\hline & & & 000 \\
\hline & & & \\
\hline & & & \\
\hline & & 00000 & 000000 \\
\hline & & & \\
\hline & & -13. & \\
\hline & -6.4 & -12 & 000000 \\
\hline & -6.4 & -12. & 000000 \\
\hline & & & \\
\hline $\mathrm{H}$ & & 22000000 & 68000000 \\
\hline & 5000000 & 73000000 & 1.617597000000 \\
\hline & & & 0.755569000000 \\
\hline & & & \\
\hline & -5.028134000000 & -16.838601000000 & 1.735739000000 \\
\hline
\end{tabular}




\begin{tabular}{|c|c|c|c|}
\hline & -5.616671000000 & -17.021568000000 & \\
\hline & & & \\
\hline & -7.716201000000 & & \\
\hline & -9.155261000000 & & \\
\hline & -7.661464000000 & & \\
\hline & -7.067247000000 & & \\
\hline & -9.205227000000 & & \\
\hline & -9.796481000000 & & 7000000 \\
\hline & 2000000 & 04000000 & 51000000 \\
\hline & 3000000 & & \\
\hline & 3000000 & & 00000 \\
\hline & 9000000 & & 3000000 \\
\hline & & & \\
\hline & -14.5 & & \\
\hline & -3.8 & & \\
\hline & -4.39 & & 00000 \\
\hline & -3.2 & & \\
\hline & -3.2 & & \\
\hline & & & 000 \\
\hline & -5.0 & & \\
\hline & & & \\
\hline & -2.2 & & \\
\hline & -4.1 & & \\
\hline & -4.1 & & \\
\hline & & & \\
\hline & -1.6 & & 0000 \\
\hline & -1.3 & & \\
\hline & -0.8 & & \\
\hline & & & 0000 \\
\hline & -1.8 & & 000 \\
\hline & -2.5 & & 000 \\
\hline & & & 000 \\
\hline & & & \\
\hline & -8.3 & & \\
\hline ) & & & \\
\hline & & & \\
\hline & -17.0 & & 00000 \\
\hline D & & & 0000 \\
\hline $\mathrm{O}$ & & & \\
\hline $\mathrm{O}$ & -4.0 & -17.8 & 00000 \\
\hline & -7.2 & & 00000 \\
\hline O & & & \\
\hline $\mathrm{O}$ & -3.2 & & \\
\hline $\mathrm{O}$ & -2.5 & & 000000 \\
\hline $\mathrm{O}$ & -0.7 & 00000 & 00000 \\
\hline $\mathrm{O}$ & & & \\
\hline $\mathrm{O}$ & -12.6 & & 2.094938000000 \\
\hline $\mathrm{O}$ & 2000000 & 12.772686000000 & 4.002125000000 \\
\hline & -10.96 & & 1.030374000000 \\
\hline & & & \\
\hline & & 9.900392000000 & 0.10294200000 \\
\hline
\end{tabular}




$\begin{array}{cccc}\mathrm{C} & -13.084643000000 & 11.513313000000 & 3.196386000000 \\ \mathrm{H} & -12.443123000000 & 12.405178000000 & 3.262604000000 \\ \mathrm{H} & -13.027056000000 & 10.966256000000 & 4.149679000000 \\ \mathrm{C} & -1.027224000000 & 19.666315000000 & -1.484855000000 \\ \mathrm{H} & -1.645738000000 & 20.005822000000 & -0.640633000000 \\ \mathrm{H} & -0.076605000000 & 20.205947000000 & -1.481537000000 \\ \mathrm{H} & -1.561755000000 & 19.868692000000 & -2.425014000000 \\ \mathrm{C} & -16.331533000000 & 13.239125000000 & 3.858932000000 \\ \mathrm{H} & -16.542040000000 & 13.867434000000 & 4.728301000000 \\ \mathrm{H} & -16.454192000000 & 13.830640000000 & 2.939343000000 \\ \mathrm{H} & -17.034781000000 & 12.393226000000 & 3.837551000000 \\ \mathrm{C} & -18.495878000000 & -10.685428000000 & -3.353300000000 \\ \mathrm{H} & -18.833412000000 & -11.381402000000 & -4.125674000000 \\ \mathrm{H} & -18.700504000000 & -11.111293000000 & -2.359626000000 \\ \mathrm{H} & -19.038138000000 & -9.733361000000 & -3.453778000000 \\ \mathrm{C} & -4.628341000000 & -19.220415000000 & 2.050204000000 \\ \mathrm{H} & -3.801209000000 & -19.922902000000 & 2.181528000000 \\ \mathrm{H} & -5.295294000000 & -19.270071000000 & 2.923867000000 \\ \mathrm{H} & -5.198626000000 & -19.488134000000 & 1.148177000000 \\ \mathrm{C} & 10.958372000000 & 7.067592000000 & 1.081844000000 \\ \mathrm{H} & 10.177549000000 & 7.741030000000 & 0.712929000000 \\ \mathrm{H} & 11.018508000000 & 7.195680000000 & 2.169009000000 \\ \mathrm{H} & 11.917203000000 & 7.356500000000 & 0.642099000000\end{array}$


Table S5: Coordinates for energy minimized structure of Complex 5.

\begin{tabular}{|c|c|c|c|}
\hline & -7.157018000000 & & \\
\hline & -9.293013000000 & -8.215393000000 & 0.142373000000 \\
\hline & -5.225470000000 & -5.801353000000 & 0.275713000000 \\
\hline & -9.781670000000 & -3.744197000000 & 1.697621000000 \\
\hline & -9.782291000000 & -3.850248000000 & \\
\hline & -10.405157000000 & -3.189925000000 & 3.711731000000 \\
\hline & -9.684579000000 & -0.542405000000 & -2.068384000000 \\
\hline & -10.542366000000 & 19019000000 & 37000000 \\
\hline & -9.717347000000 & -3.637900000000 & 000000 \\
\hline & & & \\
\hline & -4.81 & & \\
\hline & 000000 & -6.2 & 000 \\
\hline & 1000000 & 4000000 & 905000000 \\
\hline & -6.146994000000 & -7.98 & 287000000 \\
\hline & -8.15 & -5.5 & \\
\hline & -8.94 & -4.6 & \\
\hline & -5.35 & $-4.2^{\prime}$ & \\
\hline & -5.92 & -4.0 & \\
\hline & -5.9 & -3.9 & \\
\hline & -4.87 & -7.5 & \\
\hline & -8.91 & -4.5 & -0. \\
\hline & -9.6 & & 000 \\
\hline & -10.2 & & 0000 \\
\hline & -4.00 & -8.36 & -2.2 \\
\hline & -2.99 & -8.0 & -2.4 \\
\hline & -10.5 & & 000 \\
\hline & -11.1 & & 000 \\
\hline & -4.04 & -3.45 & \\
\hline & -3.3 & -3.1 & \\
\hline & -3.8 & -3.4 & 2.4 \\
\hline & -6.59 & -9.17 & -1.7 \\
\hline & -7.60 & -9.4 & 0000 \\
\hline & -5.8 & -10 . & 000 \\
\hline & -6.27 & $-11 .($ & 00000 \\
\hline & -8.10 & -5.4 & 00000 \\
\hline & -6.1 & & \\
\hline & -8.0 & -5.5 & 0000 \\
\hline & -7.45 & -6.2 & 00000 \\
\hline & -5.78 & -9.9 & 0000 \\
\hline I & -6.1 & -10.9 & 00000 \\
\hline$C$ & -11.98 & 0.1 & 279000000 \\
\hline & -12.9 & 3000000 & 0419000000 \\
\hline & -11.9 & & 00000 \\
\hline & -8.97 & -4.8 & 397000000 \\
\hline $\mathrm{H}$ & 2000000 & 508000000 & 4.799370000000 \\
\hline & -10.91 & 78000000 & -1.857345000000 \\
\hline & -8.86 & & \\
\hline & -8.817696000000 & -4.692426000000 & -4.303207000000 \\
\hline $\mathrm{C}$ & -4.078902000000 & -8.514504000000 & 2.690176000000 \\
\hline
\end{tabular}




\begin{tabular}{|c|c|c|c|}
\hline & & & \\
\hline & -4.919419000000 & -7.687565000000 & \\
\hline & -2.165669000000 & & \\
\hline & -1.668518000000 & & \\
\hline & -1.596216000000 & -2.037240000000 & 0.295757000000 \\
\hline & & & -2.791047000000 \\
\hline & -3.815050000000 & 96711000000 & 411000000 \\
\hline & -2.270710000000 & & 5000000 \\
\hline & -1.855481000000 & & 6000000 \\
\hline & -4.49 & -6.2 & 8000000 \\
\hline & -4.77 & & 0000 \\
\hline & -3.4 & & 0000 \\
\hline & & & \\
\hline & & & \\
\hline & & & \\
\hline & & & 3. \\
\hline & -3.4 & & \\
\hline & & & 000 \\
\hline & & & \\
\hline & -7.6 & & \\
\hline & -0.2 & & \\
\hline & & & \\
\hline & & & \\
\hline & & & \\
\hline & & & \\
\hline & & & \\
\hline & & & \\
\hline & & & \\
\hline & & & \\
\hline & & & \\
\hline & & & 000 \\
\hline & & & \\
\hline & & & \\
\hline & & & \\
\hline & -2.8 & & \\
\hline & & & \\
\hline & -3.1 & & \\
\hline & $-3.3^{\prime}$ & & \\
\hline & & & \\
\hline & & & \\
\hline & -0.4 & & 000 \\
\hline & & & 000 \\
\hline & & & \\
\hline $\mathrm{N}$ & 00000 & & 000000 \\
\hline & 000000 & & 2000000 \\
\hline & & & 22000000 \\
\hline & & & 0290000000 \\
\hline $\mathrm{C}$ & -12.798444000000 & & -2.712908000000 \\
\hline & 2000000 & & -2.494585000000 \\
\hline & & & \\
\hline & -12.627040000000 & 4.100967000000 & -2.361483000000 \\
\hline
\end{tabular}




\begin{tabular}{|c|c|c|c|}
\hline & & & \\
\hline & -11.585779000000 & 4.390545000000 & -2.562873000000 \\
\hline & -12.978595000000 & 4.458104000000 & -0.905598000000 \\
\hline & -14.481937000000 & & \\
\hline & -12.374005000000 & 3.884576000000 & -0.196285000000 \\
\hline & & & 0.916799000000 \\
\hline & -14.958005000000 & 32327000000 & 0.452779000000 \\
\hline & -15.075773000000 & & \\
\hline & -13.234823000000 & 5.787736000000 & 48000000 \\
\hline & 7348000000 & & \\
\hline & & & \\
\hline & 5000000 & & \\
\hline & & & \\
\hline & -15 & & \\
\hline & & & \\
\hline & -14 . & & \\
\hline & -15. & & \\
\hline & & & \\
\hline & -12 . & & \\
\hline & & & \\
\hline & & & \\
\hline & & & \\
\hline & & & \\
\hline & & & \\
\hline & & & \\
\hline & & & \\
\hline & & & \\
\hline & & & \\
\hline & & & \\
\hline & & & \\
\hline & & & \\
\hline & & & \\
\hline & & & \\
\hline & & & \\
\hline & & & \\
\hline & & & \\
\hline$C$ & & & -0.2 \\
\hline & & & \\
\hline C & & & \\
\hline & & & \\
\hline & & & \\
\hline & & -0.9 & \\
\hline & & & \\
\hline $\mathrm{C}$ & & 3000000 & 0000000 \\
\hline $\mathrm{H}$ & & & 07000000 \\
\hline $\mathrm{C}$ & 382000000 & 516000000 & 0.421449000000 \\
\hline $\mathrm{C}$ & & & \\
\hline $\mathrm{H}$ & 11.815273000000 & & 1.382397000000 \\
\hline & 12.051809000000 & -3.265079000000 & 0.487246000000 \\
\hline & & & -0.965158000000 \\
\hline & 13.519814000000 & -0.613426000000 & -0.094815000000 \\
\hline
\end{tabular}




\begin{tabular}{|c|c|c|c|}
\hline & 5.797581000000 & & \\
\hline & & & \\
\hline & & & 706114000000 \\
\hline & & & -0.135303000000 \\
\hline & 6.255507000000 & -1.816715000000 & 1000000 \\
\hline & & & 000000 \\
\hline & & & \\
\hline & 465000000 & 9000000 & 2000000 \\
\hline & & & 8000000 \\
\hline & & & \\
\hline & 3000000 & & 9000000 \\
\hline & 00 & & 88000000 \\
\hline & & & \\
\hline & & & \\
\hline & & & \\
\hline & 9.1 & & \\
\hline & & & \\
\hline & & & 000 \\
\hline & & & 0000 \\
\hline & & & \\
\hline & & & \\
\hline & & & \\
\hline & & & 0000 \\
\hline & & & \\
\hline & & & \\
\hline & & & \\
\hline & & & 000 \\
\hline & & & \\
\hline & & & 0000 \\
\hline & & & 0000 \\
\hline & & & \\
\hline & & & \\
\hline & & & \\
\hline & & & \\
\hline & & & \\
\hline & & & \\
\hline & & & \\
\hline & & & \\
\hline & & & \\
\hline & & & 0000 \\
\hline & & & 00000 \\
\hline & & & \\
\hline & & & \\
\hline & & & 00000 \\
\hline & & & \\
\hline & & & \\
\hline & & & \\
\hline & & 42000000 & 0.020537000000 \\
\hline & & 12.972300000000 & 0.975259000000 \\
\hline & & & \\
\hline & 0251400000000 & 13.488273000000 & 0.114645000000 \\
\hline
\end{tabular}




\begin{tabular}{|c|c|c|c|}
\hline & & & \\
\hline & -2.638724000000 & & \\
\hline & & & \\
\hline & -3.919048000000 & & \\
\hline & -4.386793000000 & & 50000000 \\
\hline & -4.416527000000 & & 3000000 \\
\hline & -4.037851000000 & & \\
\hline & -3.537646000000 & 2720000000 & 3000000 \\
\hline & & & 7000000 \\
\hline & 10.2 & & \\
\hline & 11. & & 0000 \\
\hline & 14.4 & & \\
\hline & & & \\
\hline & 21.2 & & \\
\hline & 00 & & \\
\hline & 12.1 & & \\
\hline & 12.4 & & \\
\hline & & & \\
\hline & & & \\
\hline & -0.4 & & \\
\hline & -2.4 & & \\
\hline & -5.4 & & \\
\hline & 6.5 & & \\
\hline & & & \\
\hline & & & \\
\hline & & & \\
\hline & & & \\
\hline & & & \\
\hline & & & \\
\hline & & & \\
\hline & & & \\
\hline & & & \\
\hline & -5.3 & & \\
\hline & -6.8 & & \\
\hline & -5.3 & & \\
\hline & & & -3 . \\
\hline & & 0000 & 0000 \\
\hline & & & \\
\hline & 12. & & -3 \\
\hline & & & \\
\hline & & & \\
\hline & & & \\
\hline $\mathrm{H}$ & & & 3.102229000000 \\
\hline & 5000000 & 99722000000 & -2.382760000000 \\
\hline & & & \\
\hline & & & \\
\hline & 14.228408000000 & -15.791003000000 & -1.57708900000 \\
\hline
\end{tabular}


Table S6: Excitation energies and oscillator strengths obtained from TD-DFT calculations for complex 2.

Excitation energies and oscillator strengths:

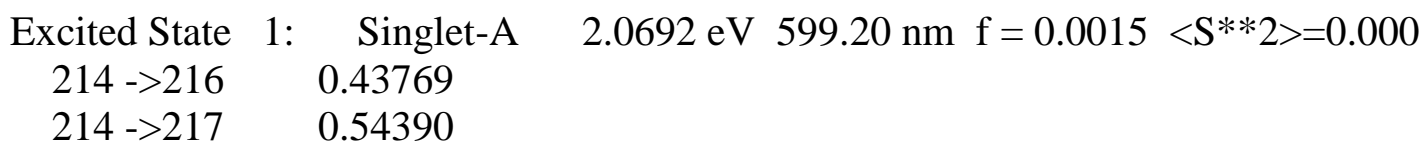

This state for optimization and/or second-order correction.

Total Energy, E(TD-HF/TD-KS) = -2623.53697400

Copying the excited state density for this state as the 1-particle RhoCI density.

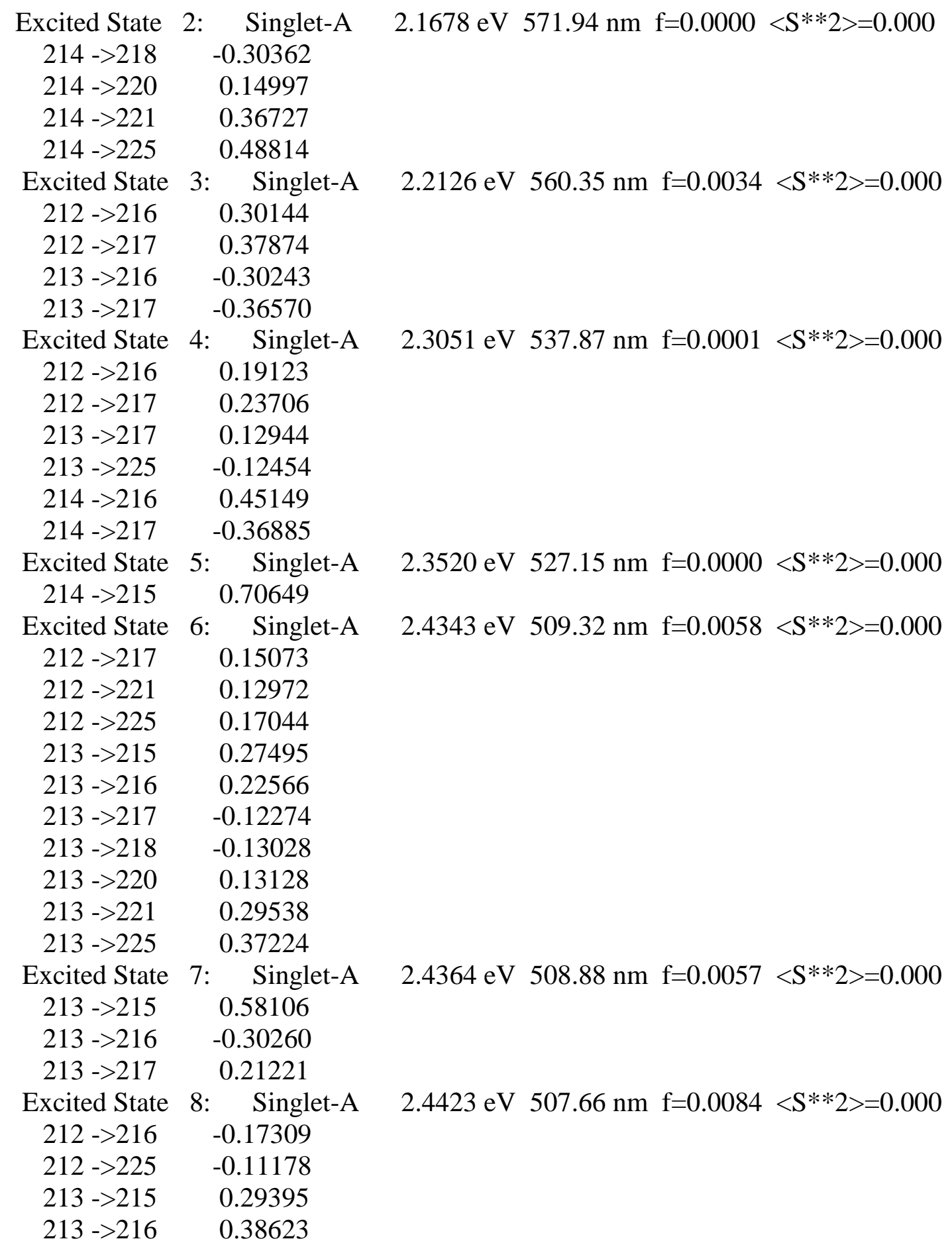




$$
\begin{array}{ll}
213->217 & -0.30381 \\
213->221 & -0.18349 \\
213->225 & -0.23193
\end{array}
$$

Excited State 9: $\quad$ Singlet-A $\quad 2.5358 \mathrm{eV} \quad 488.94 \mathrm{~nm} \mathrm{f}=0.0024<\mathrm{S} * * 2>=0.000$

$$
212->215 \quad 0.66562
$$

$212->216 \quad-0.18566$

212 ->217 0.12157

Excited State 10: Singlet-A $\left.\quad 2.5403 \mathrm{eV} \quad 488.07 \mathrm{~nm} \mathrm{f}=0.0211<\mathrm{S}^{* *} 2\right\rangle=0.000$ $212->215 \quad 0.23731$

$212->216 \quad 0.52011$

$212->217 \quad-0.33605$

213 ->216 0.19604

Excited State 11: $\quad$ Singlet-A $\quad 2.5926 \mathrm{eV} \quad 478.22 \mathrm{~nm} \mathrm{f}=0.1813<\mathrm{S} * * 2>=0.000$

$212->216 \quad 0.10634$

$212->217 \quad 0.32859$

$212->221 \quad 0.10171$

$212->225 \quad 0.12195$

$213->216 \quad 0.19796$

$213->217 \quad 0.38658$

$213->221 \quad-0.10165$

$213->225 \quad-0.11897$

$214->216 \quad-0.26897$

$214->217 \quad 0.21881$

Excited State 12: Singlet-A $\quad 2.6504 \mathrm{eV} \quad 467.79 \mathrm{~nm} \mathrm{f}=0.0268\langle\mathrm{~S} * * 2>=0.000$

$212->217 \quad-0.10708$

$212->218 \quad-0.20793$

$212->220 \quad 0.15928$

$212->221 \quad 0.34895$

$212->225 \quad 0.43741$

$213->217 \quad-0.15744$

$213->221 \quad-0.13659$

$213->225 \quad-0.16626$

Excited State 13: Singlet-A $\quad 2.8258 \mathrm{eV} \quad 438.76 \mathrm{~nm} \mathrm{f}=0.0000<\mathrm{S} * * 2>=0.000$ $214->218 \quad 0.62395$

214 ->220 0.13047

214 ->221 0.19563

214 ->225 0.18643

Excited State 14: Singlet-A $\quad 2.8695 \mathrm{eV} \quad 432.07 \mathrm{~nm} \mathrm{f}=0.5940<\mathrm{S} * * 2>=0.000$ $209->215 \quad-0.11581$

$211->215 \quad 0.69805$

Excited State 15: Singlet-A $\quad 2.9238 \mathrm{eV} \quad 424.06 \mathrm{~nm} \mathrm{f}=0.0009<\mathrm{S} * * 2>=0.000$ $212->218 \quad 0.26094$

$213->218 \quad 0.49381$

$213->221 \quad 0.10455$

$214->219 \quad 0.34491$

$214->228 \quad 0.13181$

Excited State 16: $\quad$ Singlet-A $\quad 3.0181 \mathrm{eV} \quad 410.80 \mathrm{~nm} \mathrm{f}=0.0002\langle\mathrm{~S} * * 2\rangle=0.000$

$212->218 \quad-0.19673$

$213->218 \quad-0.31325$

$214->219 \quad 0.58809$

Excited State 17: Singlet-A $\quad 3.1182 \mathrm{eV} \quad 397.61 \mathrm{~nm} \mathrm{f}=0.0218<\mathrm{S} * * 2>=0.000$ 

$213->219 \quad 0.66297$
213 ->228 0.18657

Excited State 18: Singlet-A $\quad 3.2230 \mathrm{eV} \quad 384.68 \mathrm{~nm} \mathrm{f}=0.0460<\mathrm{S} * * 2>=0.000$

$212->219 \quad 0.62145$

$212->228 \quad 0.25808$

$213->228 \quad-0.10894$

Excited State 19: $\quad$ Singlet-A $\quad 3.3991 \mathrm{eV} 364.75 \mathrm{~nm} \mathrm{f}=0.1075<\mathrm{S} * * 2>=0.000$

$212->218 \quad 0.51021$

$212->221 \quad 0.15520$

$212->222 \quad-0.10942$

$212->225 \quad 0.10144$

$213->218 \quad-0.25824$

$213->222 \quad-0.10932$

$214->220 \quad-0.22445$

Excited State 20: Singlet-A $\quad 3.4033 \mathrm{eV} \quad 364.30 \mathrm{~nm} \mathrm{f}=0.0146<\mathrm{S} * * 2>=0.000$

$212->218 \quad 0.18734$

$214->220 \quad 0.60900$

$214->221 \quad-0.24993$

Excited State 21: $\quad$ Singlet-A $\quad 3.4794 \mathrm{eV} \quad 356.34 \mathrm{~nm} \mathrm{f}=0.0815\langle\mathrm{~S} * * 2\rangle=0.000$ $209->215 \quad 0.69406$

$211->215 \quad 0.11992$

Excited State 22: $\quad$ Singlet-A $\quad 3.4964 \mathrm{eV} \quad 354.61 \mathrm{~nm} \mathrm{f}=0.0077<\mathrm{S} * * 2>=0.000$

$212->220 \quad-0.15421$

$213->220 \quad 0.62798$

$213->221 \quad-0.25319$

Excited State 23: Singlet-A $\quad 3.5243 \mathrm{eV} \quad 351.80 \mathrm{~nm} \mathrm{f}=0.0098<\mathrm{S} * * 2\rangle=0.000$

$212->228 \quad-0.10993$

$213->218 \quad-0.10732$

$213->222 \quad-0.13192$

$213->228 \quad 0.11822$

$214->219 \quad-0.15518$

$214->228 \quad 0.55001$

$214->230 \quad-0.17965$

$214->231 \quad-0.15363$

Excited State 24: Singlet-A $\quad 3.5326 \mathrm{eV} \quad 350.97 \mathrm{~nm} \mathrm{f}=0.0404<\mathrm{S} * * 2\rangle=0.000$

$212 \rightarrow 219 \quad 0.29071$

$212 \rightarrow 228 \quad-0.35210$

$212->230 \quad 0.11658$

$213->219 \quad-0.18611$

$213->228 \quad 0.36812$

$213->230 \quad-0.12261$

$213->231 \quad-0.10490$

$214->228 \quad-0.17725$

Excited State 25: Singlet-A $\quad 3.5764 \mathrm{eV} \quad 346.67 \mathrm{~nm} \mathrm{f}=0.0000<\mathrm{S} * * 2>=0.000$ $211->216 \quad 0.69900$

$211->217 \quad 0.10501$

Excited State 26: Singlet-A $\quad 3.6014 \mathrm{eV} 344.27 \mathrm{~nm} \mathrm{f}=0.0374<\mathrm{S} * * 2\rangle=0.000$

$212 \rightarrow 220 \quad 0.61131$

$212->221 \quad-0.24529$

213 ->220 0.16291

Excited State 27: $\quad$ Singlet-A $\quad 3.6088 \mathrm{eV} 343.56 \mathrm{~nm} \mathrm{f}=0.0000<\mathrm{S} * * 2>=0.000$ 
$211->216 \quad-0.10543$

$211->217 \quad 0.69890$

Excited State 28: $\quad$ Singlet-A $\quad 3.6149 \mathrm{eV} 342.98 \mathrm{~nm} \mathrm{f}=0.0093<\mathrm{S} * * 2>=0.000$ $214->222 \quad 0.69098$

Excited State 29: $\quad$ Singlet-A $\quad 3.7517 \mathrm{eV} 330.47 \mathrm{~nm} \mathrm{f}=0.0013<\mathrm{S} * * 2>=0.000$ $212->219 \quad-0.10445$

$212->222 \quad 0.10544$

$212->228 \quad 0.36016$

$212->230 \quad-0.11633$

$213->222 \quad-0.35251$

$213->228 \quad 0.33379$

$213->230 \quad-0.11049$

Excited State 30: $\quad$ Singlet-A $\quad 3.7579 \mathrm{eV} 329.93 \mathrm{~nm} \mathrm{f}=0.0020<\mathrm{S} * * 2>=0.000$ $212->222 \quad-0.20994$

$212->228 \quad 0.22617$

$213->222 \quad 0.50943$

$213->228 \quad 0.23709$

$214->228 \quad 0.11058$ 
Table S7: Excitation energies and oscillator strengths obtained from TD-DFT calculations for complex $\mathbf{3}$.

Excitation energies and oscillator strengths:

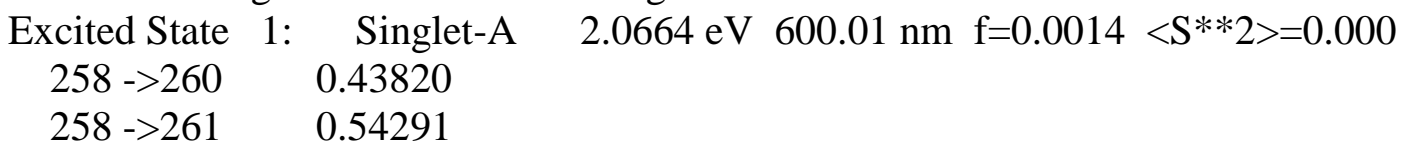

This state for optimization and/or second-order correction.

Total Energy, E(TD-HF/TD-KS) = -3130.06796660

Copying the excited state density for this state as the 1-particle RhoCI density.

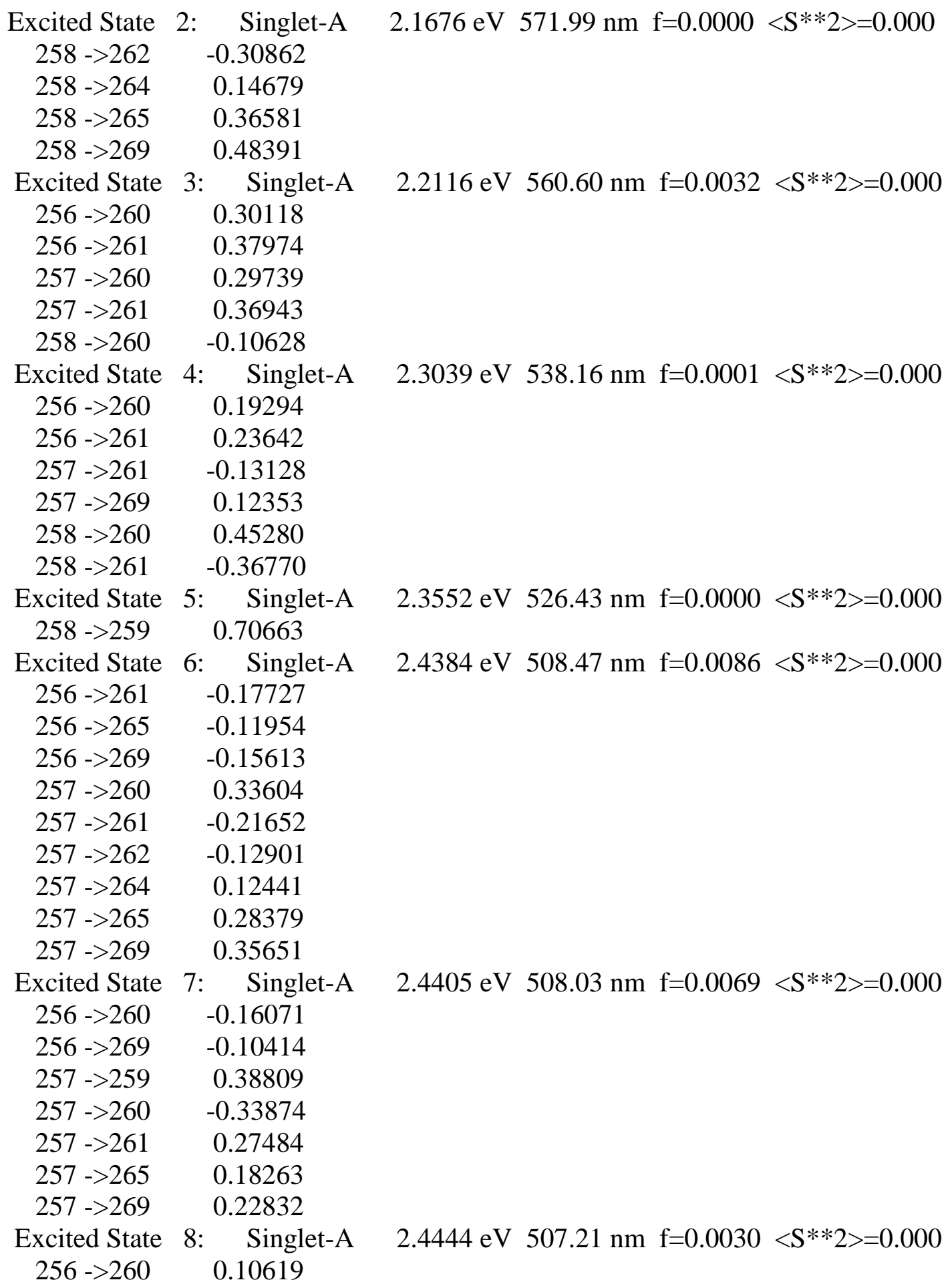


$\begin{array}{lr}257 \text {->259 } & 0.59010 \\ 257 \text {->260 } & 0.23864 \\ 257 \text {->261 } & -0.19114 \\ 257 \text {->265 } & -0.10574 \\ 257 \text {->269 } & -0.13298\end{array}$

Excited State 9: $\quad$ Singlet-A $\quad 2.5389 \mathrm{eV} \quad 488.33 \mathrm{~nm} \mathrm{f}=0.0167<\mathrm{S} * * 2>=0.000$ $256->259 \quad-0.39716$

$256->260 \quad 0.45761$

$256->261 \quad-0.29110$

$257->260 \quad-0.18102$

Excited State 10: $\quad$ Singlet-A $\quad 2.5421 \mathrm{eV} \quad 487.72 \mathrm{~nm} \mathrm{f}=0.0084<\mathrm{S} * * 2\rangle=0.000$ $256->259 \quad 0.58467$

$256->260 \quad 0.31189$

$256->261 \quad-0.19544$

$257->260 \quad-0.12236$

Excited State 11: $\quad$ Singlet-A $\quad 2.5925 \mathrm{eV} \quad 478.24 \mathrm{~nm} \mathrm{f}=0.1924\langle\mathrm{~S} * * 2\rangle=0.000$

$256->260 \quad-0.10248$

$256->261 \quad-0.34240$

$256->269 \quad-0.10642$

$257->260 \quad 0.21651$

$257->261 \quad 0.38064$

$257->269 \quad-0.10571$

$258->260 \quad 0.26394$

$258->261 \quad-0.22236$

Excited State 12: Singlet-A $\quad 2.6533 \mathrm{eV} \quad 467.29 \mathrm{~nm} \mathrm{f}=0.0222\langle\mathrm{~S} * * 2\rangle=0.000$ $256->262 \quad-0.20952$

$256->264 \quad 0.15991$

$256->265 \quad 0.35425$

$256->269 \quad 0.44108$

$257->261 \quad 0.14028$

$257->265 \quad 0.13736$

257 ->269 0.16592

Excited State 13: Singlet-A $\quad 2.8222 \mathrm{eV} \quad 439.32 \mathrm{~nm} \mathrm{f}=0.0000<\mathrm{S} * * 2>=0.000$ $258 \rightarrow 262 \quad 0.62136$

$258->264 \quad 0.13004$

$258->265 \quad 0.19902$

$258->269 \quad 0.18952$

Excited State 14: $\quad$ Singlet-A $\quad 2.8721 \mathrm{eV} \quad 431.68 \mathrm{~nm} \mathrm{f}=0.5966\langle\mathrm{~S} * * 2\rangle=0.000$ $251->259 \quad-0.11487$ 255 ->259 0.69819

Excited State 15: Singlet-A $\quad 2.9203 \mathrm{eV} \quad 424.56 \mathrm{~nm} \mathrm{f}=0.0009<\mathrm{S} * * 2>=0.000$ $256->262 \quad-0.25551$

$257->262 \quad 0.49681$

$257->265 \quad 0.10835$

$258->263 \quad-0.34212$

$258->273 \quad-0.13108$

Excited State 16: Singlet-A $\quad 3.0150 \mathrm{eV} \quad 411.23 \mathrm{~nm} \mathrm{f}=0.0003<\mathrm{S} * * 2\rangle=0.000$

$256->262 \quad-0.19299$

$257->262 \quad 0.31266$

$258->263 \quad 0.58911$

Excited State 17: $\quad$ Singlet-A $\quad 3.1169 \mathrm{eV} \quad 397.78 \mathrm{~nm} \mathrm{f}=0.0215<\mathrm{S} * * 2>=0.000$ 
$\begin{array}{ll}257->263 & 0.66250 \\ 257->273 & 0.18828\end{array}$

Excited State 18: $\quad$ Singlet-A $\quad 3.2220 \mathrm{eV} 384.81 \mathrm{~nm} \mathrm{f}=0.0458<\mathrm{S} * * 2>=0.000$ $256->263 \quad 0.62188$

$256->273 \quad 0.25989$

$257->263 \quad-0.10317$

257 ->273 0.10567

Excited State 19: Singlet-A $\quad 3.3977 \mathrm{eV} \quad 364.91 \mathrm{~nm} \mathrm{f}=0.1250\langle\mathrm{~S} * * 2\rangle=0.000$ $256->262 \quad 0.54311$

$256->265 \quad 0.16749$

$256->266 \quad-0.11343$

$256->269 \quad 0.11072$

$257->262 \quad 0.26942$

257 ->266 0.11942

Excited State 20: $\quad$ Singlet-A $\quad 3.4000 \mathrm{eV} \quad 364.66 \mathrm{~nm} \mathrm{f}=0.0014<\mathrm{S} * * 2\rangle=0.000$ $258 \rightarrow 264 \quad 0.64773$ $258->265 \quad-0.26125$

Excited State 21: Singlet-A $\quad 3.4835 \mathrm{eV} \quad 355.91 \mathrm{~nm} \mathrm{f}=0.0811<\mathrm{S} * * 2\rangle=0.000$ $251->259 \quad 0.69427$

255 ->259 0.11897

Excited State 22: $\quad$ Singlet-A $\quad 3.4960 \mathrm{eV} \quad 354.64 \mathrm{~nm} \mathrm{f}=0.0075 \quad\langle\mathrm{~S} * * 2\rangle=0.000$ $256->264 \quad 0.15971$

$257->264 \quad 0.62832$

$257->265 \quad-0.24948$

Excited State 23: $\quad$ Singlet-A $\quad 3.5288 \mathrm{eV} \quad 351.35 \mathrm{~nm} \mathrm{f}=0.0064<\mathrm{S} * * 2\rangle=0.000$

257 ->262 0.10893

$257->266 \quad 0.13107$

$258->263 \quad-0.16534$

$258->273 \quad 0.58323$

$258->275 \quad-0.13276$

$258->276 \quad-0.20187$

Excited State 24: $\quad$ Singlet-A $\quad 3.5392 \mathrm{eV} \quad 350.32 \mathrm{~nm} \mathrm{f}=0.0433<\mathrm{S} * * 2>=0.000$

$256->263 \quad-0.30323$

$256->273 \quad 0.37510$

$256->276 \quad-0.13183$

$257->263 \quad-0.19132$

257 ->273 0.38842

$257->276 \quad-0.13711$

Excited State 25: $\quad$ Singlet-A $\quad 3.5764 \mathrm{eV} \quad 346.67 \mathrm{~nm} \mathrm{f}=0.0000<\mathrm{S} * * 2>=0.000$ $255->260 \quad 0.69624$

255 ->261 0.12197

Excited State 26: $\quad$ Singlet-A $\quad 3.5776 \mathrm{eV} \quad 346.55 \mathrm{~nm} \mathrm{f}=0.0000<\mathrm{S} * * 2>=0.000$ $254->259 \quad 0.70708$

Excited State 27: Singlet-A $\quad 3.6002 \mathrm{eV} \quad 344.39 \mathrm{~nm} \mathrm{f}=0.0382<\mathrm{S} * * 2>=0.000$

$256->264 \quad 0.61181$

$256->265 \quad-0.24014$

$257->264 \quad-0.16594$

Excited State 28: $\quad$ Singlet-A $\quad 3.6018 \mathrm{eV} 344.23 \mathrm{~nm} \mathrm{f}=0.0000\langle\mathrm{~S} * * 2\rangle=0.000$ $255->260 \quad-0.12237$

$255->261 \quad 0.69616$

Excited State 29: $\quad$ Singlet-A $\quad 3.6120 \mathrm{eV} \quad 343.26 \mathrm{~nm} \mathrm{f}=0.0093<\mathrm{S} * * 2>=0.000$ 
258 ->266 0.69201

Excited State 30: Singlet-A $\quad 3.7554 \mathrm{eV} \quad 330.15 \mathrm{~nm} \mathrm{f}=0.0021 \quad<\mathrm{S} * * 2\rangle=0.000$

$256->266 \quad 0.22527$

$256->273 \quad 0.11704$

$257->266 \quad 0.59838$

$257->273 \quad-0.10335$

$258->273 \quad-0.12841$ 
Table S8: Excitation energies and oscillator strengths obtained from TD-DFT calculations for complex 4.

Excitation energies and oscillator strengths:

Excited State 1: Singlet-A $1.9627 \mathrm{eV} 631.69 \mathrm{~nm} \mathrm{f}=1.1345\langle\mathrm{~S} * * 2\rangle=0.000$

$$
436 \text {-> } 437 \quad 0.70764
$$

This state for optimization and/or second-order correction.

Total Energy, E(TD-HF/TD-KS) = -5467.29529102

Copying the excited state density for this state as the 1-particle RhoCI density.

Excited State 2: Singlet-A $2.0906 \mathrm{eV} 593.05 \mathrm{~nm} \mathrm{f}=0.0000\langle\mathrm{~S} * * 2\rangle=0.000$ 435 -> $437 \quad 0.70686$

Excited State 3: Singlet-A $\quad 2.1761 \mathrm{eV} 569.77 \mathrm{~nm} \mathrm{f}=0.0002\langle\mathrm{~S} * * 2\rangle=0.000$ 434 -> $437 \quad 0.70678$

Excited State 4: Singlet-A $\quad 2.2363 \mathrm{eV} 554.42 \mathrm{~nm} \mathrm{f}=0.0013\langle\mathrm{~S} * * 2\rangle=0.000$ 435 -> $438 \quad 0.53735$ 435 -> $439 \quad 0.45175$

Excited State 5: Singlet-A $\quad 2.2790 \mathrm{eV} 544.02 \mathrm{~nm} \mathrm{f}=0.0001\langle\mathrm{~S} * * 2\rangle=0.000$ 433 -> $437 \quad 0.70682$

Excited State 6: Singlet-A $\quad 2.3802 \mathrm{eV} 520.90 \mathrm{~nm} \mathrm{f}=0.0039\langle\mathrm{~S} * * 2\rangle=0.000$

$$
\begin{array}{ll}
433 \text {-> } 438 & 0.31422 \\
433 \text {-> } 439 & 0.26309 \\
434 \text {-> } 438 & 0.37919 \\
434 \text {-> } 439 & 0.30463 \\
435 \text {-> } 438 & -0.17746 \\
435 \text { > } 439 & 0.23411
\end{array}
$$

Excited State 7: $\quad$ Singlet-A $\quad 2.4353 \mathrm{eV} 509.12 \mathrm{~nm} \mathrm{f}=0.0003\langle\mathrm{~S} * * 2\rangle=0.000$

$$
\begin{array}{ll}
433 \text {-> } 438 & -0.33401 \\
433 \text {-> } 439 & -0.28010 \\
435 \text {-> } 438 & -0.35009 \\
435 \text {-> } 439 & 0.42105
\end{array}
$$

Excited State 8: Singlet-A $\quad 2.5569 \mathrm{eV} \quad 484.91 \mathrm{~nm} \mathrm{f}=0.0154\left\langle\mathrm{~S}^{* *} 2\right\rangle=0.000$ 


$$
\begin{array}{ll}
433 \text {-> } 438 & -0.12155 \\
433 \text {-> } 439 & 0.21244 \\
434 \text {-> } 438 & -0.45186 \\
434 \text {-> } 439 & 0.47698
\end{array}
$$

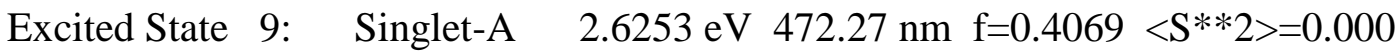

$$
\begin{array}{ll}
432 \text {-> } 437 & 0.68017 \\
436 \text {-> } 440 & -0.17995
\end{array}
$$

Excited State 10: $\quad$ Singlet-A $\quad 2.6511 \mathrm{eV} \quad 467.68 \mathrm{~nm} \mathrm{f}=0.0229\langle\mathrm{~S} * * 2\rangle=0.000$

$$
\begin{array}{ll}
433 \text {-> } 438 & 0.47837 \\
433 \text {-> } 439 & -0.43826 \\
434 \text {-> } 438 & -0.22103
\end{array}
$$

Excited State 11: $\quad$ Singlet-A $\quad 2.7048 \mathrm{eV} \quad 458.38 \mathrm{~nm} \mathrm{f}=0.0004<\mathrm{S} * * 2>=0.000$ 436 -> $438 \quad 0.70477$

Excited State 12: $\quad$ Singlet-A $\quad 2.7059 \mathrm{eV} \quad 458.19 \mathrm{~nm} \mathrm{f}=0.2223<\mathrm{S} * * 2>=0.000$

$$
\begin{array}{ll}
433 \text {-> } 438 & -0.17596 \\
433 \text {-> } 439 & -0.32315 \\
433 \text {-> } 441 & 0.11381 \\
434 \text {-> } 438 & 0.28610 \\
434 \text {-> } 439 & 0.39013 \\
435 \text {-> } 438 & 0.20395 \\
435 \text {-> } 439 & -0.22816
\end{array}
$$

Excited State 13: $\quad$ Singlet-A $\quad 2.7206 \mathrm{eV} \quad 455.72 \mathrm{~nm} \mathrm{f}=0.0028<\mathrm{S} * * 2>=0.000$

$$
\begin{array}{ll}
435 \text {-> } 441 & 0.48656 \\
435 \text {-> } 446 & 0.18131 \\
435 \text {-> } 452 & -0.43757
\end{array}
$$

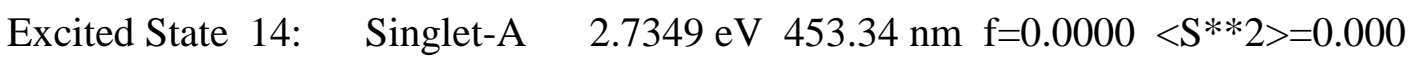

$$
436 \text {-> } 439 \quad 0.70513
$$

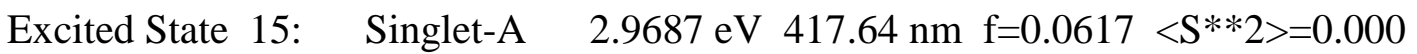

$$
431->437 \quad 0.69216
$$


Excited State 16: Singlet-A $\quad 3.0007 \mathrm{eV} \quad 413.18 \mathrm{~nm} \mathrm{f}=0.0022<\mathrm{S} * * 2>=0.000$

$$
\begin{array}{ll}
433 \text {-> } 441 & 0.17041 \\
433 \text {-> } 452 & -0.18895 \\
434 \text {-> } 441 & -0.37176 \\
434 \text {-> } 446 & -0.17241 \\
434 \text {-> } 452 & 0.39019 \\
435 \text {-> } 442 & -0.21505 \\
435 \text {-> } 456 & -0.15222
\end{array}
$$

Excited State 17: $\quad$ Singlet-A $\quad 3.0601 \mathrm{eV} \quad 405.16 \mathrm{~nm} \mathrm{f}=0.0000<\mathrm{S} * * 2>=0.000$

$$
\begin{array}{ll}
434 \text {-> } 456 & -0.11707 \\
435 \text {-> } 441 & 0.49849 \\
435 \text {-> } 446 & -0.20845 \\
435 \text {-> } 452 & 0.39067
\end{array}
$$

Excited State 18: $\quad$ Singlet-A $\quad 3.1009 \mathrm{eV} 399.83 \mathrm{~nm} \mathrm{f}=0.0014<\mathrm{S} * * 2>=0.000$

$$
\begin{array}{ll}
433->441 & -0.21922 \\
433->452 & -0.15866 \\
434->441 & 0.49283 \\
434->446 & -0.18563 \\
434->452 & 0.33743
\end{array}
$$

Excited State 19: $\quad$ Singlet-A $\quad 3.1787 \mathrm{eV} \quad 390.05 \mathrm{~nm} \mathrm{f}=0.0002<\mathrm{S} * * 2>=0.000$

$$
\begin{array}{ll}
434 \text {-> } 441 & -0.13809 \\
434 \text {-> } 452 & 0.12354 \\
435 \text {-> } 442 & 0.66896
\end{array}
$$

Excited State 20: $\quad$ Singlet-A $\quad 3.1929 \mathrm{eV} 388.31 \mathrm{~nm} \mathrm{f}=0.1119<\mathrm{S} * * 2>=0.000$

$$
\begin{array}{ll}
430 \text {-> } 437 & 0.55947 \\
436 \text {-> } 440 & 0.41551
\end{array}
$$

Excited State 21: $\quad$ Singlet-A $\quad 3.2164 \mathrm{eV} \quad 385.47 \mathrm{~nm} \mathrm{f}=0.0399<\mathrm{S} * * 2>=0.000$

$$
\begin{array}{ll}
423 \text {-> } 437 & 0.15049 \\
424->437 & 0.67619
\end{array}
$$

Excited State 22: $\quad$ Singlet-A $\quad 3.2883 \mathrm{eV} \quad 377.05 \mathrm{~nm} \mathrm{f}=0.0106<\mathrm{S} * * 2>=0.000$ 
$434->442 \quad 0.69028$

Excited State 23: $\quad$ Singlet-A $\quad 3.3963 \mathrm{eV} \quad 365.06 \mathrm{~nm} \mathrm{f}=1.5910<\mathrm{S} * * 2>=0.000$

$$
\begin{array}{ll}
411 \text { - } 437 & 0.11076 \\
430 \text {-> } 437 & -0.40640 \\
432 \text {-> } 437 & 0.15132 \\
436 \text {-> } 440 & 0.52020
\end{array}
$$

Excited State 24: $\quad$ Singlet-A $\quad 3.4204 \mathrm{eV} 362.49 \mathrm{~nm} \mathrm{f}=0.0030<\mathrm{S} * * 2>=0.000$ 436 -> $441 \quad 0.68742$

Excited State 25: $\quad$ Singlet-A $\quad 3.4211 \mathrm{eV} 362.41 \mathrm{~nm} \mathrm{f}=0.0709<\mathrm{S} * * 2>=0.000$

$$
\begin{array}{ll}
433 \text {-> } 441 & 0.40841 \\
433 \text {-> } 443 & 0.14825 \\
433 \text {-> } 446 & 0.20102 \\
433 \text {-> } 452 & -0.36254 \\
434 \text {-> } 441 & 0.18136 \\
434 \text {-> } 452 & -0.17605 \\
436 \text {-> } 441 & -0.15220
\end{array}
$$

Excited State 26: $\quad$ Singlet-A $\quad 3.4323 \mathrm{eV} 361.23 \mathrm{~nm} \mathrm{f}=0.0840<\mathrm{S} * * 2>=0.000$

$$
\begin{array}{ll}
433 \text {-> } 442 & 0.67549 \\
433 \text {-> } 456 & 0.12124
\end{array}
$$

Excited State 27: $\quad$ Singlet-A $\quad 3.4649 \mathrm{eV} 357.83 \mathrm{~nm} \mathrm{f}=0.0679<\mathrm{S} * * 2>=0.000$

$$
\begin{array}{ll}
411 \text {-> } 437 & 0.47680 \\
417 \text {-> } 437 & -0.43873 \\
429 \text {-> } 437 & 0.17835 \\
436 \text {-> } 440 & -0.10962
\end{array}
$$

Excited State 28: $\quad$ Singlet-A $\quad 3.4723 \mathrm{eV} 357.07 \mathrm{~nm} \mathrm{f}=0.0074<\mathrm{S} * * 2>=0.000$

$$
\begin{array}{ll}
421 \text {-> } 437 & -0.16434 \\
423 \text {-> } 437 & 0.58215 \\
436 \text {-> } 443 & 0.16206 \\
436 \text {-> } 444 & 0.23396
\end{array}
$$

Excited State 29: $\quad$ Singlet-A $\quad 3.5098 \mathrm{eV} \quad 353.25 \mathrm{~nm} \mathrm{f}=0.0183<\mathrm{S} * * 2>=0.000$ 
414 -> $437 \quad 0.69149$

Excited State 30: $\quad$ Singlet-A $\quad 3.5134 \mathrm{eV} \quad 352.89 \mathrm{~nm} \mathrm{f}=0.0015<\mathrm{S} * * 2\rangle=0.000$
435 -> $443 \quad 0.57114$
$435->444 \quad-0.37718$
$435->446 \quad-0.12413$ 
Table S9: Excitation energies and oscillator strengths obtained from TD-DFT calculations for complex $\mathbf{5}$.

Excitation energies and oscillator strengths:

Excited State 1: Singlet-A $1.9639 \mathrm{eV} 631.31 \mathrm{~nm} \mathrm{f}=1.1270\langle\mathrm{~S} * * 2\rangle=0.000$

$$
480 \text {-> } 481 \quad 0.70763
$$

This state for optimization and/or second-order correction.

Total Energy, E(TD-HF/TD-KS) = -5974.16664891

Copying the excited state density for this state as the 1-particle RhoCI density.

Excited State 2: Singlet-A $\quad 2.0906 \mathrm{eV} 593.05 \mathrm{~nm} \quad \mathrm{f}=0.0000\langle\mathrm{~S} * * 2\rangle=0.000$

$$
479 \text {-> } 481 \quad 0.70691
$$

Excited State 3: $\quad$ Singlet-A $\quad 2.1754 \mathrm{eV} 569.94 \mathrm{~nm} \mathrm{f}=0.0000\langle\mathrm{~S} * * 2\rangle=0.000$

$$
478 \text {-> } 481 \quad 0.70678
$$

Excited State 4: $\quad$ Singlet-A $\quad 2.2400 \mathrm{eV} 553.50 \mathrm{~nm} \mathrm{f}=0.0013\langle\mathrm{~S} * * 2\rangle=0.000$

$$
\begin{array}{ll}
479 \text {-> } 482 & 0.53020 \\
479 \text {-> } 483 & 0.46056
\end{array}
$$

Excited State 5: Singlet-A $\quad 2.2815 \mathrm{eV} 543.44 \mathrm{~nm} \mathrm{f}=0.0000\langle\mathrm{~S} * * 2\rangle=0.000$

$$
477 \text {-> } 481 \quad 0.70683
$$

Excited State 6: Singlet-A $\quad 2.3857 \mathrm{eV} 519.70 \mathrm{~nm} \mathrm{f}=0.0046\langle\mathrm{~S} * * 2\rangle=0.000$

$$
\begin{array}{ll}
477 \text {-> } 482 & 0.29818 \\
477 \text {-> } 483 & 0.26081 \\
478 \text {-> } 482 & 0.36737 \\
478 \text {-> } 483 & 0.31420 \\
479 \text {-> } 482 & -0.20172 \\
479 \text { > } 483 & 0.24417
\end{array}
$$

Excited State 7: $\quad$ Singlet-A $\quad 2.4397 \mathrm{eV} 508.20 \mathrm{~nm} \mathrm{f}=0.0006\langle\mathrm{~S} * * 2\rangle=0.000$

$$
\begin{array}{ll}
477 \text {-> } 482 & -0.34041 \\
477 \text {-> } 483 & -0.29714 \\
479 \text {-> } 482 & -0.35018 \\
479 \text {-> } 483 & 0.40479
\end{array}
$$

Excited State 8: $\quad$ Singlet-A $\quad 2.5607 \mathrm{eV} \quad 484.18 \mathrm{~nm} \mathrm{f}=0.0157\langle\mathrm{~S} * * 2\rangle=0.000$ 


$$
\begin{array}{ll}
477 \text { - } 482 & -0.12620 \\
477 \text {-> } 483 & 0.20222 \\
478 \text {-> } 482 & -0.46076 \\
478 \text {-> } 483 & 0.47191
\end{array}
$$

Excited State 9: $\quad$ Singlet-A $\quad 2.6274 \mathrm{eV} \quad 471.89 \mathrm{~nm} \mathrm{f}=0.4101<\mathrm{S} * * 2>=0.000$

$$
\begin{array}{ll}
476 \text {-> } 481 & 0.68007 \\
480 \text {-> } 484 & 0.18016
\end{array}
$$

Excited State 10: $\quad$ Singlet-A $\quad 2.6554 \mathrm{eV} \quad 466.91 \mathrm{~nm} \mathrm{f}=0.0225<\mathrm{S} * * 2>=0.000$

$$
\begin{array}{ll}
477 \text { - } 482 & 0.48677 \\
477 \text {-> } 483 & -0.42922 \\
478 \text {-> } 482 & -0.22161
\end{array}
$$

Excited State 11: $\quad$ Singlet-A $\quad 2.7090 \mathrm{eV} \quad 457.67 \mathrm{~nm} \mathrm{f}=0.2303<\mathrm{S} * * 2>=0.000$

$$
\begin{array}{ll}
477 \text {-> } 482 & -0.16733 \\
477 \text {-> } 483 & -0.32501 \\
477 \text {-> } 485 & 0.11301 \\
478 \text {-> } 482 & 0.28938 \\
478 \text {-> } 483 & 0.38973 \\
478 \text {-> } 485 & 0.10205 \\
479 \text {-> } 482 & 0.20197 \\
479 \text {-> } 483 & -0.23010
\end{array}
$$

Excited State 12: $\quad$ Singlet-A $\quad 2.7119 \mathrm{eV} \quad 457.18 \mathrm{~nm} \mathrm{f}=0.0010<\mathrm{S} * * 2>=0.000$

$$
480 \text {-> } 482 \quad 0.70253
$$

Excited State 13: $\quad$ Singlet-A $\quad 2.7186 \mathrm{eV} \quad 456.06 \mathrm{~nm} \mathrm{f}=0.0013<\mathrm{S} * * 2>=0.000$

$$
\begin{array}{ll}
479 \text { - } 485 & 0.49328 \\
479 \text {-> } 490 & 0.18194 \\
479 \text {-> } 496 & 0.43582
\end{array}
$$

Excited State 14: Singlet-A $\quad 2.7419 \mathrm{eV} \quad 452.18 \mathrm{~nm} \mathrm{f}=0.0000<\mathrm{S} * * 2>=0.000$

$$
480 \text {-> } 483 \quad 0.70407
$$

Excited State 15: Singlet-A $\quad 2.9688 \mathrm{eV} \quad 417.63 \mathrm{~nm} \mathrm{f}=0.0623<\mathrm{S} * * 2>=0.000$ $474->481 \quad 0.69229$ 
Excited State 16: Singlet-A $\quad 2.9995 \mathrm{eV} \quad 413.35 \mathrm{~nm} \mathrm{f}=0.0000<\mathrm{S} * * 2>=0.000$

$$
475 \text {-> } 481 \quad 0.70706
$$

Excited State 17: $\quad$ Singlet-A $\quad 3.0013 \mathrm{eV} \quad 413.10 \mathrm{~nm} \mathrm{f}=0.0031<\mathrm{S} * * 2>=0.000$

$$
\begin{array}{ll}
477 \text { - } 485 & -0.18316 \\
477 \text {-> } 496 & -0.18952 \\
478 \text {-> } 485 & 0.37849 \\
478 \text {-> } 490 & 0.16857 \\
478 \text {-> } 496 & 0.38073 \\
479 \text {-> } 486 & 0.21826 \\
479 \text {-> 501 } & 0.15055
\end{array}
$$

Excited State 18: Singlet-A $\quad 3.0611 \mathrm{eV} \quad 405.03 \mathrm{~nm} \mathrm{f}=0.0000<\mathrm{S} * * 2>=0.000$

$$
\begin{array}{ll}
478 \text {-> } 501 & -0.11584 \\
479->485 & 0.49463 \\
479->487 & -0.10075 \\
479->490 & -0.21370 \\
479->496 & -0.39496
\end{array}
$$

Excited State 19: Singlet-A $\quad 3.1028$ eV $399.59 \mathrm{~nm} \mathrm{f}=0.0016<\mathrm{S} * * 2>=0.000$

$$
\begin{array}{ll}
477 \text {-> } 485 & -0.21954 \\
477 \text {-> } 496 & 0.16663 \\
478->485 & 0.48495 \\
478->490 & -0.19092 \\
478 \text {-> } 496 & -0.34173
\end{array}
$$

Excited State 20: $\quad$ Singlet-A $\quad 3.1807 \mathrm{eV} 389.80 \mathrm{~nm} \mathrm{f}=0.0001 \quad\langle\mathrm{~S} * * 2>=0.000$

$$
\begin{array}{ll}
478->485 & -0.13256 \\
478->496 & -0.12781 \\
479 \text {-> } 486 & 0.66839
\end{array}
$$

Excited State 21: $\quad$ Singlet-A $\quad 3.1930 \mathrm{eV} \quad 388.30 \mathrm{~nm} \mathrm{f}=0.1111<\mathrm{S} * * 2>=0.000$

$$
\begin{array}{ll}
473 \text {-> } 481 & 0.55951 \\
480 \text {-> } 484 & -0.41542
\end{array}
$$

Excited State 22: $\quad$ Singlet-A $\quad 3.2167 \mathrm{eV} \quad 385.43 \mathrm{~nm} \mathrm{f}=0.0401<\mathrm{S}^{* *} 2>=0.000$ 


$$
\begin{array}{ll}
465->481 & -0.14500 \\
466 \text {-> } 481 & 0.67719
\end{array}
$$

Excited State 23: $\quad$ Singlet-A $\quad 3.2902 \mathrm{eV} 376.83 \mathrm{~nm} \mathrm{f}=0.0110<\mathrm{S} * * 2>=0.000$

$$
478 \text {-> } 486 \quad 0.69019
$$

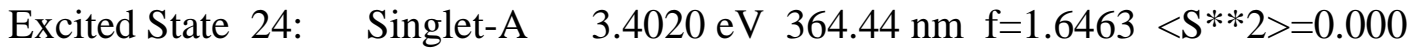

$$
\begin{array}{ll}
473 \text {-> } 481 & 0.41413 \\
476 \text {-> } 481 & -0.15568 \\
480 \text {-> } 484 & 0.52944
\end{array}
$$

Excited State 25: $\quad$ Singlet-A $\quad 3.4154 \mathrm{eV} \quad 363.02 \mathrm{~nm} \mathrm{f}=0.0075\langle\mathrm{~S} * * 2\rangle=0.000$

$$
480->485 \quad 0.70322
$$

Excited State 26: $\quad$ Singlet-A $\quad 3.4198 \mathrm{eV} \quad 362.55 \mathrm{~nm} \mathrm{f}=0.0851<\mathrm{S} * * 2\rangle=0.000$
477 -> $485 \quad 0.41410$
477 -> $487 \quad 0.16601$
477 -> $490 \quad 0.20693$
477 -> $496 \quad 0.36393$
478 -> $485 \quad 0.19003$
$478->490 \quad 0.10274$
$478->496 \quad 0.18408$

Excited State 27: $\quad$ Singlet-A $\quad 3.4353 \mathrm{eV} 360.92 \mathrm{~nm} \mathrm{f}=0.0817\langle\mathrm{~S} * * 2>=0.000$
477 -> 486
0.67209
$477->501$
0.12068

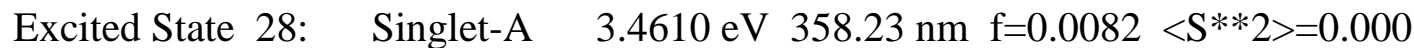

$$
\begin{array}{ll}
452 \text {-> } 481 & 0.51739 \\
458 \text {-> } 481 & -0.43103 \\
471 \text {-> } 481 & 0.16956
\end{array}
$$

Excited State 29: $\quad$ Singlet-A $\quad 3.4749 \mathrm{eV} \quad 356.80 \mathrm{~nm} \mathrm{f}=0.0048<\mathrm{S} * * 2\rangle=0.000$

$$
\begin{array}{ll}
463 \text {-> } 481 & 0.17920 \\
465 \text {-> } 481 & 0.58441 \\
480 \text {-> } 488 & -0.27933
\end{array}
$$


Excited State 30: $\quad$ Singlet-A $\quad 3.4777 \mathrm{eV} 356.51 \mathrm{~nm} \mathrm{f}=0.0000<\mathrm{S} * * 2>=0.000$ 472 -> $481 \quad 0.70701$

SavETr: write IOETrn $=770$ NScale $=10$ NData $=16$ NLR=1 NState $=30$ LETran $=550$. 